PNNL Administrative/Technical Procedures

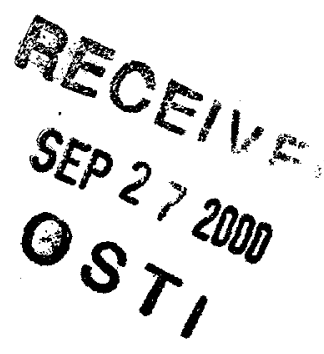

\title{
Surface Environmental \\ Surveillance Procedures Manual
}

September 2000

Prepared for the U.S. Department of Energy under Contract DE-ACO6-76RLO 1830

Pacific Northwest National Laboratory Operated for the U.S. Department of Energy by Battelle 


\section{DISCLAIMER}

This report was prepared as an account of work sponsored by an agency of the United States Government. Neither the United States Government nor any agency thereof, nor Battelle Memorial Institute, nor any of their employees, makes any warranty, express or implied, or assumes any legal liability or responsibility for the accuracy, completeness, or usefulness of any information, apparatus, product, or process disclosed, or represents that its use would not infringe privately owned rights. Reference herein to any specific commercial product, process, or service by trade name, trademark, manufacturer, or otherwise does not necessarily constitute or imply its endorsement, recommendation, or favoring by the United States Government or any agency thereof, or Battelle Memorial Institute. The views and opinions of authors expressed herein do not necessarily state or reflect those of the United States Government or any agency thereof.

\section{PACIFIC NORTHWEST NATIONAL LABORATORY \\ operated by \\ BATTELLE \\ for the \\ UNITED STATES DEPARTMENT OF ENERGY \\ under Contract DE-AC06-76RLO 1830}

Printed in the United States of America

Available to DOE and DOE contractors from the

Office of Scientific and Technical Information, P.O. Box 62, Oak Ridge, TN 37831; prices available from (615) 576-8401.

Available to the public from the National Technical Information Service, U.S. Department of Commerce, 5285 Port Royal Rd., Springfield, VA 22161 


\section{DISCLAIMER}

Portions of this document may be illegible in electronic image products. Images are produced from the best available original document. 
PNL-MA-580, Rev. 3

PNNL Administrative/Technical Procedures

Surface Environmental

Surveillance Procedures Manual

Editors:

R. W. Hanf

T. M. Poston

September 2000

Pacific Northwest National Laboratory

Richland, Washington 99352 
PNL-MA-580, Rev. 3

Environmental Characterization and Risk Assessment Group

\section{SURFACE ENVIRONMENTAL SURVEILLANCE PROCEDURES MANUAL}

In case of termination or transfer, return this manual to Document Control, K3-70.

T. M. Poston, Manager

Surface Environmental Surveillance Project

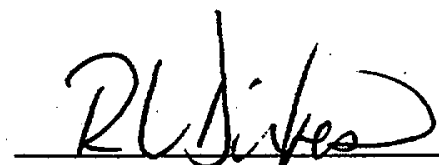

R. L. Dirkes, Manager

Public Safety and Resource Protection Program

Pacific Northwest National Laboratory

Richland, Washington 99352 
* 2.0 RESPONSIBILITIES

3.0 AIR SAMPLING PROCEDURES

$03 / 98$

3.1 PARTICULATE AIR SAMPLES

$02 / 00$

3.2 TRITIUM SAMPLES

$02 / 00$

3.3 IODINE-129 SAMPLES

03/98

4.0 SURFACE-WATER SAMPLING PROCEDURES

$01 / 00$

4.1 GRAB SAMPLES

$01 / 00$

4.2 COMPOSITE WATER SAMPLES

$01 / 00$

4.3 CONTINUOUS SAMPLES.

$01 / 00$

4.4 COLUMBIA RIVER TRANSECT SAMPLING

$01 / 00$

4.5 COLUMBIA RIVER SEDIMENT SAMPLING

$01 / 00$

4.6 SAMPLING COLUMBIA RIVER RIVERBANK SPRINGS

$03 / 98$

4.7 TEMPERATURE MEASUREMENT PROCEDURE. $10 / 98$

4.8 CONDUCTIVITY MEASUREMENT PROCEDURE. $10 / 98$

4.9 pH MEASUREMENT PROCEDURE. $10 / 98$

4.10 WATER FIITRATION PROCEDURE. $05 / 99$

5.0 SOIL AND VEGETATION SAMPLING PROCEDURES. $10 / 98$

5.1 SURFACE SOIL SAMPLES. $10 / 98$

5.2 TERRESTRIAL VEGETATION SAMPLES

$10 / 98$

6.0 FARM PRODUCT SAMPLING PROCEDURES.............................................. $\quad 03 / 98$

6.1 MIK SAMPLES

$03 / 98$

6.2 CROP SAMPLES

$03 / 98$

6.3 WINE SAMPLES $03 / 98$

7.0 WILDLIFE SAMPLING PROCEDURES

$02 / 99$

7.1 FISH SAMPLES

$02 / 99$

* This section is also distributed to Community-Operated Environmental Surveillance Program (COESP) personnel. 
ISSUE DATE

7.2 WATERFOWL SAMPLES 03/98

7.3 RABBIT SAMPLES $03 / 98$

7.4 GAME BIRD SAMPLES 03/98

7.5 DEER AND ELK SAMPLES $02 / 99$

8.0 MISCELLANEOUS PROCEDURES 08/99

8.2 RADIATION WORK PERMITS $03 / 98$

8.3 UNUSUAL FINDINGS NOTIFICATION. 02/99

8.4 RADIOLOGICAL SURVEYS OF SAMPLES $03 / 98$

8.5 PROCEDURE FOR THE SAFE HANDLING, TRANSPORT, AND STORAGE OF FIREARMS

$03 / 98$

8.6 DETERMINING GEOGRAPHIC POSITIONS USING THE TRIMBLE GEOEXPLORER II

9.0 RADIATION SURVEY PROCEDURES $03 / 99$

9.1 ENVIRONMENTAL THERMOLUMINESCENT DOSIMETER 03/99

9.2 PRESSURIZED IONIZATION CHAMBER $03 / 99$

9.3 SHORELINE DOSE RATE AND CONTAMINATION MEASUREMENTS 


\subsection{INTRODUCTION}

ENVIRONMENTAL Hanford Site environmental surveillance is conducted by the Pacific SURVEILLANCE Northwest National Laboratory (PNNL)* for the U.S. Department of Energy (DOE) under the Surface Environmental Surveillance Project (SESP). The basic requirements for site surveillance are set forth in DOE Order 5400.1, General Environmental Protection Program Requirements. Guidance for the SESP is provided in DOE Order 5484.1, Environmental Protection, Safety, and Health Protection Information Reporting Requirements and DOE Order 5400.5, Radiation Protection of the Public and Environment. Guidelines for environmental surveillance activities are provided in DOE/EH-0173T, Environmental Regulatory Guide for Radiological Effluent Monitoring and Environmental Surveillance. An environmental monitoring plan for the Hanford Site is outlined in DOE/RL 91-50 Rev. 2, Environmental Monitoring Plan, United States Department of Energy, Richland Operations Office.

Environmental surveillance data are used in assessing the impact of current and past site operations on human health and the environment, demonstrating compliance with applicable local, state, and federal environmental regulations, and verifying the adequacy of containment and effluent controls.

SESP sampling schedules are reviewed, revised, and published each calendar year in the Hanford Site Environmental Surveillance Master Sampling Schedule. Environmental samples are collected by SESP staff in accordance with the approved sample collection procedures documented in this manual. Personnel training requirements are documented in SESP-TP01 Rev.2, Surface Environmental Surveillance Project Training Program.

MANUAL SCOPE/USE
This manual documents the procedures that are used by SESP staff [including Community-Operated Environmental Surveillance Program (COESP) personnel] for the collection of environmental samples, and the performance of radiation surveys and other field measurements, on and around the Hanford Site. Specific responsibilities for personnel involved in SESP environmental surveillance activities are defined in Section 2.0 of this manual.

\begin{tabular}{|c|c|c|}
\hline 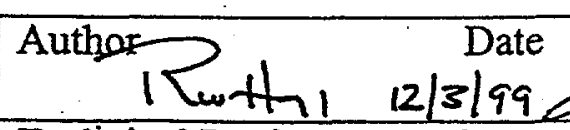 & 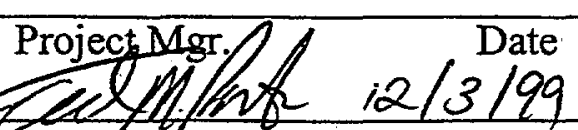 & QAD Representative $1217 / 99$ \\
\hline $\begin{array}{l}\text { Techinical Reviewer : Date } \\
\text { ß3mbltz- i2/3/99 }\end{array}$ & & Revision No. 5 \\
\hline
\end{tabular}


USE CATEGORY

MANUAL REVISIONS AND UPDATES
This manual is intended for use by SESP management and staff. Project specific training is required for all individuals collecting SESP samples or conducting field measurements. Training is required to ensure that procedures are understood and properly applied. Training also ensures that representative samples are collected, and environmental radiation surveys are performed in a safe and consistent manner. Samples must be collected and measurements must be performed consistently both from one sample time to the next and between individuals performing the work to ensure that analytical results are comparable between locations and over time.

The procedures in this manual fall under the Standards-Based Management System (SBMS) "Information Use" category and are to be used for regularly conducted routine operations. The procedures can be performed from memory and it is not necessary that they be available at the work site. General adherence to the procedures is adequate.

Some project operations may fall into the informal category of "Craft Operations." Under this category, trained, qualified individuals may perform an operation without a written procedure if approval to do so is granted by line management.

The procedures described in this manual are reviewed annually by SESP management to ensure that major revisions to existing procedures and new procedures are incorporated promptly. Small corrections or revisions that do not warrant complete manual updates may be issued to manual holders in the form of interim procedures. Interim procedures may be used for documenting changes to existing procedures. Interim procedures will be issued on a temporary basis (up to 1 year) and will be valid until the appropriate section in this manual is updated. After initial issuance and training, it is the responsibility of each manual holder to retain a copy of the interim procedure and be familiar with its contents.

To ensure that the procedures in this manual are accurate, complete, in the correct format, and, most importantly, usable, the following requirements must be met before a new, revised, or interim procedure is issued:

- All new, interim, or revised procedures must undergo technical review and approval by the appropriate task leader (generally the section author), the project manager, the project quality engineer, and the technical staff. Issuance approval of all but the technical staff must be documented on the procedures in the form of dated signatures. 
SUPPLEMENTAL INFORMATION

MANUAL CONTROL
- Appropriate training must be provided to all SESP staff involved in sample collection activities before new, revised, or interim procedures are used. Such training shall be documented in the SESP personnel training files.

In addition to the procedures in this manual, supplemental information, such as sample collection checklists, procedure flow charts, condensed procedures, etc, may be produced by various individuals within the SESP, approved by the cognizant media task leader, and distributed to SESP staff. Supplemental information will only be used to clarify or support existing approved procedures. To the extent possible, supplemental information will be prepared and reviewed to ensure consistency with the approved procedures. If a discrepancy between the supplemental information and the approved procedures in this manual is observed, the appropriate media task leader or the Sample Collection Task Leader must be contacted for clarification. If the appropriate personnel are unavailable for assistance, the procedures in this manual (PNL-MA-580) will be followed until the discrepancy can be resolved. All such discrepancies should be brought to the attention of the Sample Collection Task Leader or the appropriate media task leader in a timely fashion.

The Surface Environmental Surveillance Procedures Manual is a controlled document through PNNL=s Document Control Section. Project management approval of manual content is documented through sign-offs on the title page of each manual section.

Each manual is uniquely numbered and assigned to a specific individual. All updates will be mailed to the individual manual holders along with a receipt acknowledgment form that must be signed, dated, and returned to the manual controller within a specified period of time. It is the responsibility of the assigned manual holders to return their acknowledgment forms and to incorporate all changes in a timely manner, thereby keeping their manual current. Periodic audits may be conducted to ensure that manuals are being properly maintained. Manuals that are no longer needed, such as would be the case if an individual left the SESP, should be returned to the SESP manual controller for reassignment.

* PNNL is operated by Battelle Memorial Institute for the U.S. Department of Energy 


\subsection{RESPONSIBILITIES}

INTRODUCTION

PROJECT MANAGER

MEDIA TASK LEADERS
This section outlines the overall responsibilities of SESP staff who are accountable for the collection and transport of environmental samples, the performance of environmental radiation surveys, the proper completion of sample chain-of-custody paperwork, and the maintenance of project manuals. Included are both the specific responsibilities of project staff according to job category, and the general responsibilities of all SESP staff participating either actively or passively in environmental sampling activities.

Responsible for the technical quality and completeness of all procedures associated with the project. The Project Manager must ensure that:

- an approved procedure is in place for each routine SESP field sampling activity

- project manuals are reviewed and updated on an annual basis

- SESP staff are properly trained prior to engaging in field collection activities

- all applicable Job Safety Analysis (JSA) sheets are reviewed annually and approved by PNNL Laboratory Safety.

Responsible for planning and scheduling the collection of environmental samples; evaluating and selecting sampling equipment; determining sampling locations, frequencies, and sample analyses; preparing the procedures included in this manual; and training SESP personnel to collect samples, conduct surveys, or obtain measurements according to the procedures in this manual or to approved interim or supplemental procedures.

Additional responsibilities include:

- ensuring that an approved procedure is in place for each routine SESP field sampling or survey activity

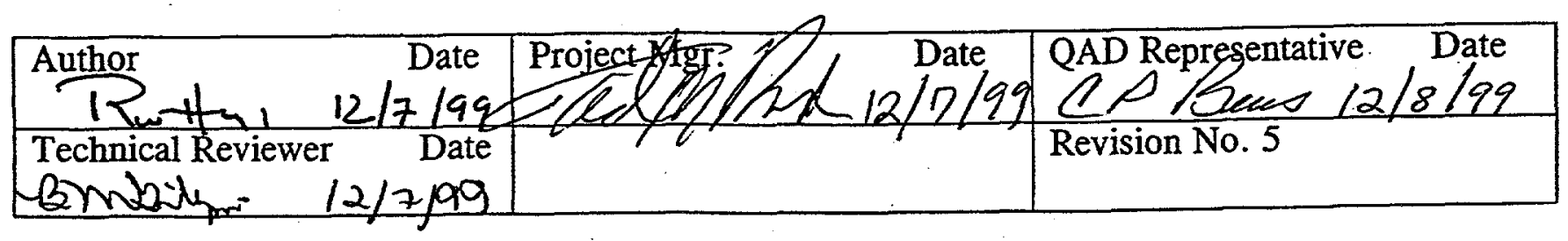


- ensuring that approved procedures are technically sound, accurate, and complete, and are updated to reflect operational changes

- ensuring that the project manuals are reviewed and updated on an annual basis

- ensuring that necessary manual updates and revisions are done in a timely manner

- ensuring that SESP staff are properly trained prior to engaging in field collection activities

- coordinating work requiring the use of environmental monitoring personnel through the Sample Collection Task Leader

- preparing all supplemental guidance for collecting environmental samples and ensuring that it is correct, and consistent with the direction provided in this manual

- ensuring that station equipment is functioning as expected

SAMPLE COLLECTION TASK LEADER
Responsible for coordinating the sample collection field crew and for arranging the timely collection of SESP routine and special samples and the completion of field surveys and measurements. The Sample Collection Task Leader must ensure that:

- sample collections, surveys, and measurements are conducted in accordance with the procedures outlined in this manual and/or in accordance with approved interim or supplemental procedures

- sample collections, surveys, and measurements are conducted in accordance with the sampling schedule outlined in the Environmental Surveillance Master Sampling Schedule

- all necessary sampling, survey, and measurement equipment is properly maintained and calibrated, that all maintenance and calibration records are properly filed, and that new equipment is purchased to replace aging or inadequate sampling equipment

- routine sampling equipment is available and in working condition prior to scheduled sampling 
- broken or outdated equipment is repaired or replaced in a timely manner

- stations are kept clean and orderly

- an adequate supply of materials and equipment necessary for collecting SESP samples and performing surveys and measurements is maintained

- job-specific training is provided to sample collection personnel prior to their deployment in the field

- appropriate safety training is provided to sample collection personnel and that JSA sheets are available on demand for the staff to review

- sample collection personnel are knowledgeable of the procedures outlined in this manual and any approved interim or supplemental procedures

- chain-of-custody paperwork (trip sheets) is properly and accurately filled out by sample collection personnel before samples are delivered to the analytical laboratory

- copies of all completed trip sheets are returned to the SESP Data Management Task Leader in a timely manner.

SAMPLE COLLECTION PERSONNEL
Collect (or assist with the collection of) environmental samples, conduct radiation surveys, and perform field measurements in accordance with the procedures outlined in this manual, approved interim or supplemental procedures, appropriate radiation work procedures, or as directed by the Project Manager or Sample Collection, Media, or COESP Task Leader. In addition to responsibilities listed below, COESP personnel are responsible for all requirements specified in each individual's statement of work. Sample collection personnel are also responsible for:

- attending SESP training sessions as required

- knowing the sampling procedures associated with the work they are assigned or are conducting. If necessary, pertinent procedures will be reviewed prior to doing the work.

- maintaining or replacing sampling equipment as appropriate or when instructed to do so by the Sample Collection Task Leader.

- ensuring the sampling equipment is prepared for use in the field, and the equipment is properly cleaned and stored following sampling 
- notifying the Sample Collection (or COESP) Task Leader or appropriate media task leader if: 1) samples are not collected or work is not performed as scheduled, 2) unusual conditions are observed while sampling that might impact sampling or sampling results, 3) sampling equipment and/or procedures are unsafe, and 4) actual sampling procedures differ from the procedures outlined in this manual

- handling, storing, or delivering samples in accordance with the procedures described herein

- completing chain-of-custody paperwork accurately and according to the procedures outlined in this manual

- providing suggestions for improvements in procedures, in equipment, or in the operation of the program itself.

GENERAL STAFF RESPONSIBILITIES
All project staff are responsible for maintaining and updating the project manuals assigned to them when changes or updates to the manuals are issued. Each manual is uniquely numbered and assigned to a specific individual. All updates will be mailed to the individual manual holders along with a receipt acknowledgement form that must be signed, dated, and returned to the manual controller within a specified period of time. It is the responsibility of the assigned manual holders to incorporate all changes and return the receipt acknowledgment form in a timely manner. Periodic audits may be conducted to ensure that manuals are being properly maintained. Manuals that are no longer needed, such as would be the case if an individual left the SESP should be returned to the SESP manual controller for reassignment.

All project staff are expected to perform their work in a safe and proper manner and to notify the appropriate task leader of any unsafe conditions or requirements. Project staff will be responsible for reviewing and understanding all applicable Job Safety Analyses (JSAs) prior to conducting any sampling activities.

All project staff are responsible for ensuring that sampling equipment is properly stored and that storage areas are kept neat and orderly. 
INTRODUCTION

\subsection{AIR SAMPLING PROCEDURES}

The collection and analysis of air samples are of importance in environmental monitoring because air is a primary pathway of radionuclides to the public from the Hanford environs. Air sampling provides a means to assess the environmental impact of site operations, demonstrate compliance with applicable guidelines, check the effectiveness of containment and effluent control systems, and evaluate the potential doses to offsite populations from airborne radionuclides.

Air samples are collected continuously at numerous locations, including those on the site, at the site perimeter, and in both nearby and distant communities.

Samples are collected for all or some of the following constituents at each station, depending on its location with respect to potential sources:

- particulate radioactivity (Section 3.1)

- tritium in the form of water vapor (HTO) (Section 3.2)

- iodine-129 (Section 3.3).

Figure 3.0.1 illustrates the sampling systems currently in use.

Figures 3.1.1 and 3.3.1 include flow diagrams illustrating the step-bystep processes for collecting particulate, tritium $\left({ }^{3} \mathrm{H}\right)$, and iodine- $129\left({ }^{129}\right)$ samples.

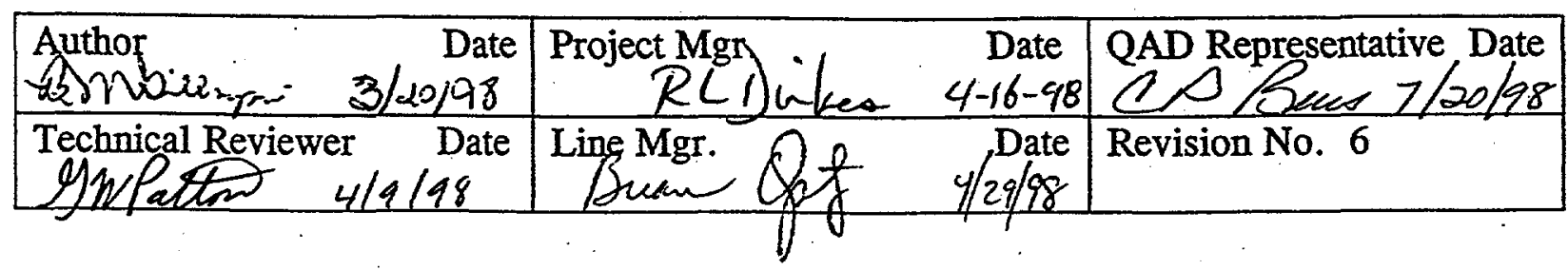


Section 3.0

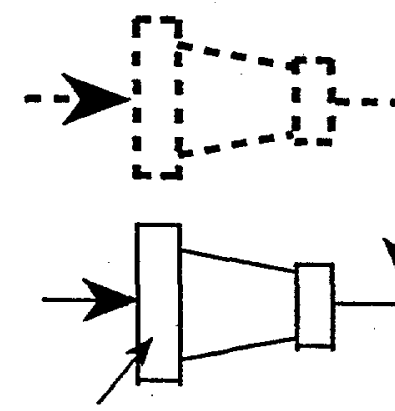

Glass Fiber Filter

(Particulates)
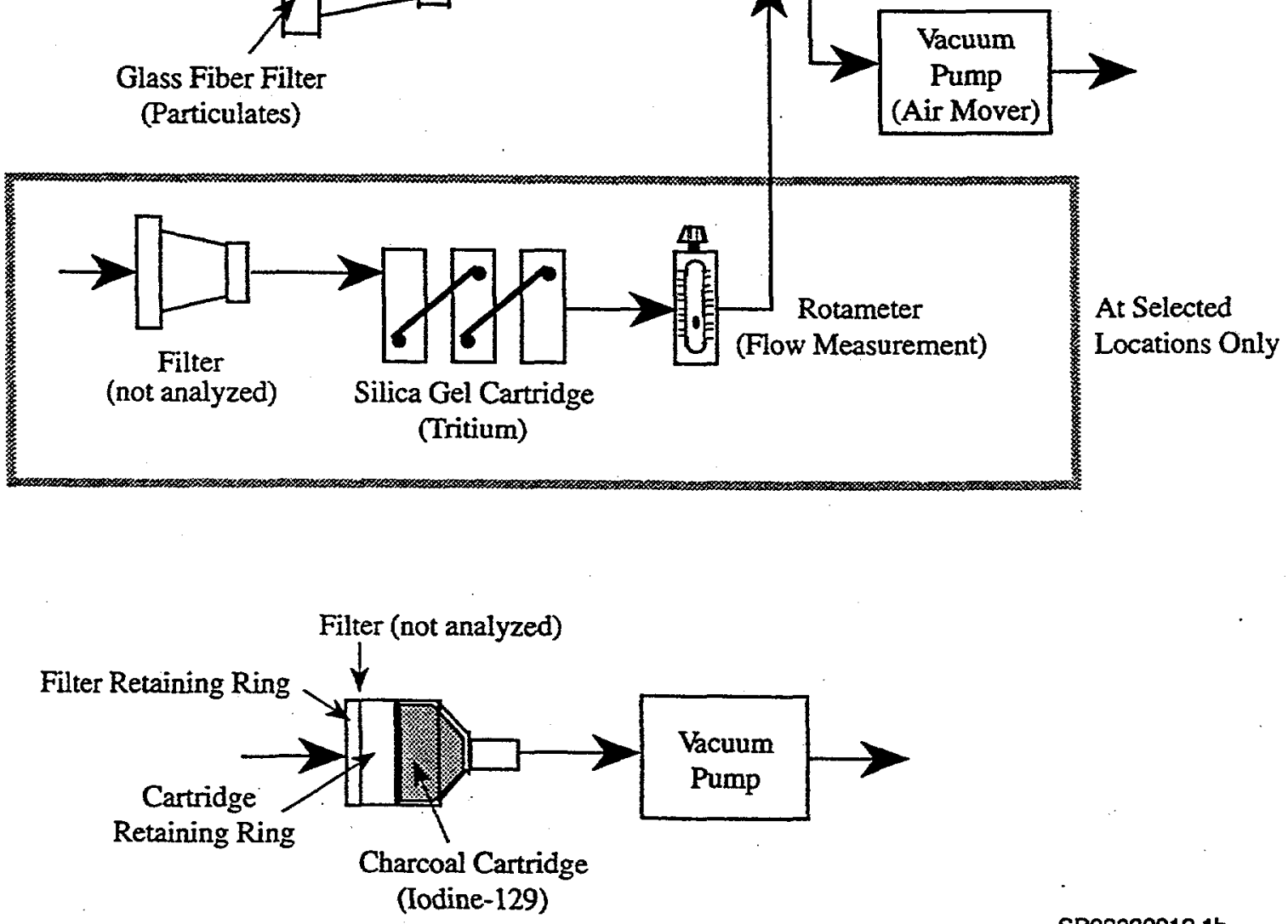

Figure 3.0.1. Air Sampling Systems for Particulate, Particulate and Tritium, and Iodine-129 Collection 
INTRODUCTION

EQUIPMENT

\subsection{PARTICULATE AIR SAMPLES}

This procedure governs the collection of particulate air samples every two weeks at all air sampling locations. Total beta and, at selected locations, total alpha measurements are made on individual filters after a 72-hour holding period that allows for the decay of naturally occurring radon and thorium radioactive decay products. Individual filters from locations within defined geographic areas are then composited and analyzed for gamma-emitting radionuclides and other radionuclides, including plutonium, strontium, and uranium.

Figure 3.1.1 is a flow diagram summarizing the process for collecting particulate and ${ }^{3} \mathrm{H}$ samples. The flow diagram is included for quick reference and training purposes.

The following equipment may be needed when collecting particulate samples:

- clean filter-head assemblies

- filter heads with filters installed (Figure 3.0.1)

- filter holder carrying rack with plastic jars for covers

- air flow calibrator with current calibration label

- extra glass fiber filters

- rainguards for filter holders

- plastic tubing (3/8- and $1 / 2$-in. ID)

- hose clamps (large and small, plastic and metal)

- spare vacuum pumps

- assorted tools (pliers, screwdriver, etc.)

- clean rags

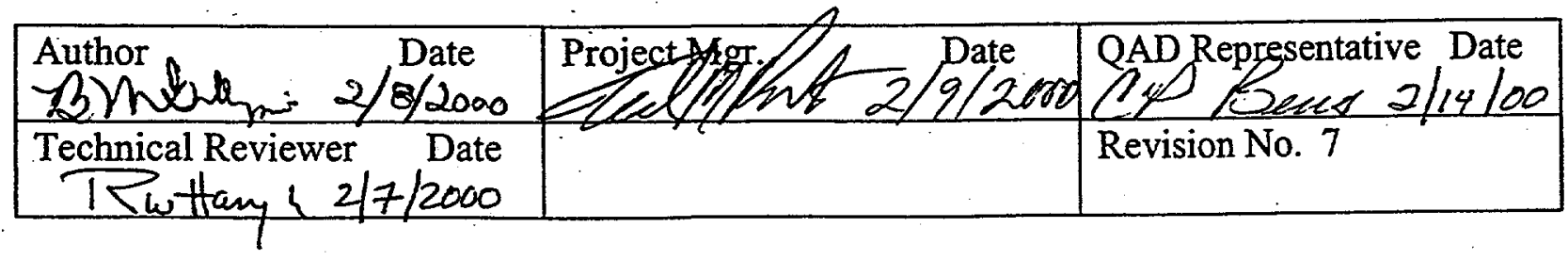


- appropriate radiation survey instruments

- sample labels

- trip sheet (also referred to as trip log)

- PNL-MA-580 SESP Procedures Manual

SAMPLE COLLECTION

\section{AS-FOUND OBSERVATIONS}

- insecticide spray for bees.

A supply of fresh, unexposed filter head assemblies is kept in the field sampling truck in a wooden filter head assembly carrying rack. The analytical laboratory loads the filter heads with unexposed filter paper. The monitoring team picks up a supply of these fresh, unexposed filter head assemblies when samples are submitted to the laboratory for analysis. As a general rule, pick up as many fresh filter head assemblies as the number of samples submitted. This will maintain an adequate supply of fresh, unexposed filter heads in the carrier for the next day's sampling efforts.

Ensure that two matched heads (those painted the same color) are obtained for each double filter-head ${ }^{(a)}$ station on the trip schedule.

Calibrate the air sampling system every time you change a filter head, whether it is a scheduled change or a special sample change. Write the number of the calibrator on the trip sheet in the space provided.

Ensure that the calibrator has a current (up to date) calibration label. Calibrators are to be calibrated annually and must not be used if the recalibration date has passed.

NOTE: During warm months, bees frequently build nests in the sampling hutches. Contact the Sample Collection Task Leader for insecticide spray.

Note on the trip sheet any conditions near the sample site that might affect sample results, such as construction and farming activities.

Note on the trip sheet any problems with the sampling system before disturbing it in any way.

(a) Two matched filter heads, each operating at $1.5 \mathrm{ft}^{3} / \mathrm{min}$ on one pump drawing $3.0 \mathrm{cfm}$. 
If the vacuum pump or the running-time meter (RTM) is not operating:

- record pump numbers of bad pump and of replacement pump on the trip sheet

- replace pump

- describe apparent problem and its cause on trip sheet.

If the system appears to have been operating properly, check the RTM:

- If it reads approximately $336 \mathrm{~h}$ :

-record the number of hours on the trip sheet

-record the hours on the time log found at sample location.

- If it reads less than $168 \mathrm{~h}$, in addition to the above:

-mark trip sheet "No Alpha/Beta Analysis, Composite Only"

-draw lines through alpha and beta on the sample label. Initial and date the changes

-Record any apparent cause for the "short" sample on the trip sheet

-If the RTM is not working but the sampler is still running, then calculate the exposure hours, and enter this value on the "exposure hours" portion of the trip sheet.

AS-FOUND FLOW RATES
Before disturbing the station in any way:

Observe the as-found ${ }^{3} \mathrm{H}$ flow rate by reading the appropriate in-line rotameter. Ensure that the rotameter is vertical when you read it. If the sample is scheduled for collection, record the as-found flow rate on the trip sheet.

Measure the as-found flow rate for the particulate sampling loop as an in-line measurement as follows:

CAUTION: Use extreme care to avoid the loss of particulate material from the filter paper while handling the filter heads (do not place filter heads in pockets, set face down, bump, touch filter with fingers or expose to the weather). 
- Remove the exposed filter head (or matched head assembly) and install the flow calibrator in its place.

- Reinstall the exposed filter head (or matched head assembly) upstream of the calibrator, that is, in the calibrator inlet.

- Hold the calibrator vertical and read the flow rate.

Record the flow rate as the end flow calibration reading on the trip sheet. Verify that the information on the label is accurate.

NOTE: The flow rate for a double-head assembly will be the total for both heads. You must divide this number by two when you record the flow rate of each sample on the trip sheet and labels.

NOTE: When there is no observed end flow (power outage or pump failure), write " 0.0 observed end flow" and "use start flow = end comments section of the trip sheet. Record the "start flow" value on the "end flow" portion of the trip sheet.

FILTER CHANGE Remove the exposed filter head.

Examine the exposed filter(s). Record, on the trip sheet, any abnormalities, such as moisture damage, heavy accumulations of particulate materials, clogging due to snow or ice, wrinkles, or tears.

Attach the sample label to the side of each filter head, then place the exposed filter head(s) in a storage holder and cover it (them) with a plastic cover(s).

MAINTENANCE

Check that the overall sampling system is properly configured (see Figure 3.0.1).

Replace worn, brittle, or cracked tubing.

Check for loose connections, bad disconnects, etc. Repair or replace components as necessary.

Wipe excess dust from the entire system, and clean out hutch.

Air sample pumps should be replaced at least annually. As a pump is placed in service, write the in-service date on the pump. 
Pump replacement will be coordinated by the Sample Collection Task Leader based on pump availability.

NEW FILTER INSTALLATION AND CALIBRATION
Install the flow calibrator in line with the new filter-head unit at the calibrator inlet.

Adjust the flow in the particle loop to 1.5 (3.0) cubic $\mathrm{ft}$ per min (cfm).

NOTE: In the case of a double filter-head station, the flow must be set in the same manner, but at $3.0 \mathrm{cfm}$. It may not be possible to achieve a full $3.0 \mathrm{cfm}$ from all pumps; if not, it should be set to the maximum flow possible between 2.5 and $3.0 \mathrm{cfm}$. If the maximum achievable flow is less than $2.5 \mathrm{cfm}$, the pump should be replaced.

Record the flow rate in the "next flow" column on the trip sheet.

Remove the calibrator.

Install the new filter head(s) and reinstall the rainguard(s).

If there is a ${ }^{3} \mathrm{H}$ loop, adjust its flow to 0.4 cubic $\mathrm{ft}$ per hour (cfh).

Ensure that the ${ }^{3} \mathrm{H}$ rotameter ball is free to move throughout the length of the scale of the rotameter by adjusting the rotameter needle valve back and forth while the pump is running.

If a ${ }^{129} I$ sampler is present at the site, record the as-found flow rate, change the paper filter, and adjust the flow to $1.5 \mathrm{~cm}$.

Record on the trip sheet the air calibrator number, time off, end flow, exposure hours, pump number, next flow, and any abnormalities observed. Confirm that the date on, time on, start flow and date off, if preprinted on the trip sheet, are accurate. Ensure that all this information is on the trip sheet before submitting samples for analysis.

Reset the RTM to the zero hour.

See Section 8.1, Trip Sheets, for requirements for completing trip sheets and submitting samples to an analytical laboratory.
TRIP SHEET AND

SAMPLE

SUBMISSION

REQUIREMENTS 


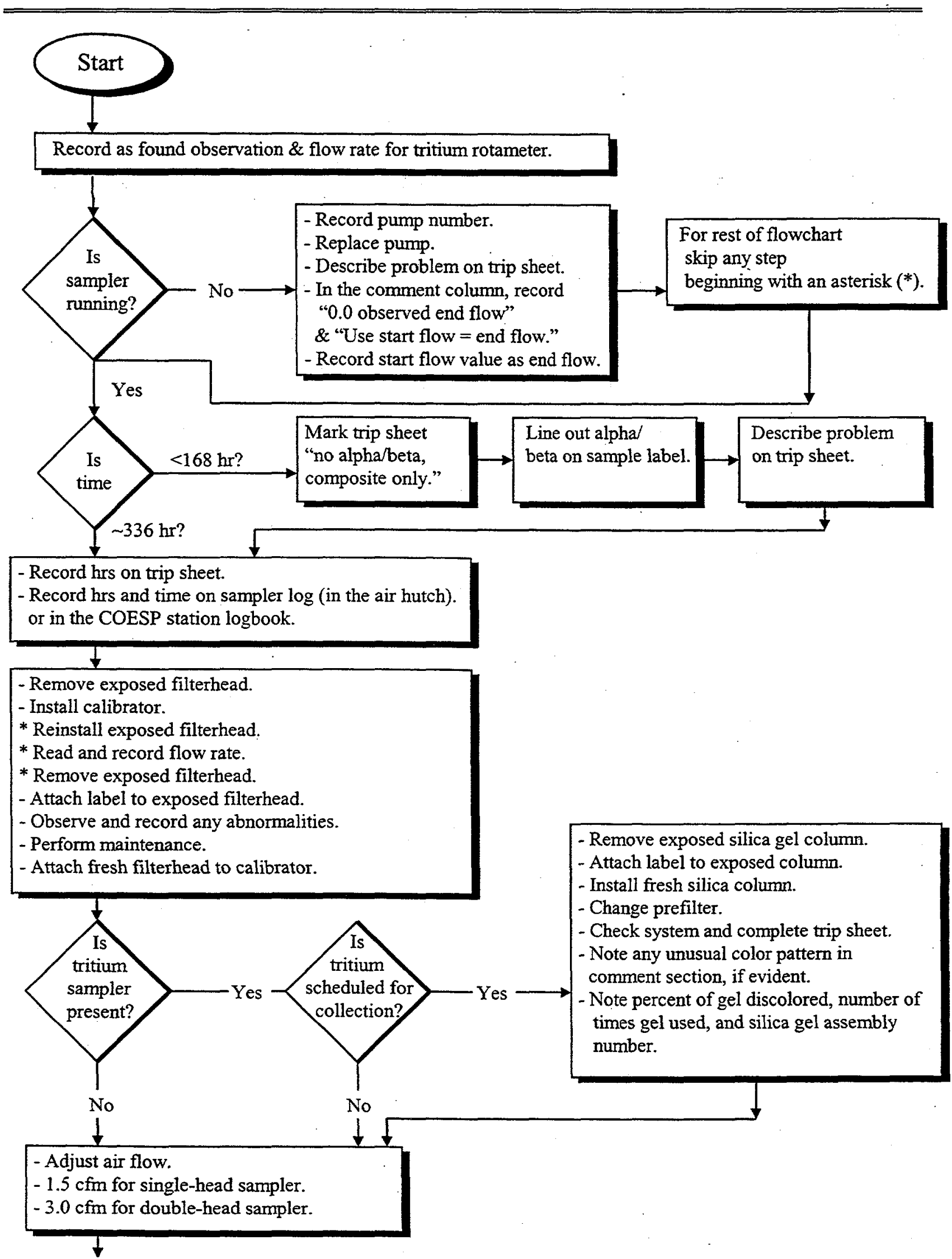

Continued on next page

Figure 3.1.1 Procedure for Collecting Particulate and Tritium Samples 


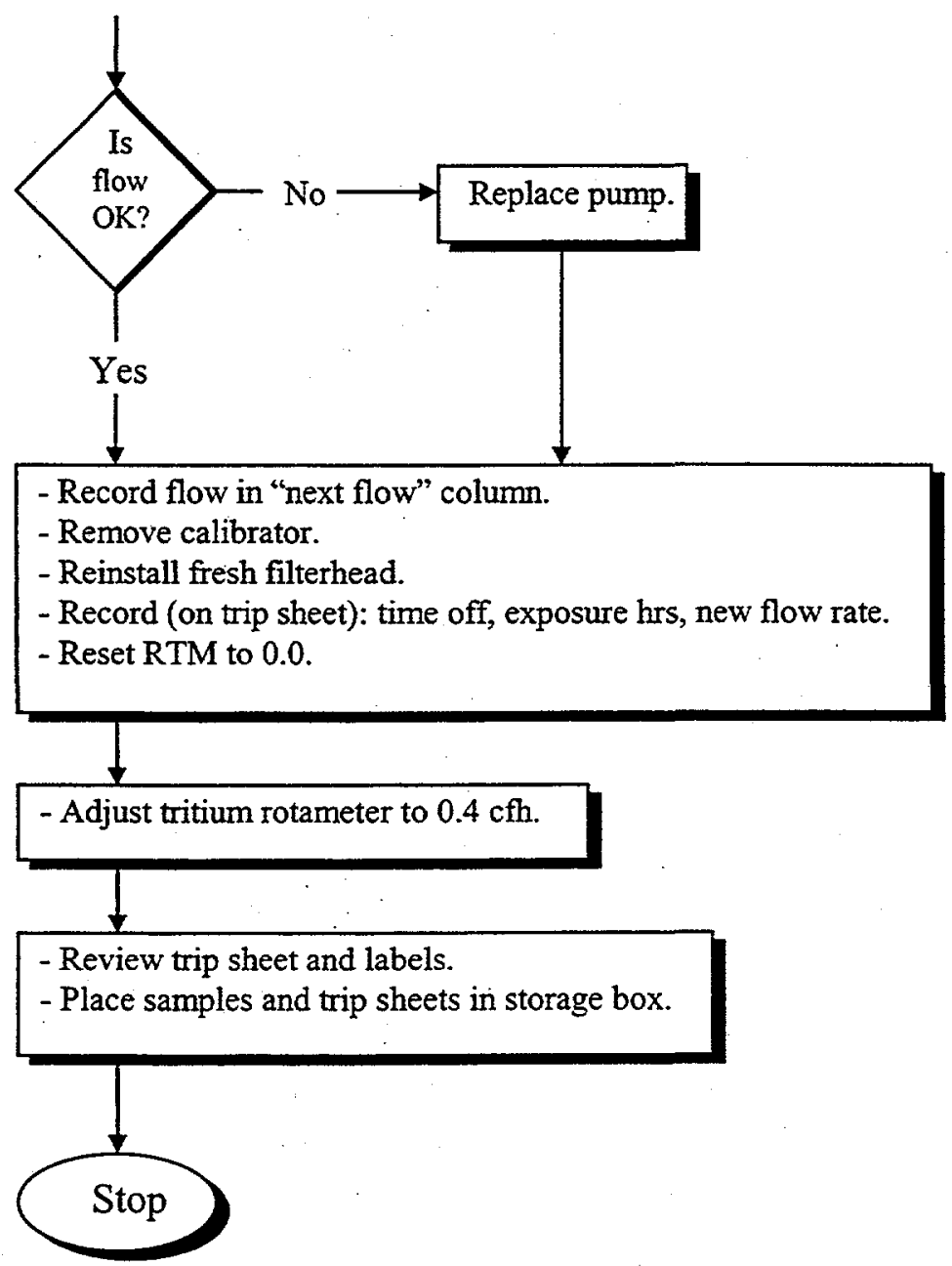

Figure 3.1.1. Procedure for Collecting Particulate and Tritium Samples (contd) 


\subsection{TRITIUM SAMPLES}

INTRODUCTION

EQUIPMENT

PREPARATION PROCEDURE
Atmospheric tritium $\left({ }^{3} \mathrm{H}\right)$ collection columns are placed at locations that could be impacted by Hanford Site operations. Silica gel is used to collect ${ }^{3} \mathrm{H}$ in the form of water vapor (HTO). Tritium samples are collected and analyzed monthly. Figure 3.1.1 summarizes the process of collecting particulate and ${ }^{3} \mathrm{H}$ samples.

In addition to the items listed for the collection of the particulate filter samples (see Section 3.1), the following equipment may be needed to collect ${ }^{3} \mathrm{H}$ samples:

- fresh silica gel columns. Fresh gel can be identified by the bright blue color of the gel.

- plastic tubing (3/8-in. ID)

- hose clamps - metal screw type

- filters

- sample labels

- tape

- rainguard for filter holder

- spare rotameters

- trip sheet

- PNL-MA-580 SESP Procedures Manual.

A supply of fresh, unexposed silica-gel column assemblies is kept in the field sampling truck. The analytical laboratory loads the silica-gel column assemblies. The monitoring team picks up a supply of these fresh, unexposed silica-gel column assemblies when samples are submitted to the laboratory for analysis.

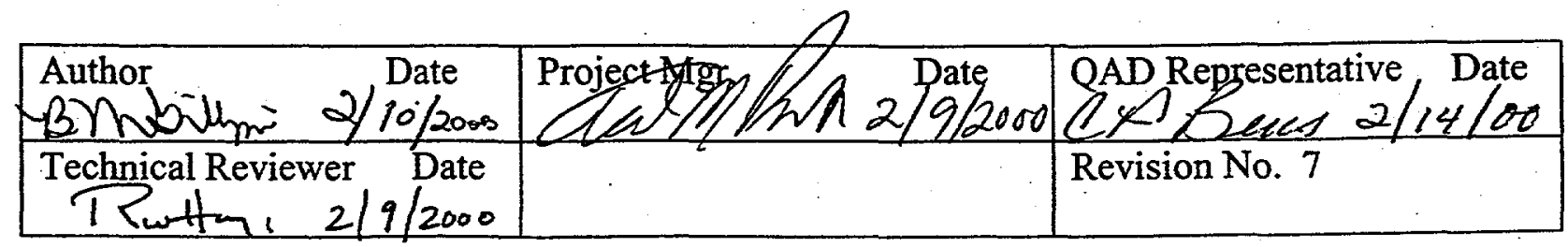


Section 3.2

Issued: $02-00$

Supersedes: $03-98$

PNL-MA-580

Page 2

As a general rule, pick up as many fresh silica-gel column assemblies as the number of samples submitted. This will maintain an adequate supply of fresh, unexposed silica-gel column assemblies in the carrier for the next day's sampling efforts.

NOTE: Ensure that all columns are tightly sealed and capped.

Be certain that rubber gaskets are in place and caps are screwed down tightly against them.

Ensure that all fittings on columns are tight.

SAMPLE COLLECTION
Observe silica gel column assembly in use. The silica gel at the air inlet should be lighter in color (pinkish or a light blue), while that at the outlet should remain dark blue. Note on trip sheet how much of the sampler has discolored.

Before disturbing the system in any way, record the as-found flow rate observed on the ${ }^{3} \mathrm{H}$ rotameter on the trip sheet. If the rotameter is inoperable, record on trip sheet and replace rotameter.

Record total exposure hours using the RTM time log on the hutch door (or in the station logbook at COESP stations) for total sample period. If the RTM time log at the hutch is incomplete or illegible, exposure hours are available on previous trip sheets.

Notify Sample Collection Task Leader if:

- no color change from blue to light blue or pink is observed

- entire length of all three columns is pink or light blue

- color change pattern is unusual (e.g., first and last column discolored but middle column still blue or 2 nd and 3 rd column discolored and 1st column still blue). Unusual saturation patterns could be indicative of a leak.

If exposure hours are less than approximately 336 :

- notify the Sample Collection Task Leader, who will decide if the sample should be submitted to the analytical laboratory.

Remove existing column assembly from sample system by disconnecting the quick connect fittings at the inlet and outlet of the column assembly.

Attach the sample label to the exposed sample.

Install the fresh silica gel column assembly so that air flow is from top to bottom in the columns. 
Ensure that all columns are tightly sealed and capped and the quick connect fittings are secure.

Change the filter and reinstall the rainguard. The filter is not analyzed and should be discarded.

Remove dust from all system components.

Ensure that:

- quick connect fittings are secure

- columns are in vertical position

- rotameter is in vertical position

- rotameter is set at 0.4 cubic ft per hour (cfh).

Complete the trip sheet by entering the time off, end flow, exposure hours, and next flow in the appropriate locations. Verify that the start flow, and date off are printed on the trip sheet and are accurate. Note any unusual observations, the number of times the silica gel has been used (e.g., 2nd use, 3rd use), the amount of silica gel (as a percent), that has changed color, and the silica gel assembly number.

TRIP SHEET AND SAMPLE SUBMISSION REQUIREMENTS
See Section 8.1, Trip Sheets, for requirements for completing trip sheets and submitting samples to an analytical laboratory. 


\subsection{IODINE-129 SAMPLES}

INTRODUCTION

EQUIPMENT
Charcoal-cartridge samples from a few specially selected locations are collected monthly. These monthly samples are then composited for analysis of ${ }^{129} \mathrm{I}$ on a quarterly basis. The charcoal cartridges are preloaded in the cartridge holders for easy deployment in the field. The tandem filter holders are delivered to the analytical laboratory for ${ }^{129} \mathrm{I}$ analysis following each monthly exposure period.

Figure 3.3.1 is a flow diagram summarizing the process for changing charcoal cartridges for ${ }^{129}$ I samples. The flow diagram is included for quick reference and training purposes.

The following equipment may be needed when collecting ${ }^{129}$ I samples:

- new charcoal cartridges loaded in tandem filter cartridge holders, labeled by location

- key to locked storage box at 320 Building

- filters

- vacuum pump

- flow calibrator

- plastic bags

- sample labels

- rain guard for filter holder

- tape

- trip sheet

- PNL-MA-580 SESP Procedures Manual.

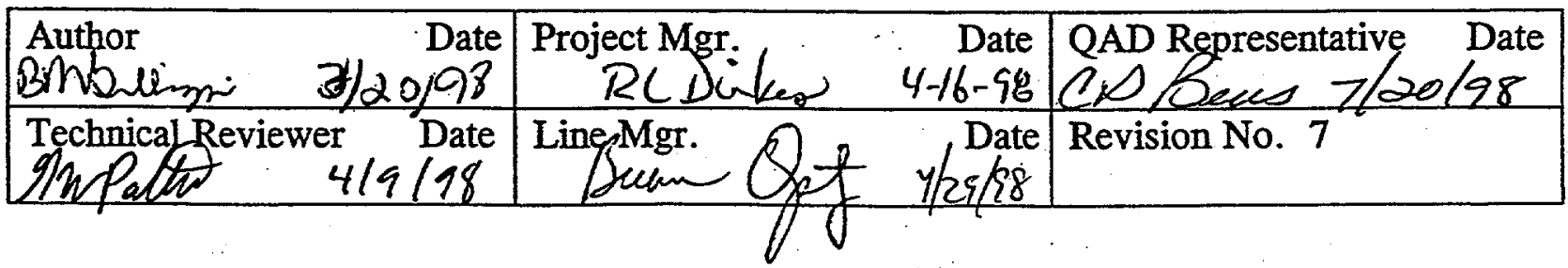


SAMPLE COLLECTION
A supply of the next month's four fresh, unexposed charcoal-cartridge filter head assemblies is kept in the field sampling truck. The analytical staff in 320 Building laboratory load the filter heads with unexposed charcoal, prepare the filter heads assembly, place it in a plastic bag, and store the set in the 320 Building locked storage box. The monitoring team picks up a supply of these fresh, unexposed charcoal cartridge filter head assemblies as samples are submitted to the laboratory for analysis. As a general rule, each month pick up a set of the fresh charcoal cartridge filter assemblies. This will maintain an adequate supply of fresh, unexposed filter heads in the carrier for the next ${ }^{129}$ I sampling efforts.

Measure the as-found flow rate as described in Section 3.1, page 3, and record the reading on the trip sheet.

Ensure that the hose clamps are secure.

Remove the exposed charcoal-cartridge holder. Because ${ }^{129} I$ is easily cross-contaminated, handle the holder carefully. DO NOT OPEN THE CARTRIDGE HOLDER.

Place cartridge holder in a plastic bag and seal with tape.

Put the label on the plastic bag.

NOTE: Prefilters are to be changed at the midpoint of the ${ }^{129} I$ exposure period as part of the particulate sampling schedule (see Section 3.1). The exposed prefilter should be discarded. Filters will already be installed in the tandem filter cartridge heads when they are picked up. Filters should be left in the heads when samples are returned to the analytical laboratory.

Install the flow calibrator in line, with the new filter holder upstream of the calibrator.

NOTE: Each filter holder has a location name on it. Use filter assemblies at their designated sites to reduce cross-contamination.

Set the flow rate to 1.5 cubic $\mathrm{ft}$ per $\min (\mathrm{cfm})$, remove the calibrator, and install the filter holder and rain guard.

Record on the trip sheet the air calibrator number, time off, end flow rate, pump number, next flow rate, exposure hours, and any abnormalities observed. 
Issued: $03-98$

TRIIP SHEET AND

SAMPLE

SUBMISSION

REQUIREMENTS
See Section 8.1, Trip Sheets, for further requirements for completing trip sheets and submitting samples to an analytical laboratory. 


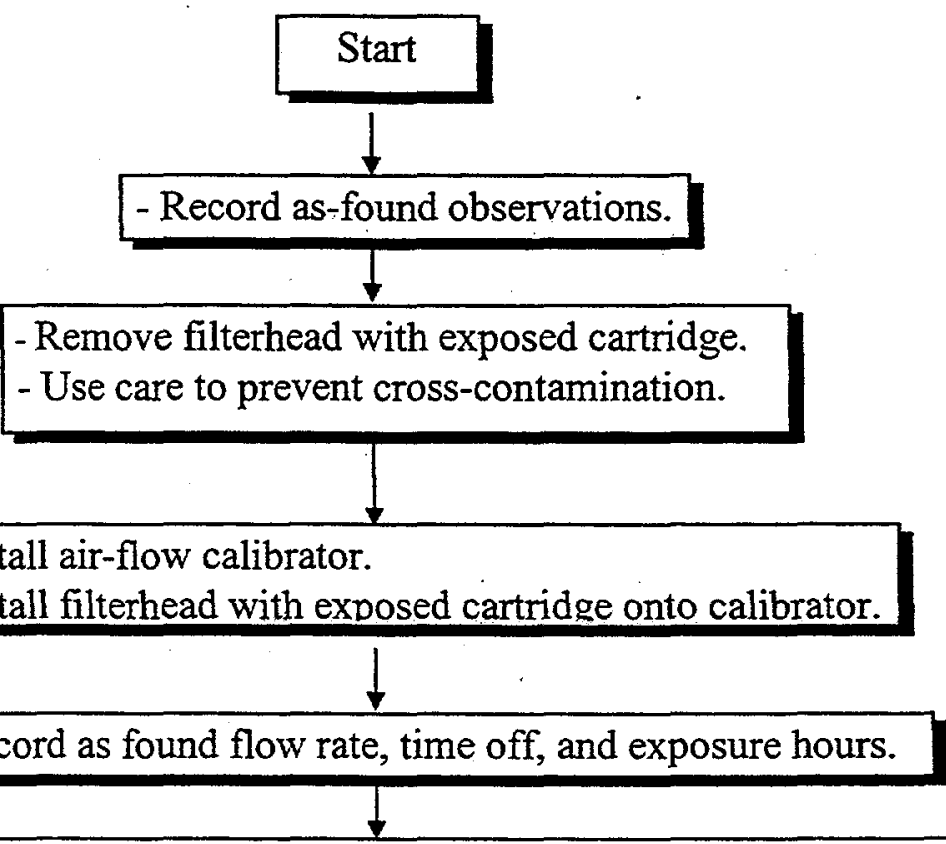

- Remove filterhead with exposed cartridge from calibrator.

- To prevent contamination do not open the filterhead to remove the cartridge.

- Place filterhead with exposed cartridge in a plastic bag and seal.

- Attach label to bag.

- Install fresh filterhead with cartridge (for that specific location) onto calibrator.

- Set flow to 1.5 cubic ft per $\min (\mathrm{cfm})$.

- Remove calibrator.

- Remove fresh filterhead with cartridge from calibrator.

- Install fresh filterhead with cartridge on sample line.

$$
7
$$

- Record flow rate in "Next Flow" column. Record time on.

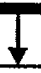

- Sample collection personnel review trip sheet for accuracy and completeness.

- Sample Collection Task Leader reviews trip sheet.

- Deliver samples to locked storage at back of 320 Bldg.

- Write "Placed into 320 Locked Storage" in "Relinq To" space.

- Leave front copy of trip sheet with samples.

- Pick up new filterhead from storage box (if available).

- Deliver back copy of trip sheet to Sample Collection Task Leader.

FIGURE 3.3.1. Procedure for Collecting Iodine-129 Samples 


\subsection{SURFACE-WATER SAMPLING PROCEDURES}

INTRODUCTION

COLUMBIA RIVER
The collection and analysis of water samples are integral parts of the SESP. Water samples are routinely collected from the Columbia River, local irrigation canals, riverbank springs, and on-site ponds. In addition, on-site drinking water systems are sampled through the Drinking Water Monitoring Project. These samples provide a means of assessing the impact of Hanford Site operations, determining the compliance status with applicable standards, evaluating the effectiveness of effluent control and monitoring systems, and evaluating the potential dose to the public from waterborne radionuclides.

Three types of water samples are routinely collected as described below:

- Grab samples (Section 4.1) are typically used when the water characteristics are relatively stable; the stream does not flow continuously; information on minimum, maximum, and variability (time or spatial) is desired; or the parameters to be analyzed are likely to change during storage time.

- Composite samples (Section 4.2) are used to determine average concentrations and provide certainty that pollutants did not flow by the sample location between sample dates.

- Continuous samples (Section 4.3) are used in determining average concentrations and allow for the very large volumes of water needed to detect those contaminants present at very low concentrations.

Grab samples are generally collected manually, while the composite and continuous samples are collected using automatic sampling systems. In some cases, hand or mechanically operated pumps are used to collect grab samples.

The Columbia River is a significant pathway to the public for contaminants associated with liquid effluents resulting from Hanford Site operations. Radiological and nonradiological pollutants enter the river along the Hanford Reach as a result of direct effluent discharges and through seepage of contaminated groundwater.

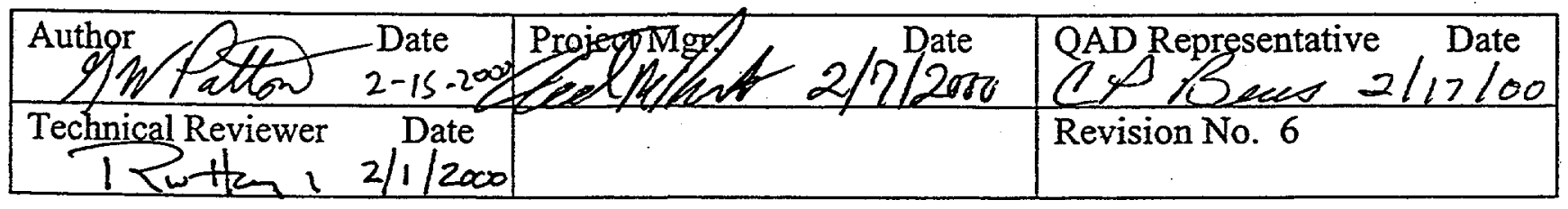


IRRIGATION WATER

ON-SITE POND WATER

DRINKING WATER

RIVERBANK SPRINGS
As such, the river is sampled routinely at several locations, using different collection methods and various frequencies, depending on the specific constituent of interest and the information desired.

Permanent monitoring stations have been established at Priest Rapids Dam and the Richland Pump House. Composite and continuous samples are used to determine the average radionuclide concentrations at these selected locations. In addition, grab samples are collected routinely along crosssections of the Columbia River for nonradiological water quality analysis and to study the spatial variability of contaminant concentrations.

Grab samples of irrigation water originating from the Columbia River downstream of Hanford are collected routinely during the irrigation season. Irrigation water is identified as a link in the pathway for pollutants in liquid effluents to reach the public.

Although on-site ponds are inaccessible to the public and do not constitute a direct off-site environmental impact, routine sampling of the ponds is performed because they are accessible to migratory waterfowl, creating a potential biological pathway for the dispersion of contaminants. Periodic sampling of the ponds also provides an independent check on effluent control and monitoring systems. Grab samples are generally collected because fluctuations in contaminant concentrations are not expected to be significant.

Drinking water samples are collected routinely in accordance with federal and state regulations. Samples are collected from all on-site sanitary water sources.

Contaminated groundwater enters the Columbia River along the Hanford Reach via surface and sub-surface seepage. Those seeps or seep areas located above the water level of the river are commonly called riverbank springs. Grab samples are collected from the riverbank springs periodically to determine the concentrations of contaminants entering the river via this pathway. 


\subsection{GRAB SAMPLES}

INTRODUCTION

PERSONNEL

EQUIPMENT
Grab samples are discrete samples collected at a single location over a short period of time, typically less than 15 minutes. As such, grab samples are used to characterize water quality at a single point in time and space. Grab samples can be collected manually or with an automated sampling device. This sampling method is generally used when the stream does not flow continuously, when the water quality characteristics are relatively constant, or when the parameters to be analyzed are likely to change during storage.

Grab samples are collected from the Columbia River, on-site ponds, irrigation water canals, and on-site drinking water supply systems.

NOTE: This grab sample procedure does not apply to Columbia River riverbank springs. The grab sampling procedure for the Columbia River riverbank springs is addressed in section 4.6 of this document.

Figure 4.1.1 shows a flow diagram summarizing the step-by-step process for collecting a grab sample.

Field sampling must be conducted by staff who have received training on these sampling procedures and are familiar with the sampling equipment.

It is estimated that this procedure requires one (1) person for an efficient operation.

The following equipment and supplies may be needed for the collection of grab samples:

- sample bottles - see sample label for bottle requirements

- extra bottles or buckets to be used as needed to transfer samples from the water source to the sample container

- rubber hipboots or waist waders as needed

- towels

- sample labels

\begin{tabular}{|c|c|c|}
\hline Author 0 atan $\begin{array}{c}\text { Date } \\
2-15-2000\end{array}$ & Project & $\begin{array}{l}\text { QAD Representative } \text { Date } \\
\text { Seew } 2 / 17 / 00\end{array}$ \\
\hline $\begin{array}{l}\text { Technieal Reviewer } \text { Date }^{2} \\
1 / 4,2 / 9 / 2000\end{array}$ & & Revision No. 6 \\
\hline
\end{tabular}


- 2 in. wide clear tape to cover (protect) sample labels

- security tape

- trip sheet

- ball point pens and permanent marking pens.

SAMPLE COLLECTION
Obtain appropriate sample container as defined on sample label.

Proceed to sample location.

Follow requirements of any applicable Radiation Work Procedure (RWP).

Observe sample location, and record on the trip sheet any unusual conditions (e.g., excessive algae growth, heavy surface debris, or extremely large amounts of suspended sediment).

Collect the sample following these guidelines:

- Collect clean water from approximately mid-depth to avoid collecting sediment and surface debris.

- Avoid areas of floating debris.

- Avoid hitting or agitating the bottom, which would resuspend the sediments.

- Read the label to determine if any chemical preservatives have been added to the sample container. If no chemical preservatives have been added, then rinse the sample container three times with water to be sampled prior to sample collection. Do not rinse sample containers to which chemical preservatives have been added.

- When sampling flowing water, face the inlet of the sample container into the current.

- When sampling from a faucet, the faucet should be flushed thoroughly, generally 2 to 3 minutes before sample collection.

- Fill the sample container and tighten the cap firmly.

- Dry the outside of the sample container with a towel. 
- Seal the cap with security tape. Record the date, time, and sample volume on the trip sheet.

- Check that the sample date and sample number are on the label and are accurate.

NOTE: Make sure the sampling dates on all sample labels are correct. Labels are often printed days or weeks before sampling, and the dates may need to be changed to reflect the correct sample date. Also ensure the sampling dates on the trip sheets match the dates on the corresponding labels.

- Attach the sample label to the outside wall of the container.

- Cover the sample label with a strip of 2-in. wide clear tape to protect it from the water and to ensure it remains affixed to the container.

TRIP SHEET AND SAMPLE SUBMISSION REQUIREMENTS
See Section 8.1, Trip Sheets, for further requirements for completing trip sheets and submitting samples to an analytical laboratory. 


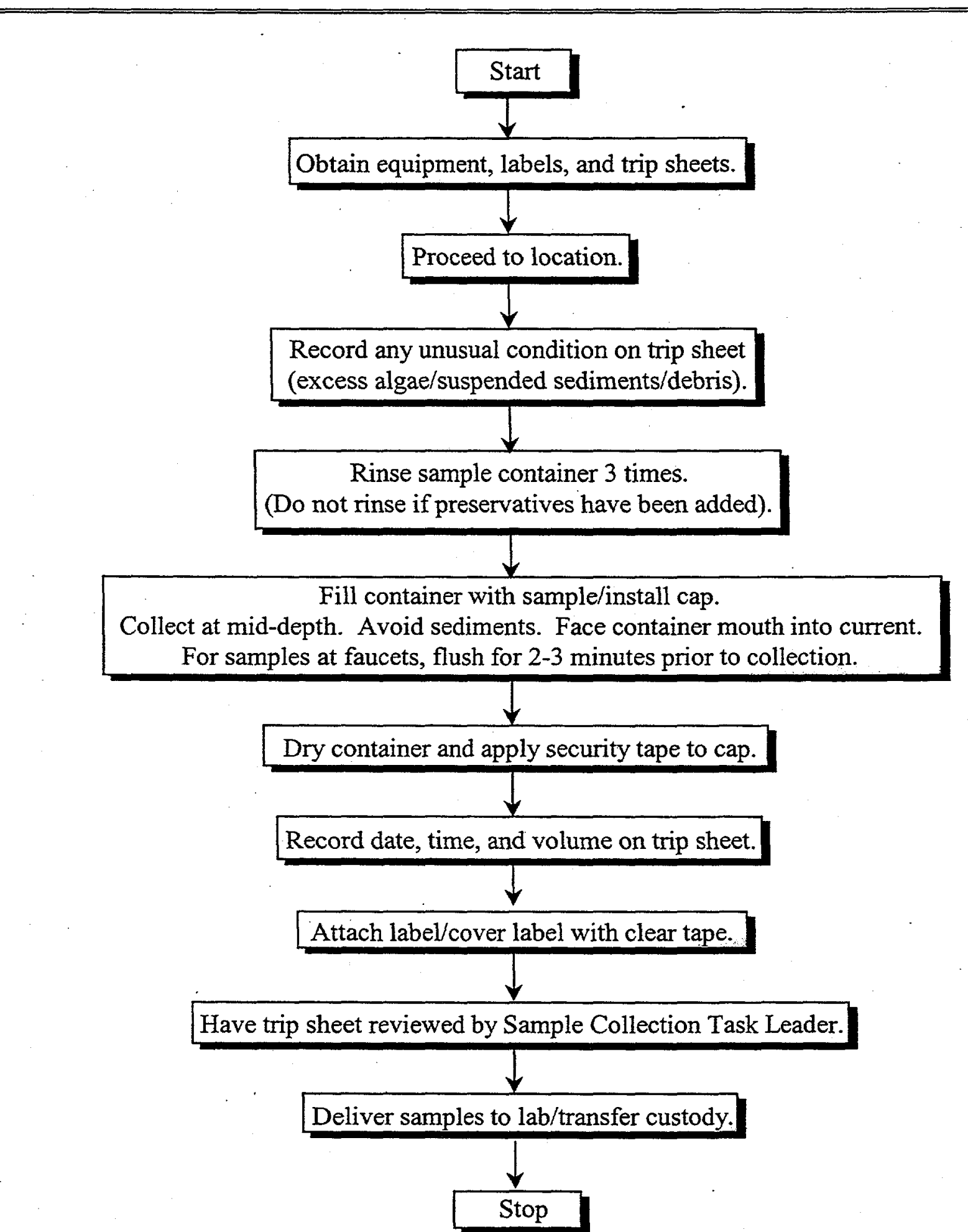

FIGURE 4.1.1. Flow Chart Summarizing the Grab Sampling Procedure for Water Samples 


\subsection{COMPOSITE WATER SAMPLES}

INTRODUCTION

PERSONNEL

EQUIPMENT
A composite water sample is a mixture of grab samples collected from a specific location at regular intervals throughout a sampling period. The individual grab samples may be collected manually; however, automatic sampling equipment is often used. Composite samples reflect the average characteristics during the sampling period and may be used to calculate mass contaminant loadings per unit time.

The Surface Environmental Surveillance Project (SESP) uses automatic composite samplers on the Columbia River at Priest Rapids Dam and the Richland Pump House.

Figure 4.2.1 shows a flow diagram summarizing the composite water sampling procedure.

Field sampling must be conducted by staff who have received training on these sampling procedures and are familiar with the sampling equipment.

It is estimated that this procedure requires one (1) person for efficient operation.

The following equipment and supplies may be needed for the collection of composite samples:

- 10-L (2.5-gal) plastic collapsible container with lid

- 100-mL graduated cylinder

- watch

- miscellaneous tools for making minor repairs

- trip sheet

- sample labels

- 2-in. wide clear tape to cover (protect) sample labels

- ballpoint pens and permanent marking pens.

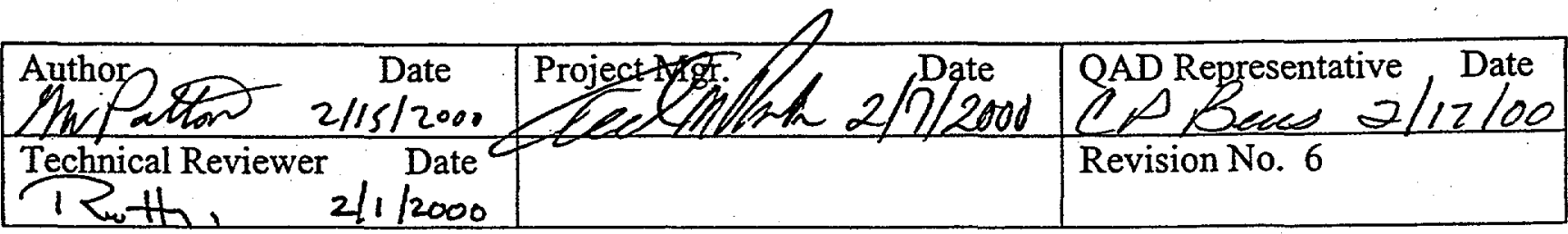


SAMPLE COLLECTION
Observe the water flow diagram of the composite sampler (Figure 4.2.2).

Obtain a clean sample container.

Proceed to the sample location.

Observe sample container in the composite sampler. The container should be approximately half full.

Remove the partially filled sample container and tighten cap firmly.

If no composite sample is available, a grab sample should be taken. The grab sample may be taken from the intake hose of the sample reservoir or, if the former is not possible at the Richland Pump House, from the end of the dock located downstream from the pump house. In either case, the sample bottle should be rinsed three times with water to be sampled prior to sample collection. Indicate on the trip sheet that a grab sample has been taken rather than a composite sample. Record the sample collection location (e.g., intake hose or dock) in the description column on the trip sheet.

Record the date on, date off, time on, time off, and sample volume on the trip sheet.

Check that the sample date and sample numbers are on the sample labels and are accurate.

NOTE: Make sure that the sampling dates on all sample labels are correct. Labels are often printed days or weeks before sampling, and the dates may need to be changed to reflect the correct sample date. Also ensure that sampling dates on trip sheets match the dates on the corresponding labels.

Attach the sample label to the sample container.

Cover the sample label with a strip of the 2-in. wide clear tape to protect it from the water and ensure it remains affixed to the container.

Seal the cap on the sample container with security tape.

Note any unusual conditions on the trip sheet, such as equipment failures, unusually high amounts of suspended solids in the sample, an unusually small or large sample volume, or an unusually small or large sample aliquot volume. 


\section{ALIQUOT VOLUME CHECK}

Check aliquot volume as follows:

- Turn sampler power off, then immediately back on. (The switch is located on the control panel beside the measuring chamber.)

- Place the graduated cylinder under the sample outlet tube.

- Observe the aliquot volume collected in the graduated cylinder. Volume should be 50 to $60 \mathrm{~mL}$.

- Record the aliquot volume collected on the trip sheet.

If: 1) the volume is less than $50 \mathrm{~mL}$ or greater than $60 \mathrm{~mL}$, proceed to "ALIQUOT VOLUME ADJUSTMENT."

2) the aliquot volume is greater than or equal to $50 \mathrm{~mL}$ and less than or equal to $60 \mathrm{~mL}$, proceed to "SAMPLE JUG PLACEMENT."
Periodically, the aliquot volume may require adjustment to ensure an adequate sample volume is collected. Be aware this activity may take more than an hour to complete, and it may be necessary to perform this activity at a later date or time. Contact the Sample Collection Task Leader or the Water Task Leader prior to performing the aliquot volume adjustment.

The volume of the aliquot collected at each time period is adjusted as follows. Refer to Figure 4.2.3 throughout the discussion.

Turn the function knob (Figure 4.2.2) to the OFF position.

Remove the wing nuts from the top of the measuring chamber.

Carefully remove the siphon spiral tube from the measuring chamber.

Loosen the set screw near the top of the outer siphon spiral tube.

Adjust the opening in the siphon spiral tube to increase or decrease the aliquot volume:

- to increase, turn counterclockwise

- to decrease, turn clockwise.

CAUTION: EASY DOES IT! Minor adjustments result in substantial variations in the aliquot volume. 
NOTE: When the spiral tube is properly adjusted for the desired aliquot volume, the center of the opening in the spiral tube should be level with the desired milliliter increment on the measuring chamber.

Tighten the set screw.

Place the siphon spiral tube back into the measuring chamber, being careful not to twist or exclude the O-rings. Tighten the wing nuts onto the top of the measuring chamber.

Recheck the sample aliquot volume (as previously discussed).

Continue repeating these steps until the desired volume ( 50 to $60 \mathrm{~mL}$ ) is obtained.

Once the desired volume has been obtained, record the initial aliquot volume (prior to adjustment) and the final adjusted aliquot volume on the trip sheet.

Turn the function knob (Figure 4.2.2) back to the TIME position.

SAMPLE CONTAINER PLACEMENT
Rinse the clean sample container three times with water from the intake line of the sample reservoir.

Place the rinsed sample container into the sample housing beneath the sample outlet tube.

\section{Check that the power is $\mathrm{ON}$.}

Check to be sure that the function knob (Figure 4.2.2) is on TIME.

\section{Check the MIN-HRS knob for appropriate setting:}

- $1 \mathrm{~h}$ for weekly samples (Priest Rapids Dam and Richland Pump House)

TRIP SHEET AND

SAMPLE

SUBMISSION REQUIREMENTS
See Section 8.1, Trip Sheets, for further requirements for completing trip sheets and submitting samples to an analytical laboratory. 


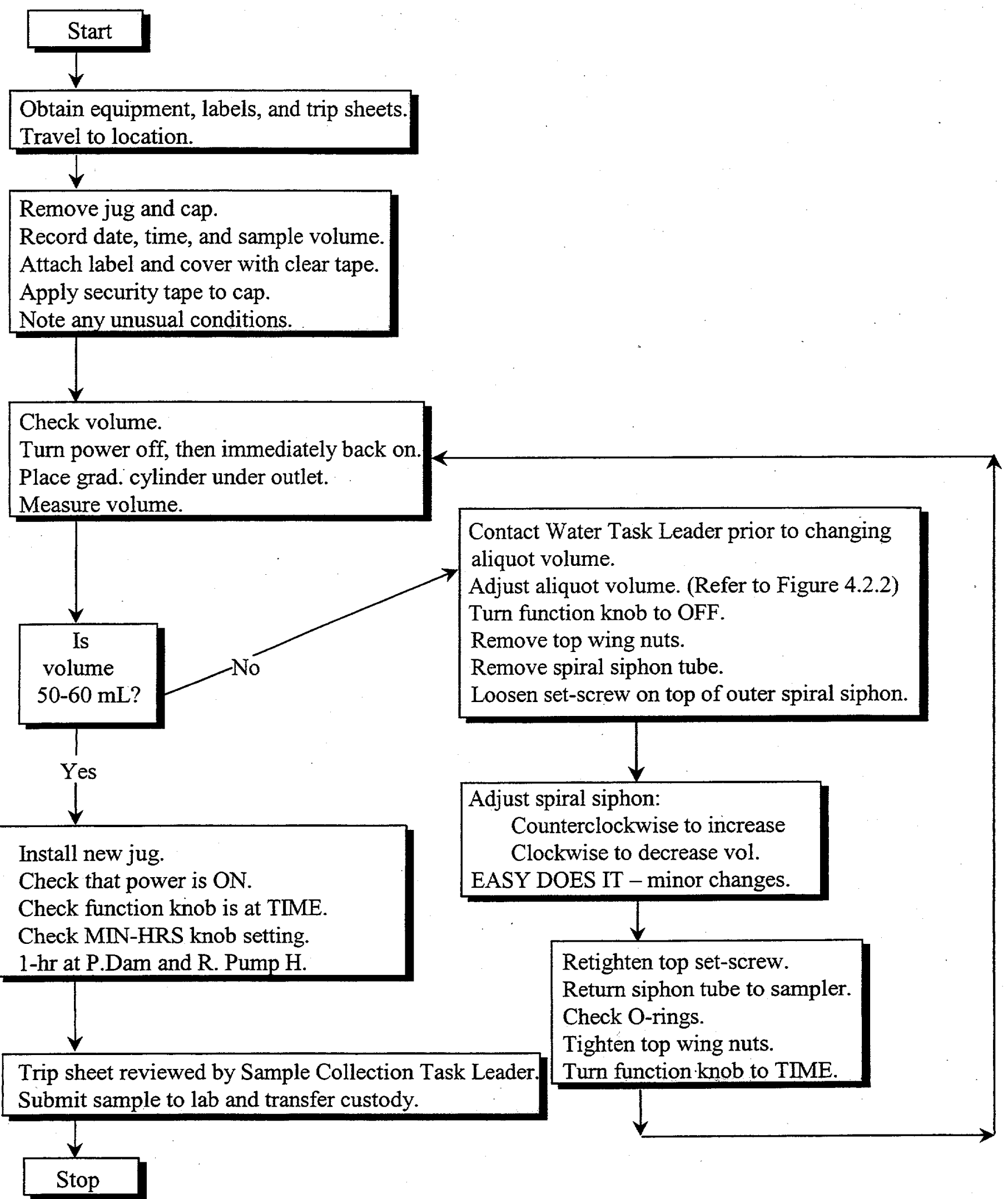

FIGURE 4.2.1 Summary of the Composite Water Sampling Procedure 
Section 4.2

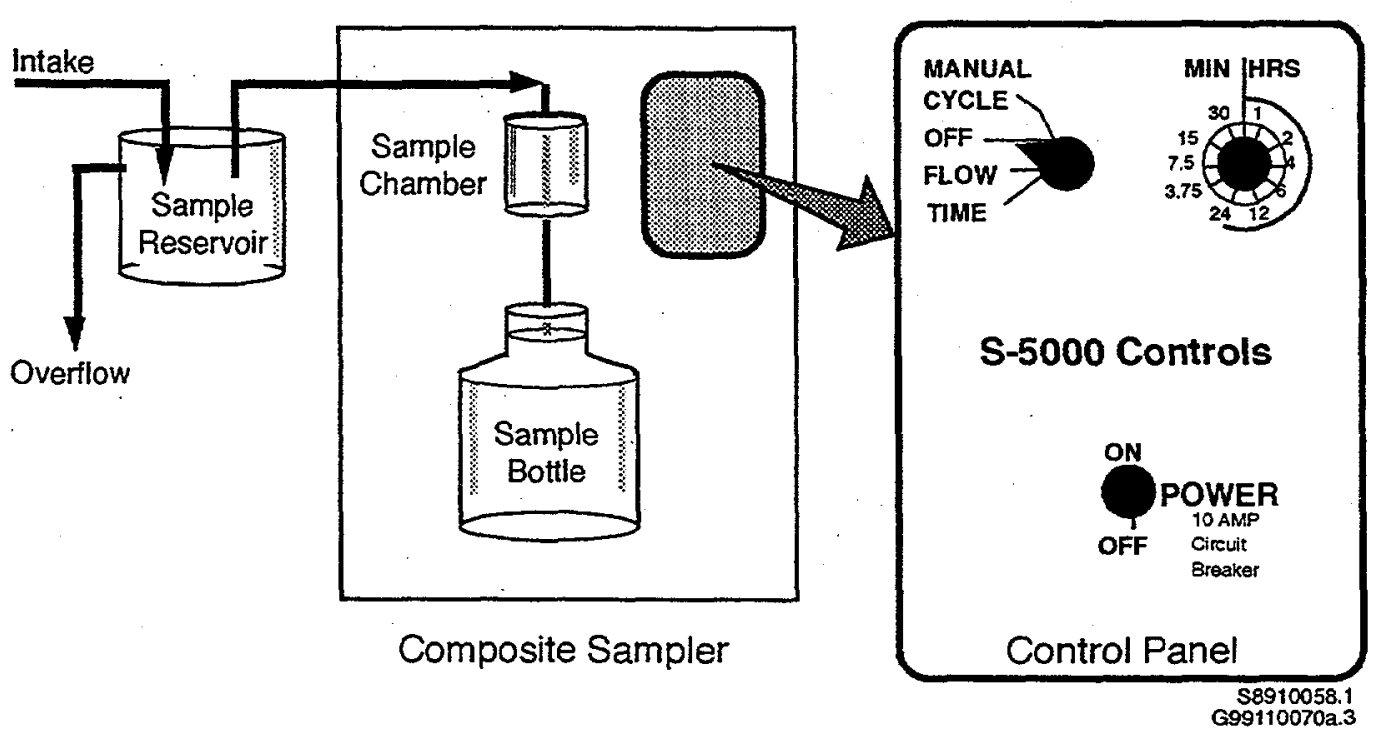

Figure 4.2.2. Composite Water Sampler Flow Diagram 


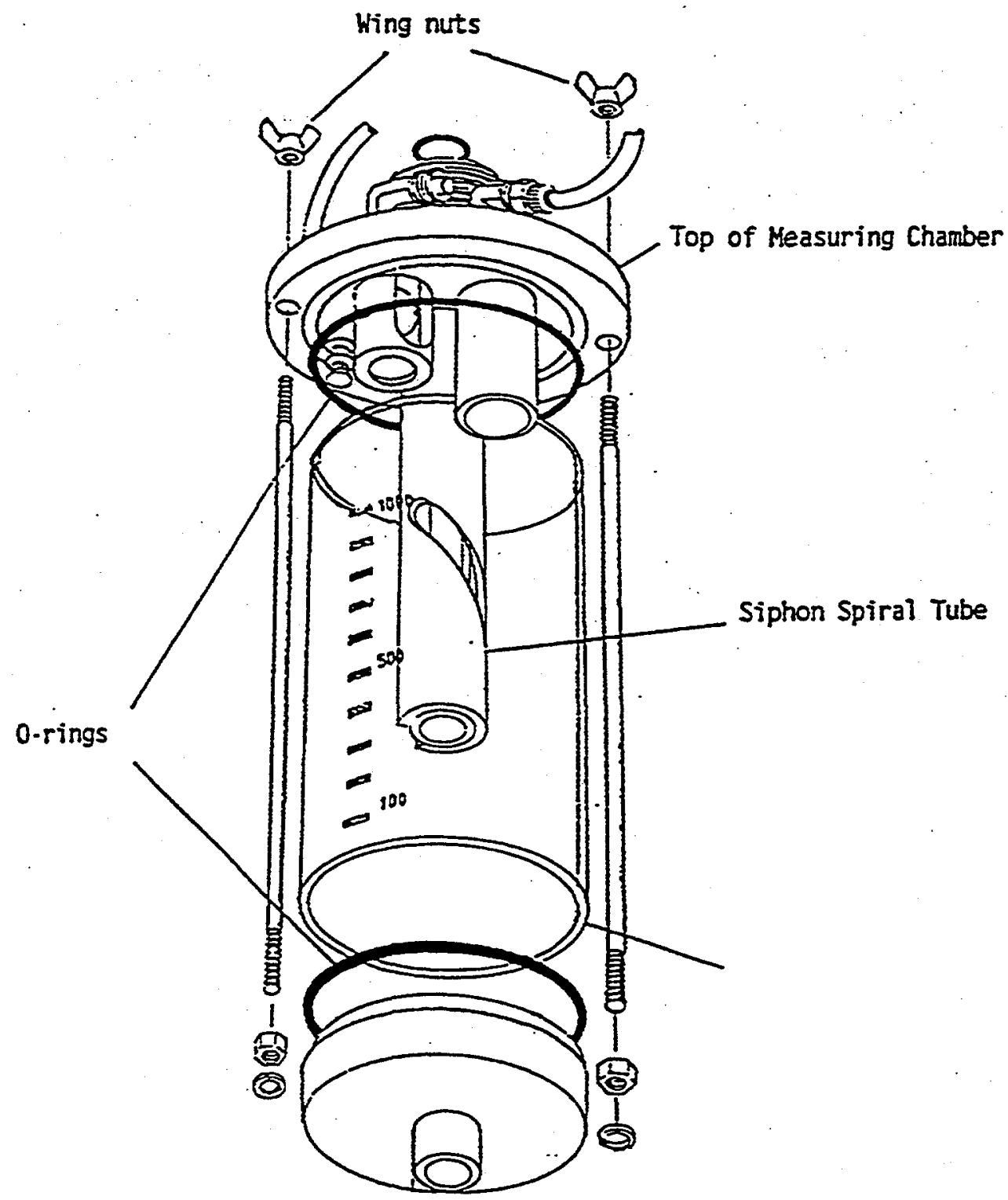

Figure 4.2.3. Measuring Chamber Detail 


\subsection{CONTINUOUS SAMPLES}

\section{INTRODUCTION}

PERSONNEL

\section{EQUIPMENT}

Continuous samples are the ultimate form of a composite sample. Water is continuously pumped through a set of filters (roughing sock filter and millipore glass fiber filter) and a mixed-bed ion-exchange column. The continuous water sample is commonly called the filter/resin sample.

Using the filter/resin arrangement allows for sampling the extremely large volumes of water needed to detect some radionuclides present in very low concentrations in Columbia River water.

Continuous (filter/resin) water sampling systems are located in monitoring stations at Priest Rapids Dam and the Richland Pump House.

Figure 4.3.1 shows a flow diagram summarizing the continuous water sampling procedure.

Field sampling must be conducted by staff who have received training on these sampling procedures and are familiar with the sampling equipment.

It is estimated that this procedure requires one (1) person for efficient operation.

The following equipment and supplies may be needed for the collection of continuous samples:

- clean "Universal II" resin columns

- clean glass fiber filters (approximately 11.5 in. in diameter)

- clean sock filters (stored in a clean plastic bag)

- wrench for loosening the handwheels on the glass fiber filter cover plate.

- forceps (clean and stored in a clean plastic bag)

- miscellaneous tools for making minor repairs

- 100-mL graduated cylinder

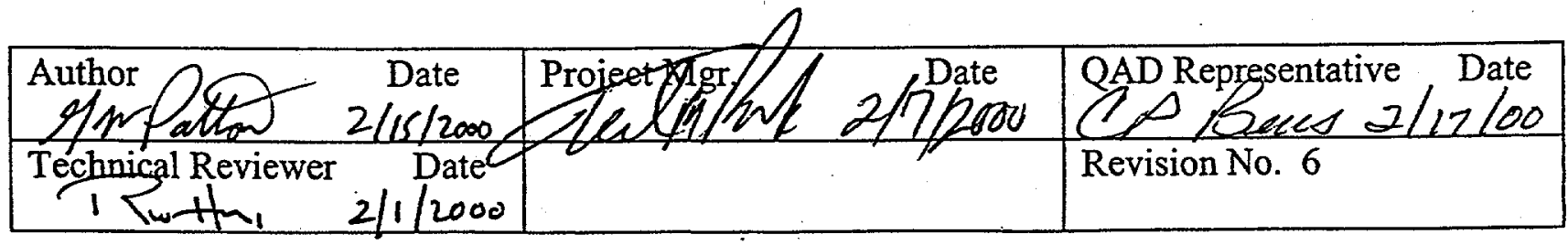


- timer (watch with second hand)

- plastic bags

- sample labels

- trip sheet

- ball point pens and permanent marking pens

- 2-in. wide clear tape to cover (protect) sample labels

- security tape

SAMPLE COLLECTION
Study the water flow diagram of the continuous filter/resin sampling system (Figure 4.3.2).

Obtain the new sock and glass fiber filters and the fresh resin columns.

Proceed to the sampling location.

Observe the sampling system for proper setup, and note any unusual conditions on the trip sheet.

Measure the volume of water passing through the system in $1 \mathrm{~min}$, using the $100-\mathrm{mL}$ graduated cylinder and timer.

NOTE: A system flow check is part of weekly maintenance for the continuous sampler and should be made even during weeks when the filter/resin system is not scheduled to be changed.

If: 1) the filter/resin system is scheduled to be changed, record the flow rate $(\mathrm{mL} / \mathrm{min})$ as "end flow" on the trip sheet and proceed to "FILTER/RESIN CHANGE OUT."

2) the filter/resin system is NOT scheduled to be changed, record the volume in the comment section of the composite sampling trip sheet and proceed to "SYSTEM CALIBRATION."

NOTE: If the filter/resin system is not scheduled to be changed, use a hand pump or siphon hose to clear the sediment from the sample intake reservoir. Doing this on a regular basis will help to keep algae levels down and will help avoid clogging the system with sediment. 
FILTER/RESIN CHANGE-OUT
Remove the pump power cord from the outlet.

Record sample time off (i.e., the time at which the power cord was removed from the outlet) on the trip sheet.

Open the pressure valve to relieve the pressure on the system.

Remove the locking clamp on the sock filter holder to change the sock filter.

Remove the sock filter, being careful not to lose any of the collected material. Avoid touching the collected material.

Place the sock filter directly into a clean plastic bag. (NOTE: Do not lay the filter down on an unsanitary surface.)

Remove the used resin column from the mounting brackets, and set it aside to partially drain.

Observe the color of the resin column. The resin should be yellowish nearly to the top. Note on the trip sheet if column is solid yellow or solid purple.

Remove the glass fiber filter cover plate by loosening the handwheels.

Remove the used glass fiber filter, using care to avoid loss of any filtered material. Forceps, which are available at each location, may be needed. Avoid touching the filtered material.

Fold the filter carefully into quarters keeping the filtered material on the inside of the fold.

Place the folded filter directly into the clean plastic bag with the sock filter. (NOTE: Do not lay the filter down on an unsanitary surface.)

Seal the plastic bag.

Clean the filter holder plates and O-rings by removing any foreign material.

Place a new filter into the filter holder, waffle side down.

Align the glass fiber filter cover plate with the lower block assembly, using the alignment stud openings. Lower the glass fiber filter cover plate carefully. 
Reassemble the filter holder, tightening the opposing handwheels in pairs to obtain a uniform seal.

Insert the new sock filter into the filter holder. Filters must be turned inside out to seal properly. Fold the top of the sock filter over the filter holder, and reset the O-ring on the filter holder to ensure a complete seal.

Install the new resin column (after removing the rubber end caps), ensuring that the O-rings are in place in the mounting brackets.

Attach the rubber end caps from the new resin column to the used one.

Fill the sock filter holder and resin column with water from the intake hose of the sample intake reservoir prior to closing the holder.

Replace the top of the filter holder, and tighten the locking band firmly.

Plug the power cord back into the outlet.

Allow the system to come to equilibrium, typically 3 to 5 minutes, before proceeding to "System Calibration."

Check that the date on, date off, time on, time off, sample number, and flow rates are recorded on the trip sheet.

Check that the date off, and sample number are on the sample labels and are accurate.

Attach the sample label for the resin column to the outside of the column itself (not the box in which the new resin column came).

Cover the sample label with a strip of the 2 -in. wide clear tape to protect it from the water and to ensure it remains affixed to the column.

Place the resin column into the box in which the new resin column came, and seal the box with security tape.

Attach the sample label for the filters to the outside of the plastic bag in which the filters were placed.

Place the sealed plastic bag with filters into another clear plastic bag, and seal the outer bag. 
SYSTEM

CALIBRATION
Measure and record the volume of water passing through the system in 1 min using the $100-\mathrm{mL}$ graduated cylinder and timer. The proper flow rate is between 45 and $60 \mathrm{~mL} / \mathrm{min}$; ideally, $50 \mathrm{~mL} / \mathrm{min}$.

If: 1) the flow rate is 45 to $60 \mathrm{~mL} / \mathrm{min}$, record the flow rate as "next flow" on the trip sheet, and proceed to the next step.

2) the flow rate is less than $45 \mathrm{~mL} / \mathrm{min}$ or greater than $60 \mathrm{~mL} / \mathrm{min}$, adjust the pump flow.

- Decrease the flow by moving pump arm towards the center position.

- Increase pump flow by moving arm away from center.

- Repeat "SYSTEM CALIBRATION" steps to check adjustment.

Check to see that the water supply to the pump reservoir is adequate but not excessive. The built-in overflow cannot handle an excessive amount. A small stream of water is adequate.

TRIP SHEET AND SAMPLE SUBMISSION REQUIREMENTS
See Section 8.1, Trip Sheets, for further requirements for completing trip sheets and submitting samples to an analytical laboratory. 


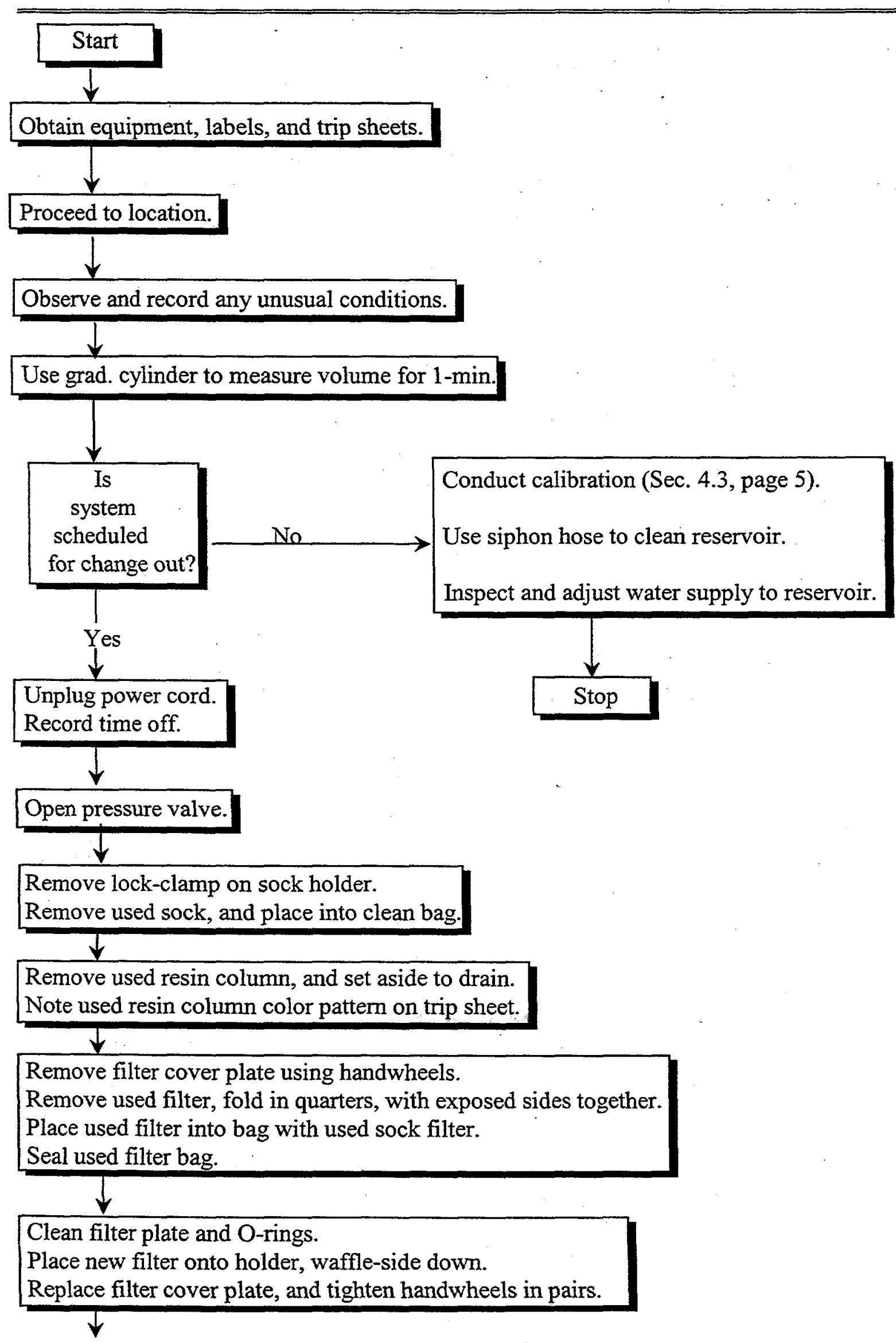

Figure 4.3.1. Procedure for Continuous Water Sampling (continued on next page) 


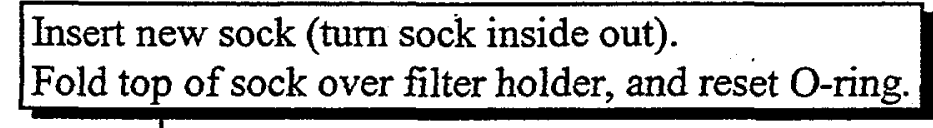

Remove rubber caps from new resin column
Install new resin column, and check O-rings.
Place rubber caps on used resin column.

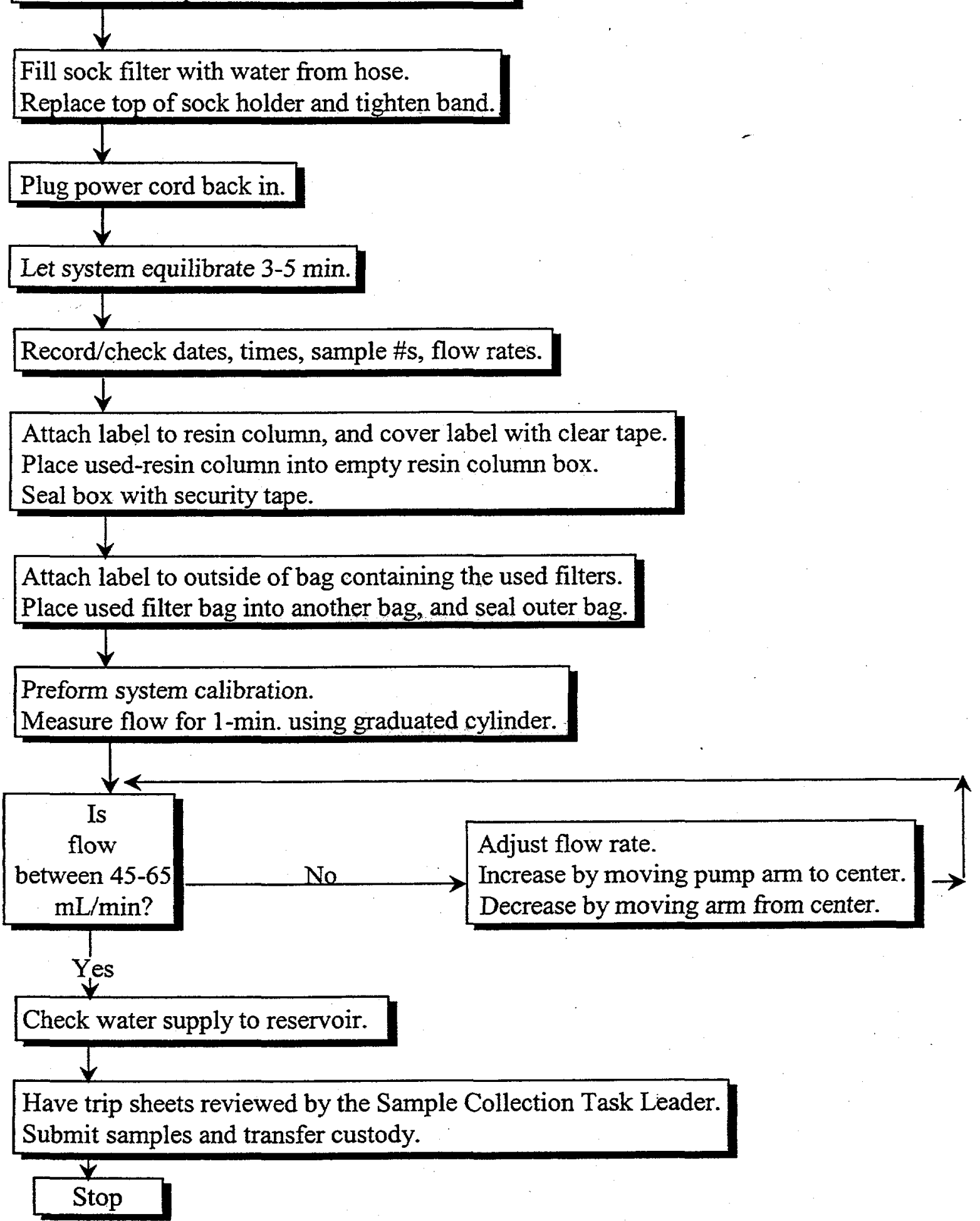

Figure 4.3.1. Procedure for Continuous Water Sampling (contd) 


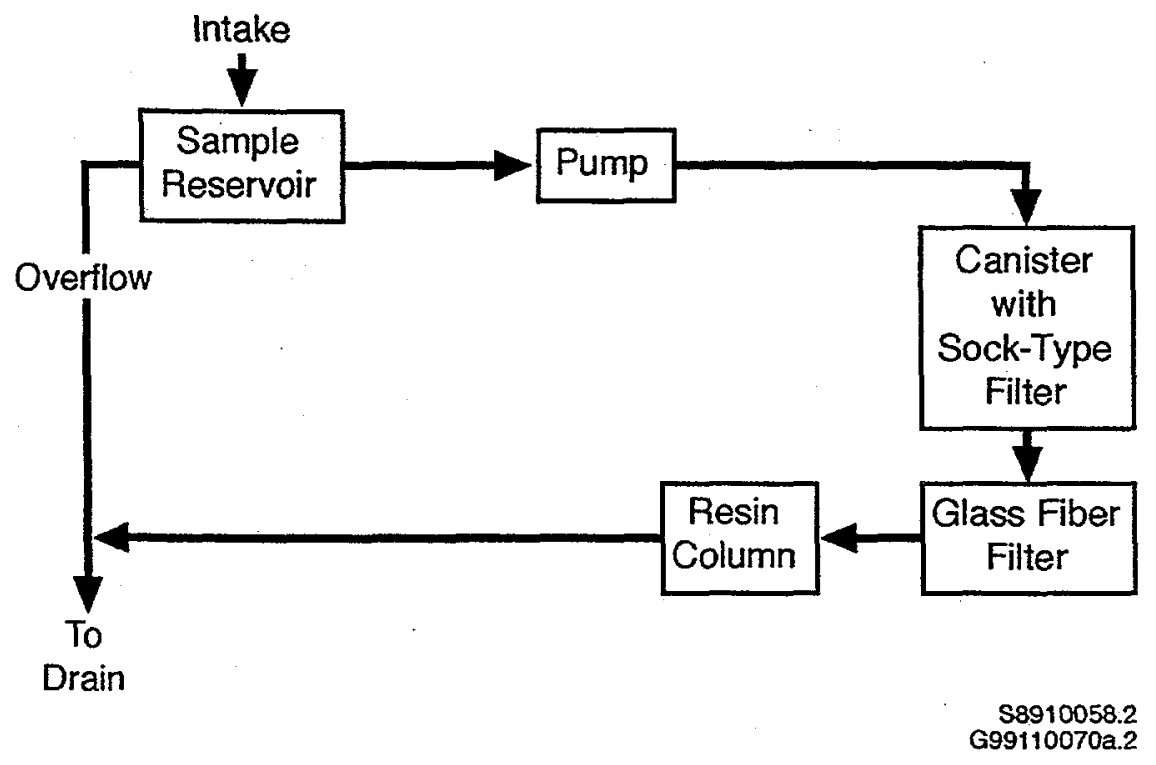

Figure 4.3.2. Continuous (Filter/Resin) Water Sampler Flow Diagram 
Section 4.4

Issued: 01-00

Supersedes: 03-98

PNL-MA-580

Page 1

\subsection{COLUMBIA RIVER TRANSECT SAMPLING}

\section{INTRODUCTION}

STAFF

RESPONSIBILITIES
Both chemical and radiological contaminants from past and present operations at the Hanford Site are known to enter the Columbia River along the Hanford Reach. The types and amounts of contaminants may be of potential concern to the public and to numerous state, federal, and local agencies, and private organizations. Samples are collected along transects of the Columbia River upstream of, downstream of, and adjacent to the Hanford Site, and analytical results from these locations are compared to identify the types and concentrations of river contaminants attributable to the Hanford Site.

- It is the responsibility of the SESP Surface Water Task Leader (or designee) to provide the proper training to the sample collection staff prior to sampling.

- Preparation of the sample bottles, chain-of-custody forms, and field record forms used for non-radiological samples is the responsibility of personnel from the Environmental Characterization and Risk Assessment Group.

- The SESP Surface Water Task Leader (or designee) must coordinate with the SESP Data Management Task Leader to ensure that the necessary trip sheets and sample labels for radiological samples are prepared on time.

- The SESP Surface Water Task Leader (or designee) must coordinate the availability of field sampling personnel and equipment with the SESP Sample Collection Task Leader.

- Staff conducting the field sampling are responsible for locating and preparing the boat and field sampling equipment.

- Delivery of the samples to the analytical laboratory, and postsampling cleanup and storage of the boat and sampling equipment are the responsibilities of the sample collection staff.

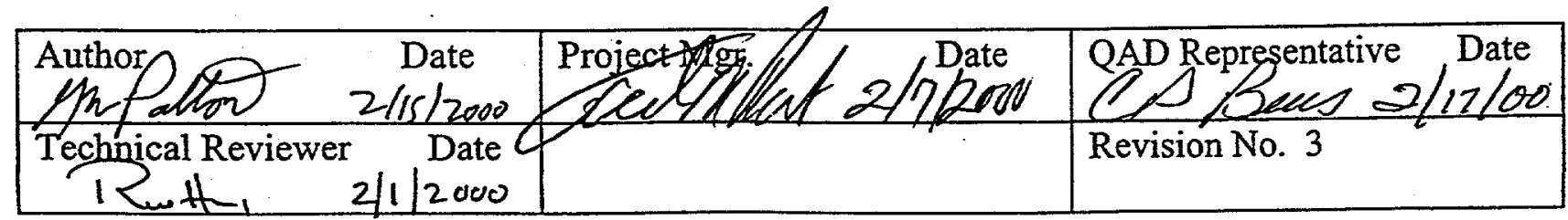


PERSONNEL

EQUIPMENT
The SESP Surface Water Task Leader (or designee) may oversee and participate in the field sampling operations, depending on schedules and circumstances.

Field sampling must be conducted by staff who have received appropriate training on these sampling procedures and are familiar with the sampling and boating equipment.

The following equipment and supplies may be needed in the boat for the collection of Columbia River transect samples.

- two-way radio or cellular telephone

- fast water (flat) anchor with at least $150 \mathrm{ft}$ of heavy duty anchor rope

- davit with winch and steel cable (see Figure 4.4.1)

- wire-line depressor (see Figure 4.4.1)

- 0.25 -in. rope (75-ft) for depressor tether line

- stainless-steel water sampling table with drain hose (samples can be collected without this)

- ring stand with one 3-finger clamp

- water-resistant green tape for attaching Tygon tubing to winch cable

- depth finder

- 12-volt water sample pump

- 1 -in. diameter Tygon (or equivalent) tubing ( $50 \mathrm{ft}$ long) for collecting samples with the 12-volt pump

- range finder and target (to be used at the request of the SESP Surface Water Task Leader)

- Global Positioning System (GPS) instrument (to be used at the request of the SESP Surface Water Task Leader)

- precalibrated battery-operated $\mathrm{pH} /$ conductivity meter

- $\mathrm{pH} /$ conductivity meter calibration standards and distilled water 
- calibrated thermometer

- spare 9-volt batteries for digital thermometer and $\mathrm{pH} /$ conductivity meter

- timer (watch)

- field notebook (optional)

- sample bottles for chemical analyses (these are pre- labeled)

- 10-L (2.5-gal) plastic collapsible containers with lids for radiological samples

- sample labels and trip sheets for samples collected for radiological analysis, chain-of-custody forms and field record forms for samples collected for chemical analysis

- evidence tape

- 2-in. clear tape to cover (protect) sample labels

- large ice chest with ice (two chests may be required)

- ball point pens and permanent marking pens

- miscellaneous tools for making minor repairs

- bolt cutters to sever the winch cable in an emergency

- leather gloves

- disposable surgeon's gloves (in appropriate sizes)

- PNL-MA-580 SESP Procedures Manual

- Environmental Sampling Locations Manual

ESTABLISHING

THE SAMPLING

LOCATIONS AND

SETTING UP THE

EQUIPMENT
Before Launching

- Install the davit and water sampling table on the boat, and attach the anchor to the electric winch line located on the bow of the boat (see Figure 4.4.1 for proper set-up). To help prevent back injury, the installation of the davit and the attachment of the anchor should be accomplished by two individuals. 
- Test the winch and sampling pump to verify that they are working properly.

CAUTION: When operating the winch, remember to keep fingers and loose clothing away from all pulleys and pinch points. Wear leather gloves when handling the winch cable to avoid injuries from frayed cable.

Identifying Sampling Locations

- Under most circumstances, sampling locations will be selected and identified by "eyeball," using landmarks (on or near the river shorelines) described in the Environmental Sampling Locations Manual.

Using a Global Positioning System (GPS) Instrument

- At the discretion of the SESP Surface Water Task Leader (or designee), sampling locations established can also be "mapped" using a GPS instrument positioned on the boat. The GPS instrument must be operated by an individual trained in its use.

Using a Range finder Instrument

NOTE: At the discretion of the SESP Water Task Leader (or designee), a range finder may be used at some sampling transects to help establish sampling locations. Refer to the operations manual supplied by the instrument manufacturer for instructions on using this equipment. A copy of this manual can be obtained from the Sample Collection Task Leader.

- Set up the range finder on the river shoreline near the transect location, and ensure that the instrument can "see" across the entire width of the river.

- Measure the distance across the river.

- Using the measured width of the river, compute the spacing of the transect sampling locations across the river. If there is an island in the transect line, also measure the width of the island (along the transect line), and space the sampling locations appropriately on both sides of the island.

- Record the distance between sampling stations in a field notebook or on the sampling trip sheet. 
- Use the range finder and two-way radio or cellular telephone to assist the boat driver in anchoring the boat at the correct locations.

- Record any landmarks used for establishing the transect line and any coordinate readings (if measured) on the sampling trip sheet or a field notebook.

Anchoring the Boat

NOTE: Secure one end of the anchor rope to the anchor winch before deploying the anchor. This will prevent the winch from feeding out all the anchor line.

NOTE: Do not allow excess slack in the anchor rope during anchoring. The slack rope may be sucked into the jet boat intake.

- It may be necessary to drop the anchor several boat lengths upstream of the actual sampling location because the river current may drag the boat downstream of the selected sampling location before the anchor can snag the bottom.

- Once anchored, shut off the boat motors.

- If for some reason anchoring is not possible, samples should not be collected.

NOTE: This technique should not be used routinely as components of the engine exhaust can contaminate some samples. Record on the sampling trip sheet that the boat motors were running while the samples were collected.

- If conditions at the selected site are inappropriate for collection (too shallow or too weedy), move to the closest appropriate location on the transect line.

- Record the location of this new sampling position in a field notebook or on the sampling trip sheet.

Setting up Sampling Equipment

- Using a cable clamp and shackle, connect the wire-line depressor to the end of the winch cable. 
- If sampling in a current, it may be appropriate to tie a 50-to 75-ft tether line ( 0.25 -in. rope) to the top of the depressor, and run the line along the exterior of the boat cabin to a cleat on the bow of the boat (see Figure 4.4.1).

NOTE: This rope will be lowered with the cable and depressor and will be used to keep the cable in a vertical position in the current. In some circumstances, if a tether is not used, the depressor (and sampling line) can be pushed downstream from the boat at an angle, resulting in an inaccurate sampling depth. Ideally, the cable should be kept vertical when sampling to ensure an accurate sampling depth.

- Attach Tygon tubing to both the intake and discharge ports of the sampling pump and tape (using water-resistant green tape) the intake end of the tubing to the winch cable so that the end of the tubing is 6 in. or so above the cable connector of the wire-line depressor.

- Tape the tubing to the cable (with strips of water-resistant green tape) every 1 to $1.5 \mathrm{ft}$ for the first 6 to $8 \mathrm{ft}$ to ensure the tubing does not slide up on the cable as the depressor and tubing are lowered into the river.

- Connect a drain hose to the water sampling table drain outlet.

- Run the tube from the sampling pump discharge port to the water sampling table (if the water sampling table is not used, the tubing should be draped over the side of the boat so that the discharge water does not enter the boat). The discharge tube can be attached to a ring stand with a 3-finger clamp. The ring stand is then set on top of the water sampling table (eliminating the need to handle the hose during sample collection).

SAMPLE COLLECTION
NOTE: To minimize potential for cross-contamination, the samples should be collected by moving from the Franklin or Grant County shore toward the Hanford Site shoreline. Collect the samples near the Hanford Site last. Remember that the Hanford Site shore is station \#1 and the Franklin or Grant County shore has the highest station number (e.g., station \#10).

- Record sampling date, time and weather conditions on the field record form.

- Record the water depth (determined with the depth finder) on the field record form. 
- Lower the water sampling intake assembly to the appropriate water depth. Use a yardstick or some other measuring technique to measure the cable as it is spooled out of the winch.

NOTE: The appropriate depth is approximately one-half of the water depth as measured with the boat's depth finder.

- Use the tether line, if necessary, to maintain the winch cable in a vertical position (See Figure 4.4.1).

- Start the sample pump. Run the pump for 5-10 min. at the first station of each transect to purge the sampling line. After the first station, the purge time can be reduced to 2-3 minutes between stations.

NOTE: Do not turn off the pump until all the samples at a specific location are collected.

Measure the temperature, $\mathrm{pH}$, and conductivity of the water (from the water stream at the water table), and record the readings on the field record form.

- Attach the sample label to the 10-L sample container. Ensure the sample date is on the label and is accurate.

NOTE: Make sure the sampling dates on all sample labels are correct. Labels are often printed days or weeks before sampling, and the dates may need to be changed to reflect the correct sample date. Also ensure that the sampling dates on the trip sheets, chain-of-custody forms, and field record forms match the dates on the corresponding labels.

- Cover the sample label on the 10-L sample container with a strip of the 2 -in.-wide clear plastic tape to protect it from the water... ensure it remains affixed to the container.

- Collect the samples from the water stream of the pump.

- If filtered water samples are required, see Section 4.10.

- Cap the sample bottles tightly.

- Seal the caps on all sample bottles (chemical and radiological) with evidence tape. 
- Put all chemical sample bottles in large plastic bags (if supplied with the sample bottles), and place the sealed bags on ice in an ice chest. If bags are not supplied, put the individual bottles on ice in the ice chest.

- Raise the wire-line depressor and the anchor, proceed to the next sampling station, and repeat the sampling procedures outlined above.

- After sampling, ensure all samples are properly labeled and that all paperwork is completely and correctly filled out.

TRIP SHEET AND

SAMPLE

SUBMISSION REQUIREMENTS
See Section 8.1, Trip Sheets, for further requirements for completing trip sheets and submitting samples to an analytical laboratory. 


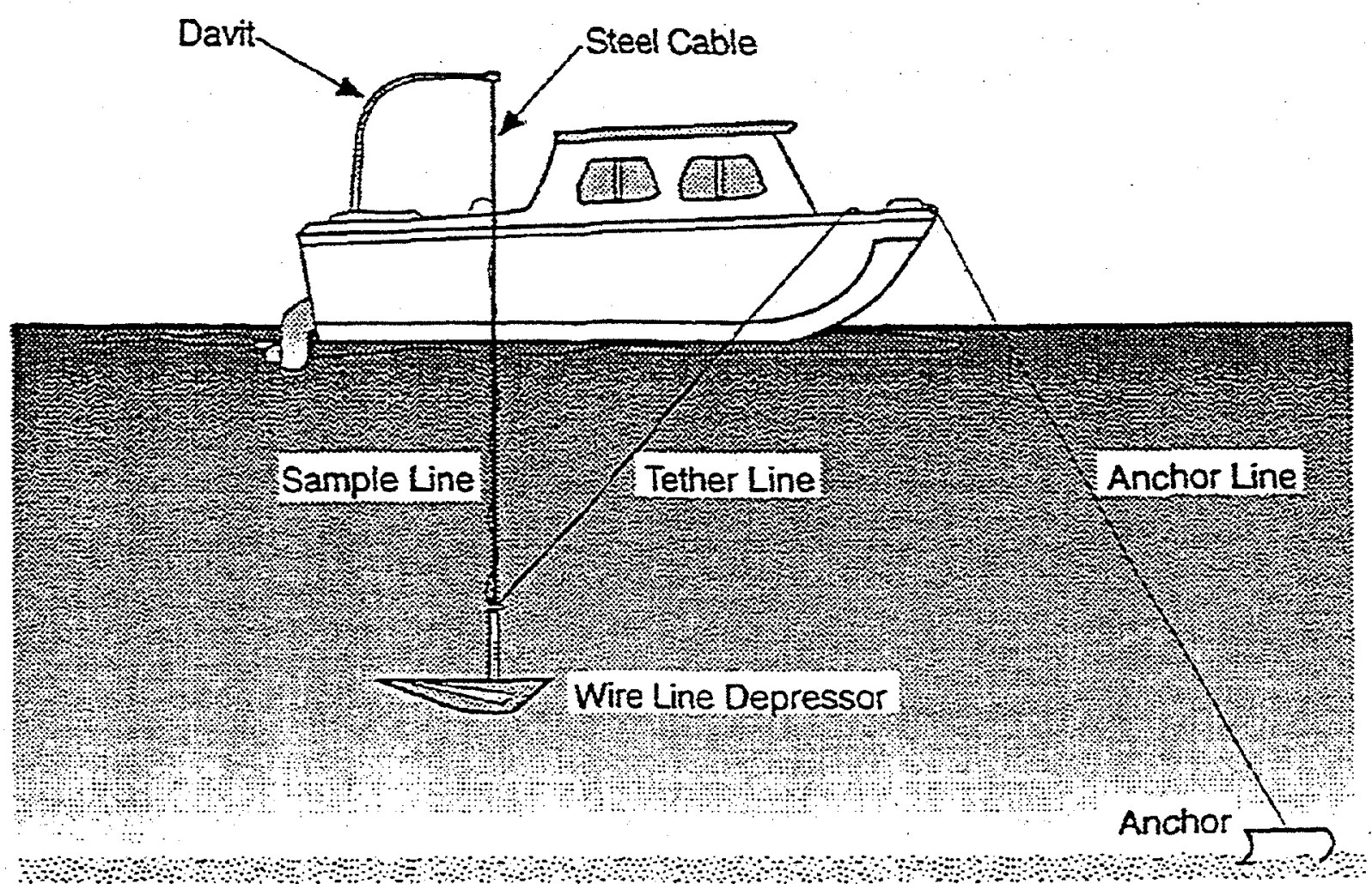

$\mathbf{5 9 5 0 4 0 5 0 . 1}$

Figure 4.4.1. Sample Vessel and Equipment 


\subsection{COLUMBIA RIVER SEDIMENT SAMPLING}

INTRODUCTION

PERSONNEL

EQUIPMENT
Contaminated effluents from the Hanford Site have been discharged to the Columbia River since operations at the Site began in the mid-1940s. Because of environmental and human health concerns and the changing mission of the Site, the amount of contaminants entering the river from the Hanford Site since 1971 has been drastically reduced. However, there is still concern that contaminants in current discharges (primarily groundwater seepage), and residual contaminants from past discharges are contained in Columbia River sediments found along and downstream of Site facilities. Therefore, samples of Columbia River surface sediments are collected annually and analyzed for radionuclides and metals. Samples are collected from specific backwater areas along the Hanford shoreline and from the reservoirs behind McNary Dam (downstream of the site) and Priest Rapids Dam (upstream of the site). In both reservoirs, samples are collected along a transect oriented perpendicular to the shoreline. Samples are collected in this manner to determine if concentration gradients exist.

Field sampling must be conducted by staff who have received appropriate training on these sampling procedures and are familiar with the sampling and boating equipment.

The following equipment and supplies may be needed for the collection of Columbia River sediment samples.

- SESP Environmental Sampling Locations Manual and PNL-MA580 Surface Environmental Surveillance Procedures Manual

- boat

- 4-wheel drive vehicle

- depth recorder

- two-way radio or cellular telephone

- hip boots

- bucket

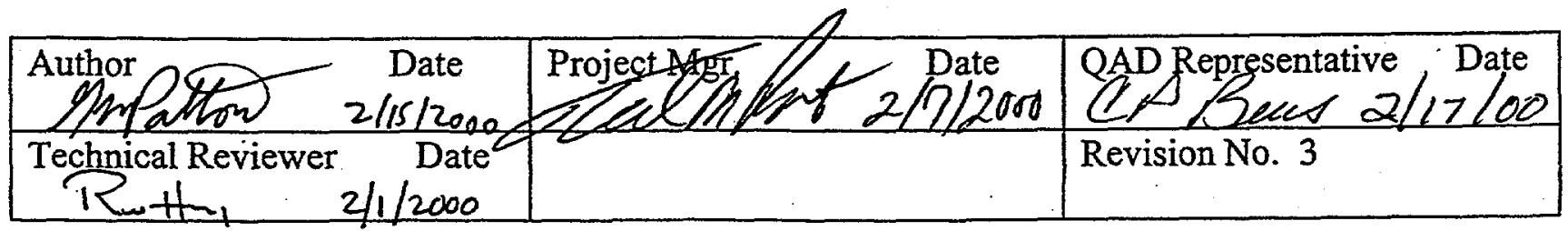


- scale

- glass sample bottles

- ice chest containing ice

- plastic spoon

- medium-size transparent plastic bags

- large-size transparent plastic bags

- large plastic storage container

- $100 \mathrm{ft}$ of $1 / 4$ or $3 / 8 \mathrm{in}$. rope

- marking pen (permanent ink)

- two portable Ponar dredges (with locking carabiners)

- trip sheets, sample labels, chain-of-custody forms, and field record forms

- evidence tape

- towels

- leather gloves

- duct tape or masking tape

- tool kit containing miscellaneous tools

- portable radiological survey instruments

- Global Positioning System (GPS) instrument (to be used at the request of the SESP Surface Water Task Leader)

- gas-powered windlass

- mount and pole for windlass

- fuel for windlass

- stainless-steel water table with drain hose 
- fast water anchor with at least $150 \mathrm{ft}$ of rope

- transect water sampler, ring stand, 3-finger clamp, and hose (Section 4.4)

GENERAL OVERVIEW OF SAMPLING PROCEDURES
River sediment samples for radiological and metals analyses are collected using a Ponar dredge. The dredge is dropped or pushed into the sediment, retrieved with a rope using either the windlass or by hand power, and emptied into a bucket lined with two plastic bags. Enough sample is collected to fill a medium-size plastic bag (for radiological analysis) and a small glass sample bottle (for metals analysis). The minimum required mass of the radiological sample is given on the trip sheet but more should be collected, if possible. Too much sample is better than too little. The sample should be relatively free of water. In some instances, it may be necessary to drop the dredge more than once to collect an adequate amount of sediment. The sediments in the bag should be thoroughly mixed before sub sampling for the metals sample.

Sampling areas should be relatively free of rocks, as rocks will interfere with the operation of the dredge.

\section{Shoreline and Slough Samples}

Slough samples can be collected from a boat or from the shoreline using a dredge or plastic spoon as described in the procedures outlined below. To the extent possible, samples should not be collected in locations that dry up because of seasonal changes in river flow or because of intermittent fluctuations in river level.

\section{$\underline{\text { Reservoir Samples }}$}

Reservoir sediment samples are collected from several locations across the width of the river. A transect perpendicular to the shoreline is established based on sampling landmarks from past years (see Environmental Sampling Locations Manual). For example, at a four sampling location site, one sample is collected on each side of the river approximately 100 yards out from the shoreline, one sample is collected approximately $1 / 3$ of the distance across the river, and one sample is collected approximately $2 / 3$ of the distance across the river. Under most circumstances, specific sampling locations will be selected by "eyeball," using the previously identified shoreline landmarks. Individual sampling locations may then be "mapped" using a portable GPS instrument. 
OPERATON OF THE WINDLASS

Check to see that the gas tank and oil reservoir on the windlass engine are full prior to leaving for the field. One tank of gas is usually sufficient; however, carry extra fuel for an extended sampling day. The engine uses normal gasoline (not gas/oil mix). If the windlass fails to operate during a sampling trip, the dredge can be retrieved manually, and sampling should continue.

Install the windlass mount and pole to the jet boat by passing it through one of the metal rod holders on the boat. The windlass should be mounted on the same side as the water table. Attach the windlass and motor to the mounting pole.

To recover the sediment dredge using the windlass:

- Start the windlass engine using the starter cord; adjust the choke as needed.

- Pass the rope through the overhead pulley on the pole mount.

- Wrap the rope around the windlass wheel one time (in the direction of rotation).

- Pull down on the rope with a hand-over-hand motion to recover the dredge. Hold the rope in place once the dredge is at the desired height.

- Using the pole mount, swing the dredge into position above the water table; the dredge can be lowered by moving the rope up toward the windlass wheel. Remove the rope from the windlass wheel before filling the sampling containers.

- The rope should be removed from the windlass wheel when being deployed to the bottom; however, the overhead pulley on the pole mount can be used if needed.

Turn off the windlass engine after all sediment has been collected at that location.

SAMPLE

COLLECTION PROCEDURES
CAUTION: Leather gloves should be worn when setting the dredge to prevent injury to fingers. Leather gloves should be worn when lowering or raising the dredge with the windlass. Be alert to pinch points on the windlass and pulley. Use caution when swinging the dredge using the pole mount. Avoid hot surfaces on the windlass engine. 
Install the stainless-steel water table and drain hose on the boat.

Proceed to sample location as defined in the Environmental Sampling Locations Manual.

Anchor the boat at one of the sampling locations along the transect line, and shut off the boat motor(s).

Depending on currents, anchoring may not be necessary at all locations.

Record the sampling depth on the trip sheet and field record form.

Securely connect one end of the $1 / 4$ or $3 / 8$ in. rope to the dredge. Ensure the knot is tight and couplings are tightly fastened.

Secure the other end of the rope to the boat.

Set an ice chest at the base of the water table. Place the large storage container (similar size as the ice chest) on top of the ice chest. Place a large plastic bag inside the storage container. The container should be positioned so the Ponar dredge can be set on the edge of the water table and, when opened, the sediment will drop into the large plastic bag.

Fit one medium plastic bag inside another so that the mouths of both bags can be opened as one bag. Place the plastic bags in a bucket, and drape the mouths of both bags over the bucket rim. The medium-size bags will be used to collect the sample from the large storage container.

"Set" the dredge in the sampling position (dredge mouth open).

Lower the dredge to the river bottom (maintaining tension on the rope). Contact with the bottom, and the release of tension on the rope, will trigger the dredge mechanism to close. A sharp tug on the rope may facilitate triggering of the dredge. Avoid abrupt movement while lowering the dredge as this may cause the dredge to close prematurely.

If the sample is being collected by wading in from the shoreline, either the dredge or plastic spoon may be used to collect the sediment.

Pull the sampler to the surface. Set the dredge on the table edge. Open the dredge, and empty its contents into the plastic bag-lined storage container. 
Thoroughly mix the sediment with a plastic spoon before filling the medium-size plastic bags and other sample containers.

Decant excess water from the sample container, if necessary, being careful to avoid the loss of fine sediments.

Weigh the sample, and continue to add sediment until an adequate amount (as specified on the trip sheet) has been collected.

Ensure that the glass sample bottle (for metals analyses) is the correct one for the location.

Verify that the correct sampling date is on the bottle and that it matches the sampling date on the corresponding chain-of-custody form.

Fill the small glass sample bottle using the plastic spoon.

Cap the bottle, and seal the cap with evidence tape.

Place the bottle on ice in an ice chest.

Close the inner plastic bag in the bucket, and seal with tape.

Verify that the correct sampling date is on the sample label and that it matches the sampling date on the corresponding trip sheet.

Ensure the sample label is the correct one for the location.

Place the sample label between the two plastic bags, print side out. It is not necessary to peel the back off of the label.

Seal the outer plastic bag with tape.

Rinse any spilled sediment off of the water table, using buckets of river water or water from the transect water pump, before proceeding to the next location.

Thoroughly rinse the sampler and plastic spoon with river water before collecting the next sample.

Ensure all paperwork is completed accurately.

TRIP SHEET AND

SAMPLE SUBMISSION REQUIREMENTS
See Section 8.1, Trip Sheets, for further requirements for completing trip sheets and submitting samples to an analytical laboratory. 


\subsection{SAMPLING COLUMBIA RIVER RIVERBANK SPRINGS}

INTRODUCTION

PERSONNEL REQUÍREMENTS

EQUIPMENT
Contaminated groundwater beneath the Hanford Site enters the Columbia River along the Hanford Site via surface and sub-surface seepage. Seeps located above the water level of the river are commonly called riverbank springs. The SESP collects water and sediment samples from selected seepage locations to monitor the types and amounts of contaminants entering the river to define the extent of contamination along the river shoreline.

Field sampling must be conducted by staff who have received appropriate training on these sampling procedures and are technically knowledgeable in the use of the sampling equipment.

The following equipment and supplies may be needed for the collection of Columbia River shoreline springs samples.

- SESP Environmental Sampling Locations Manual and PNL-MA580 Surface Environmental Surveillance Procedures Manual

- two-way radio or cellular telephone

- 10-L (2.5-gal) and 4-L (1-gal) collapsible plastic containers with lids for radiological water samples, as needed

- sample bottles for chemical analyses

- at least one large plastic soup spoon for improving the seeps and for collecting sediment samples

- small volume, hand-operated plastic siphon-pump for collecting water samples

- calibrated thermometer

- spring scale

- precalibrated battery-operated $\mathrm{pH} /$ conductivity meter

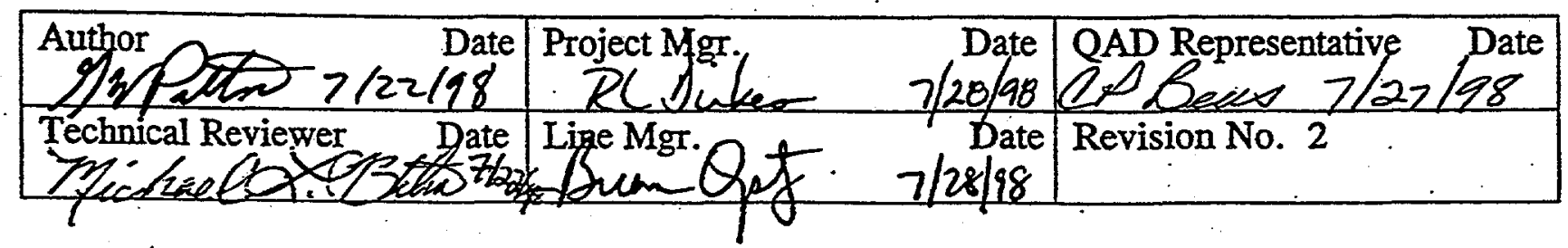


- extra batteries for the $\mathrm{pH} /$ conductivity meter

- calibration standards and distilled water for the $\mathrm{pH} /$ conductivity meter (for field calibrations, if necessary)

- large ice chest with ice

- medium-size transparent plastic bags for sediment samples

- ballpoint pens and permanent marking pens

- sample labels and trip sheets for radiological samples and chain-ofcustody and field record forms for nonradiological samples

- evidence tape

- 2-in.-wide clear tape to cover (protect) sample labels

- towels

- duct tape or masking tape for sealing plastic bags

- tool kit for minor repairs to sampling equipment

- disposable surgeon's gloves (in appropriate sizes)

- portable radiological survey instruments (GM, PAM)

- Global Positioning System (GPS).

SAMPLE

COLLECTION
NOTE: Generally, Columbia River shoreline springs are only accessible when river flows are low and shoreline "beach" areas are exposed. River flows in the Hanford Reach of the Columbia River fluctuate daily as a result of changes in discharge volume at Priest Rapids Dam. River flows are usually lower from Saturday through Monday or Tuesday.

Proceed to the sample location as defined in the Environmental Sampling Locations Manual. Identify the springs by looking for small rivulets in the shoreline sediments or for water flowing down the riverbank to the river. Springs are generally found below the vegetation line and above the water line. Flows at some springs are intermittent and may not always be apparent. 
NOTE: Springs can be approached by boat or four-wheel drive vehicles. In some cases, it is more practical to approach the sampling site by boat to avoid entering restricted or controlled areas, carrying equipment and samples for long distances on foot, and unnecessary off-road activity in sensitive wildlife areas. Access routes should be discussed with the Surface Water Task Leader or Sample Collection Task Leader prior to sampling.

\section{Water Quality Measurements}

Measure and record on the field record form the temperature, $\mathrm{pH}$, and conductivity of the spring water.

\section{Sampling Order}

Water samples are collected first, in the following order:

1) Collect nonradiological samples first

2) Collect radiological samples second.

3) Collect sediment samples after all water samples have been collected.

\section{Water Sampling Procedures}

Water samples are collected by pumping or ladling water from the spring into the sample containers. If the spring is shallow or flow is low, sample collection can be facilitated by using the plastic spoon to dig a small basin in the rocks and sediment, and allowing the spring water to accumulate. Once the basin is full and the water is free of all disturbed sediments, water can be pumped or ladled from the basin to the sample container. A thin, flat rock placed at the bottom of the basin, underneath the intake port of the pump, may help prevent resuspension of sediments while the pump is being operated.

\section{Metals, Anions, and Radionuclides}

At each sampling location, prior to collecting samples, clean the pump by pumping several liters of spring water through it. Care should be taken to collect water that is clean and free of sediments and debris. It may be necessary to pump slowly to avoid disturbing any sediments near the pump intake port.

Attach the sample label to the 10-L sample container. Verify that the correct sample date is on the label and that it matches the sampling date on the field record forms and trip sheets. 
Cover the sample label on the 10-L sample container with a strip of the 2-in.-wide clear plastic tape to protect it from the water and ensure it remains affixed to the container.

Collect the samples by slowly pumping water from the spring into the sample bottles.

Fill the bottles to the neck.

Cap the bottles tightly.

\section{Post-Sampling Field Procedures}

Seal the caps on all sample bottles (nonradiological and radiological) with evidence tape.

Put all nonradiological sample bottles on ice in an ice chest.

Enter all sampling information on the appropriate chain-of-custody forms, field record forms, and trip sheets.

IMPORTANT: Verify that the sampling dates on all sample labels, trip sheets, field record forms, and chain-of-custody forms are correct. Labels and trip sheets are often printed days or weeks before sampling and the dates may need to be changed to reflect the correct sampling date.

\section{Sediment Sampling Procedures}

Sediment samples are collected at selected springs after the water samples have been collected. Samples are analyzed for metals and radionuclides. Enough sample is collected to fill a medium-size plastic bag (for radiological analysis) and a small glass sample bottle (for metals analysis).

Use a large plastic spoon that has been rinsed with nearby river water.

Collect sediments from the vicinity of where the springs first discharge from the riverbank and place the sample into a clean plastic bag. Avoid the inclusion of rocks in the sample.

Weigh the samples and continue to add sediment until an adequate amount has been collected. The minimum sample mass is indicated on the sample trip sheet, but a larger sample should be collected if possible.

The sediment in the bag should be thoroughly mixed with the plastic spoon before subsampling for the metals sample. 
Ensure the glass sample bottle (for metals analyses) is the correct one for that location.

Verify that the correct sampling date is on the bottle and that it matches the sampling date on the corresponding chain-of-custody and field record forms.

Fill the small glass sample bottle with sediment from the plastic bag using the plastic spoon.

Cap the bottle and seal the cap with evidence tape.

Place the bottle on ice in the ice chest.

Seal the plastic bag with tape.

Place the sealed sample in another plastic bag.

Ensure that the information on the sample label is accurate.

Place the label between the plastic bags so that the information on the label can be read. It is not necessary to peel the back off the label.

Seal the outer plastic bag with tape. Ensure all paperwork is completed accurately.

TRIP SHEET AND

SAMPLE

SUBMISSION

REQUIREMENTS
Nonradiological samples must be submitted to the analytical laboratory on the day of collection unless the SESP Surface Water Task Manager agrees to a delay. If these samples are retained at PNNL overnight, the samples must be refrigerated until they can be submitted for analysis the following morning. Under no circumstances should these samples be retained longer than overnight.

See Section 8.1, Trip Sheets, for further requirements for completing trip sheets and submitting samples to an analytical laboratory. 


\subsection{TEMPERATURE MEASUREMENT PROCEDURE}

INTRODUCTION

PERSONNEL

EQUIPMENT

CALIBRATION OF THE DIGITAL THERMOMETER
This procedure is for measuring temperatures during the routine collection of water samples.

Field sampling must be conducted by staff who have received training on these procedures and are familiar with the sampling equipment. It is estimated that this procedure requires one (1) person for efficient operation.

- Calibrated electronic digital thermometer and spare digital thermometer

- Spare batteries

- Digital Thermometer Calibration Check Log (Figure 4.7.1)

- Trip sheet

- National Institute of Standards and Technology traceable thermometer

Before leaving for the field, ensure that the electronic thermometer reads within $\pm 1^{\circ} \mathrm{C}$ of the NIST traceable thermometer in the laboratory.

Fill a beaker with water close to the temperatures to be measured in the field. Place the calibrated thermometer and the digital thermometer probe into the water. The temperature is indicated by a digital display, which will normally fluctuate for a few seconds. Wait until fluctuation ceases, then record the NIST and digital thermometer serial numbers, the time, date, and temperature of both the calibration and digital thermometers on the Digital Thermometer Calibration Check Log.

If the digital thermometer is not in agreement with the calibrated thermometer, adjust according to the manufacturer's supplied instructions. If the problem persists, change the batteries. Replace the unit if needed.

The calibration record is stored in the SESP sample collectors' office until the sheet is full.

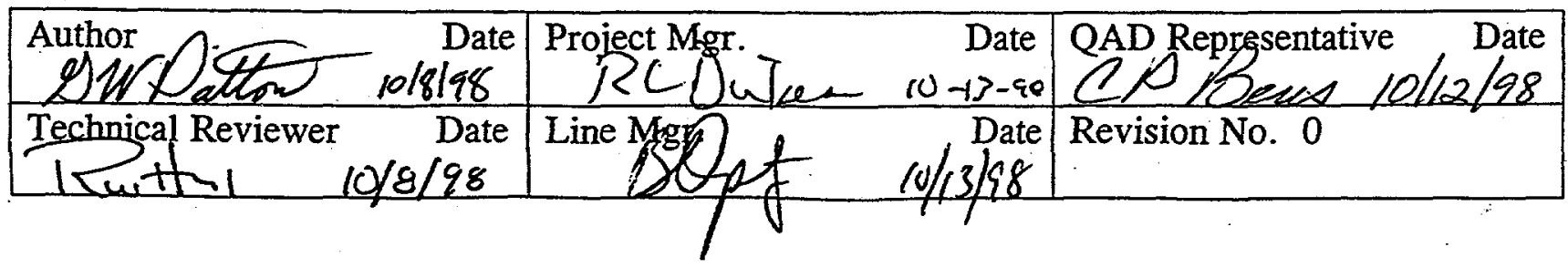


TEMPERATURE MEASUREMENT PROCEDURE
When the calibration record sheet is full, start a new calibration record sheet, and give the old form to the Sample Collection Task Leader.

Switch on the digital thermometer. Make sure it is set to read in degrees centigrade.

Place the probe into the stream of water being sampled.

The temperature is indicated by a digital display, which will normally fluctuate for a few seconds. Wait until fluctuation ceases, then record the digital thermometer serial number and temperature on the trip sheet.

If a thermometer reading is suspect, resort to using spare thermometer. If the spare thermometer is used, record the serial number of the meter on the trip sheet. 


\section{Calibration Check Log for Digital Thermometers}

NIST Thermometer \#

\begin{tabular}{|c|c|c|c|c|c|}
\hline Digital Thermometer \# & Time & Date & $\begin{array}{c}{ }^{\circ} \mathrm{C} \\
\text { NIST Value }\end{array}$ & $\begin{array}{c}{ }^{\circ} \mathrm{C} \text { Digital } \\
\text { Thermometer Value }\end{array}$ & Operator \\
\hline & & & & & \\
\hline & & & & & \\
\hline & & & & & \\
\hline & & & & & \\
\hline & & & & & \\
\hline & & & & & \\
\hline & & & & & \\
\hline & & & & & \\
\hline & & & & & \\
\hline & & & & & \\
\hline & & & & & \\
\hline & & & & & \\
\hline & & & & & \\
\hline & & & & & \\
\hline & & & & & \\
\hline & & & & & \\
\hline & & & & & \\
\hline & & & & & \\
\hline & & & & & \\
\hline & & & & & \\
\hline & & & & & \\
\hline & & & & & \\
\hline & & & & & \\
\hline
\end{tabular}

FIGURE 4.7.1. Digital Thermometer Calibration Check Log 


\subsection{CONDUCTIVITY MEASUREMENT PROCEDURE}

INTRODUCTION

PERSONNEL

EQUIPMENT
This procedure is for measuring conductivity during routine collection of water samples.

Field sampling must be conducted by staff who have received training on these procedures and are familiar with the sampling equipment. It is estimated that this procedure requires one (1) person for efficient operation.

- A field-portable conductivity meter and spare with the following specifications: (accuracy $\pm 5 \%$ of full scale or better; resolution, by either digital or analog display, to $1 \%$ of full scale or less; inclusion of a dip sensor, a cup cell, or a flow-through cell; either manual or automatic temperature compensation).

NOTE: Many suitable commercially available conductivity meters exist, and the manufacturer's catalog listing of specifications is acceptable evidence that a given instrument meets the above specifications.

- Distilled or deionized water

- A standard solution of known conductivity for conductivity meter calibration. For Hanford surface water, a standard solution having conductivity from 100 to $500 \mu \mathrm{S} / \mathrm{cm}$ is most suitable. The solution must meet the following requirements: the nominal conductance of the solution must be clearly noted on the label of the solution bottle; the temperature restrictions or requirements of the solution must be clearly noted on the label; and the tolerance must be no greater than $\pm 1 \%$ relative error.

NOTE: Commercially prepared conductance standards that meet the above requirements are acceptable for this procedure, and the manufacturer's label containing lot number and expiration date is acceptable for certification of specifications.

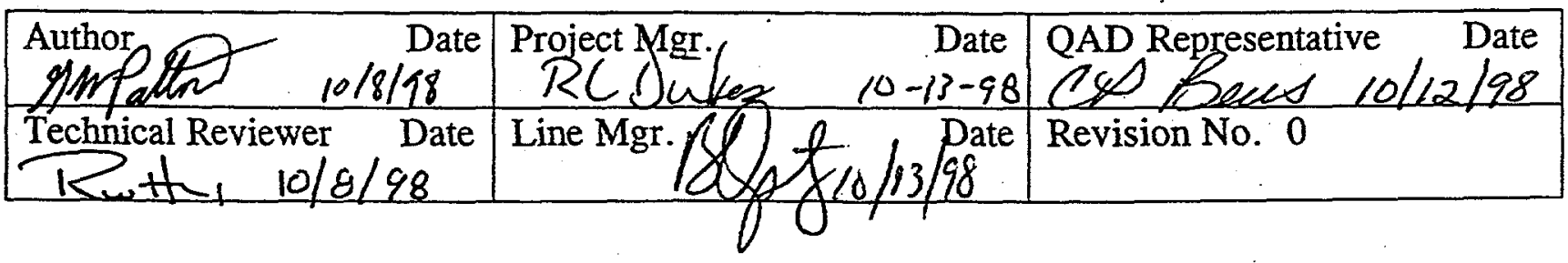


- If the meter does not include a temperature display readable to $\pm 1^{\circ} \mathrm{C}$, a thermometer accurate to $\pm 1^{\circ} \mathrm{C}$ is required. Any type of thermometer may be used, and the manufacturer's catalog listing of specifications is acceptable evidence of the required accuracy.

- The manufacturer's written instructions for the instrument(s) in use are to accompany, and be considered part of this procedure.

- Conductivity Meter Calibration Record (Figure 4.8.1).

- Trip sheet

CALIBRATION

OF THE CONDUCTIVITY METER
CONDUCTIVITY MEASUREMENT PROCEDURE
Because there is a wide variety of commercially available conductivity meters (and thermometers) suitable for use in this procedure, it is not possible to provide detailed operating instructions. In each case, follow the manufacturer's instructions. It is particularly important to strictly observe the manufacturer's recommendations regarding care and storage of the sensing elements, battery charging (where applicable) or battery life, calibrating the instrument, and conditions of use in the field. In addition to the manufacturer's instructions, the following steps must be followed:

- Calibrate the conductivity meter daily before leaving for the field, and record, date, and sign the results of the calibration on the Conductivity Meter Calibration Record Form (Figure 4.8.1), (the form remains in the SESP sample collectors' office.) Follow the manufacturer's recommendation for the calibration standard solution. If the calibration check shows greater than $\pm 5 \%$ error with respect to the standard used, the instrument must be recalibrated.

When the Calibration Record Form is full, start a new form, and give the old form to the Sample Collection Task Leader.

After calibration, discard the used portion of the standard solution. Never return it to the solution bottle.

The conductivity meter must be recalibrated at each sampling location prior to sampling

NOTE: Always replace the cap on standard solution bottle when calibration is completed.

Thoroughly rinse the cell or dip sensor with the water being sampled, and then refill with water for the conductance measurement. Record the conductance as shown on the meter display, sample temperature, and any other required data on the trip sheet. Rinse the probe or cell with distilled or deionized water before proceeding to the next sampling location. 
If the accuracy of the conductivity meter is suspect, resort to using spare conductivity meter. If the spare is used, calibrate the spare instrument in the field prior to use, recording the calibration information in the comment section of the trip sheet and on the Conductivity Calibration Record Form upon returning from the field.

Upon completion of the day's activity, return the conductivity meter and standards solution to proper storage. 


\section{Conductivity Calibration Record Form}

Calibration Standard (Supplier and Lot \#)

(Expiration Date)

\begin{tabular}{|c|c|c|c|c|}
\hline $\begin{array}{l}\text { Conductivity } \\
\text { Meter \# }\end{array}$ & Operator & Date & $\begin{array}{c}\mu \mathrm{S} \\
\text { Standard Solution } \\
\end{array}$ & $\begin{array}{c}\mu S \\
\text { Calibration Solution }\end{array}$ \\
\hline & & & & \\
\hline & & & & \\
\hline & & & & \\
\hline & & & & \\
\hline & & & & \\
\hline & & & & \\
\hline & & & & \\
\hline & & & & \\
\hline & & & & \\
\hline & & & & \\
\hline & & & & \\
\hline & & & & \\
\hline & & & & \\
\hline & & & & \\
\hline & & & & \\
\hline & & & & \\
\hline & & & & \\
\hline & & & & \\
\hline & & & & \\
\hline & & & & \\
\hline & & & & \\
\hline & & & & \\
\hline
\end{tabular}

FIGURE 4.8.1. Conductivity Meter Calibration Record Form 
INTRODUCTION

PERSONNEL

EQUIPMENT

\section{9 pH MEASUREMENT PROCEDURE}

This procedure is for measuring $\mathrm{pH}$ during the routine collection of water samples.

Field sampling must be conducted by staff who have received training on these procedures and are familiar with the sampling equipment. It is estimated that this procedure requires one (1) person for efficient operation.

- Field portable $\mathrm{pH}$ meter and spare with the following specifications: (accuracy $\pm 0.1 \mathrm{pH}$ unit or better; resolution, by either digital or analog display, to $0.01 \mathrm{pH}$ units or less; inclusion of dip electrodes, a cup cell, or a flow-through cell; either manual or automatic temperature compensation).

NOTE: Many suitable commercially available $\mathrm{pH}$ meters exist, and the manufacturer's catalog listing of specifications is acceptable evidence that a given instrument meets the above requirements.

- distilled or deionized water

- standard buffer solutions for $\mathrm{pH}$ meter calibration. At least two solutions are required, usually with nominal $\mathrm{pH}$ values of 7 and 10 . Buffer values of 7 and 10 bracket the normal $\mathrm{pH}$ of surface water at the Hanford Site. Other values may be used so long as the sample $\mathrm{pH}$ is bracketed. It is best to choose buffers whose values are near to the sample $\mathrm{pH}$.

NOTE: The buffers must meet the following requirements: the temperature restrictions of the solution must be clearly noted on the label of the solution bottle, the accuracy of the solution must be clearly noted on the label, and the tolerance must be no greater than $\pm 0.05 \mathrm{pH}$ units; nominal value, lot number, and expiration date must be clearly noted on the label, and the solutions should be color-coded.

NOTE: Commercially prepared buffer solutions that meet the above requirements are acceptable for this procedure, and the manufacturer's label is acceptable as certification of specifications.

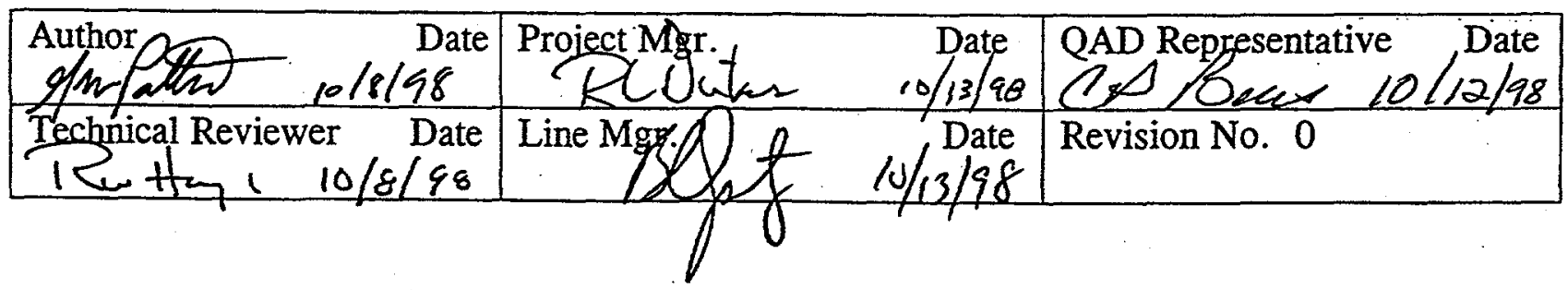


CALIBRATION OF THE pH METER
- the manufacturer's written instructions for the instrument should accompany the instrument into the field

- trip sheets

- $\mathrm{pH}$ Meter Calibration Record Form (Figure 4.9.1)

Because there is a wide variety of commercially available $\mathrm{pH}$ meters (and thermometers) suitable for use in this procedure, it is not possible to provide detailed operating instructions. In each case, follow the manufacturer's instructions. It is particularly important to strictly observe the manufacturer's recommendations regarding care and storage of the sensing electrodes, battery charging (where applicable) or battery life, calibrating the instrument, and conditions of use in the field. In addition to the manufacturer's instruction, the following steps must be followed:

Calibrate the $\mathrm{pH}$ meter daily before leaving for the field, and record, date, and sign the results of calibration on the $\mathrm{pH}$ Meter Calibration Record Form (Figure 4.9.1) (the form remains in the sample collectors' office).

When the Calibration Record Form is full, start a new form, and give the old form to the Sample Collection Task Leader.

NOTE: The principal reason for the above step is to ensure that the meter is in operational condition. Also, if this calibration step is performed using the same buffers used in the field, recalibration in the field may be avoided if meter drift is within the limits described below. Always replace cap to the buffer solution bottles when calibration is complete.

After instrument calibration or calibration check, discard the used portion of the buffer solution. Never return it to the solution bottle.

The conductivity meter must be recalibrated at each sampling location prior to sampling. Use both standard buffer solutions.

If the results for both measurements are within $0.05 \mathrm{pH}$ units of the correct values for the buffers, the meter need not be recalibrated. If not, follow the manufacturer's instructions for meter calibration. Record the calibration check or recalibration information in the comment section of the trip sheet.

Thoroughly rinse the electrode or cell with the water sample solution, then dip the electrode in (or fill the cell with) the sample solution. Record the $\mathrm{pH}$ (to the nearest 0.01 unit) on the trip sheet. After measuring sample $\mathrm{pH}$, and when completed with sampling activities at the sampling location that requires the instrument, rinse the electrode, with distilled or deionized water. 
If the accuracy of a pH meter is suspect, use the spare $\mathrm{pH}$ meter. If the spare is used, calibrate the spare instrument in the field prior to use, recording the $\mathrm{pH}$ information in the comments section of the trip sheet and on the pH Calibration Record Form located at the sample collectors' office. Ensure any faulty instruments are repaired or replaced as appropriate. Upon completion of the day's activities, store the $\mathrm{pH}$ probe according to the manufacturer's instructions. 


\section{pH Meter Calibration Record Form}

Calibration Standard

Supplier

Lot \#

Buffer \#1 pH

Expiration Date
Supplier

Lot \#

Buffer \#2 pH

Expiration Date

\begin{tabular}{|c|c|c|c|c|}
\hline \multirow[b]{2}{*}{ pH meter \# } & \multirow[b]{2}{*}{ Operator } & \multirow[b]{2}{*}{ Date } & \multicolumn{2}{|c|}{ Calibration Value } \\
\hline & & & Buffer \#1 & Buffer $\# 2$ \\
\hline & & & & \\
\hline & & & & \\
\hline & & & & \\
\hline & & & & \\
\hline & & & & \\
\hline & & & & \\
\hline & & & & \\
\hline & & & & \\
\hline & . & & & \\
\hline & & & & \\
\hline & & & & \\
\hline & & & & \\
\hline & & & & \\
\hline & & & & \\
\hline & & & & \\
\hline & & & & \\
\hline & & & & \\
\hline & & & & \\
\hline & & & & \\
\hline . & & & & \\
\hline
\end{tabular}

FIGURE 4.9.1. pH Meter Calibration Record Form 


\subsection{WATER FILTRATION PROCEDURE}

INTRODUCTION

PERSONNEL

EQUIPMENT
This procedure is for collection of filtered water samples using $0.45-\mu \mathrm{m}$ filters and is designed to supplement the whole water collection methods described in Section 4.1, Grab Samples, Section 4.4, Columbia River Transect Sampling, and Section 4.6, Sampling Columbia River Riverbank Springs. Several water pressure sources can be used for the procedure, including peristaltic pumps, the water pump used in collecting transect samples (Section 4.6), or a water tap. This procedure can be used with either a disposable, factory-prepared water filtration cartridge or a reusable filtration cartridge.

In general, the disposable, factory-prepared filtration cartridges are used for sampling water for trace level metals to minimize contamination during handling or for sampling where crosscontamination is likely. The reusable filtration cartridges are used for radionuclide sampling where handling is less likely to result in contamination or for sampling water with very high sediment content where the filter must be changed frequently. Users of the reusable cartridges must be careful to prevent cross-contamination and should use a separate cartridge for each location, if possible. When possible, the reusable filters should be prepared in a clean environment and placed into clean plastic bags, prior to transport to the field.

Field sampling must be conducted by staff who have received training on these sampling procedures and are familiar with the sampling equipment. This procedure requires one (1) person for efficient operation.

The following equipment and supplies may be needed for the collection of filtered water samples:

- disposable factory $0.45-\mu \mathrm{m}$ filter cartridge (with attached hose barbs)

- reusable field team prepared filtration cartridge

- upper Teflon nut

- Teflon upper filtration head

- black locking collar

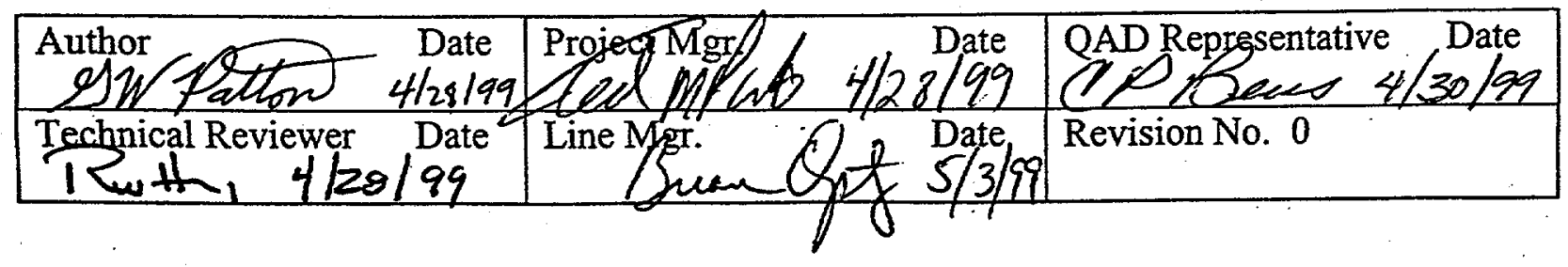


- lower Teflon filter plate

- lower Teflon nut

- 0.45- $\mu \mathrm{m}$ membrane filters ( $47-\mathrm{mm}$ diameter, cellulose nitrate)

- plastic tweezers for handling filters

- two (2) green nylon wrenches

- large plastic storage container for housing the filtration kit

- small plastic storage container for storing the filters and tweezers

- plastic bags (quart size, one per filtration cartridge)

- Teflon tubing (rigid, Teflon FEP 3/16-in. $\mathrm{ID} \times$ 1/4-in. OD)

- Silicon tubing and connections for attaching the filtration cartridges to the water source

- Masterflex portable sampling pump (peristaltic pump)

- pump housing

- easy-load pump head

- AC and DC power cords

- spare fuses (0.25 amp and $2.5 \mathrm{amp}$ )

- silicon tubing (Masterflex 15 or 24) to drive pump head (12-in. section).

SAMPLE

\section{COLLECTION}

Loading the

Reusable Filtration

Cartridge
Prepare a clean working surface by laying a clean plastic bag on the laboratory bench or on a flat surface in the field. Remove the lid from the filtration kit, and place it on plastic bag beside the kit. Remove the small box containing the filters and tweezers, and place them on the lid. Place a green wrench across the top of the open kit box, and use it as a stand for holding the filtration cartridge.

Unscrew the black locking collar on the cartridge. Place the upper portion of the cartridge and the black locking collar on a clean surface, and place the bottom of the cartridge (screened portion) on the small opening of the green wrench.

Open the white filter box. Each filter is separated by a piece of blue paper. Using the tweezers, remove and discard the top blue sheet. Using tweezers, carefully place the white membrane filter on the bottom of the cartridge. Use caution not to puncture, scratch, or crease the white filter.

Reassemble the filtration cartridge. Tighten the cartridge using the green wrenches. Place the loaded cartridge into a plastic bag. 
Sample Collection Using Water Line Pressure (Water Faucet)
If the filter must be changed in the field (for example, the filter clogs while collecting a sample), the above procedure can be reversed to remove the filter and reload a new filter. Unless otherwise directed, the filters are not analyzed and can be discarded.

At the sampling location, attach a piece of silicon tubing to the water faucet or water supply line (at most locations a fitting with a hose barb is already installed).

For the disposable filtration cartridges, simply attach the cartridge to the silicon tubing using the attached hose barb. Ensure that the water flow is in the direction indicated on the disposable cartridge.

For the reusable cartridges, insert a short piece of rigid Teflon tubing into the silicon tubing coming from the water faucet. The reusable cartridge is attached to the rigid Teflon tubing using the Teflon nut at the top of the reusable cartridge. Ensure that the water flow is in the direction indicated on the cartridge.

Place the sampling bottle on a stable surface. Turn on the water faucet to allow for a slow flow out of the filter, adjust the water flow to maintain a steady stream without causing the hose barbs to leak. Do not allow the exit end of the filtration cartridge to contact any unclean surfaces. In general, allow approximately $100 \mathrm{~mL}$ of water to pass through the filtration cartridge before collecting the sample.

During sampling, hold the filtration cartridge with the filter parallel to the floor. This ensures that the entire filter surface is used and will maintain the highest flow rate with minimal plugging.

Collect the sample according to the procedures for collecting water from a faucet (Section 4.1, Grab Samples), except that the filtration cartridge is now inline.

If multiple bottles are to be filled at the sampling location, a single filtration cartridge can be used for all samples provided sufficient flow can be maintained through the cartridge.

After collecting the sample, inspect the filter (not possible for the disposable cartridges) for any unusual patterns on the filter (e.g., leakage or holes). In most cases, a well-defined circle of sediment material will be visible on the filter. If the filtration process is suspect, make a note on the trip sheet, then recollect if additional bottles are available.

Unless otherwise instructed, after sampling, discard the filter from the reusable cartridge or discard the disposable cartridge. 
Sample Collection Using the Transect Water-Sampling System
Sample Collection Using the Masterflex Peristaltic Pump
Filtered water samples can be collected using the transect watersampling pump to supply the water pressure. Either the disposable or the reusable filtration cartridges can be used to collect the sample.

Adapt the outlet end of the water supply line to fit the filtration cartridge (as in the water faucet procedure). The transect water pump is designed to pressurize recreational vehicle water supplies and has a pressure feedback mechanism that should automatically adjust to maintain constant pressure. If the water pressure becomes too great (hose connection leak), then the pump can be manually turned off and on as needed to maintain the water pressure.

Collect the sample using the same procedures used for transect water samples (Section 4.4, Columbia River Transect Sampling), except that the filtration cartridge is now inline.

If multiple bottles are to be filled at a transect location (e.g., station $\# 1$ ), a single filtration cartridge can be used for all samples provided sufficient flow can be maintained through the cartridge. Upon moving to the next transect station (e.g., station \#2), a new filtration cartridge or new filter should be used.

After collecting the sample, inspect the filter (not possible for the disposable cartridges) for any unusual patterns on the filter (e.g., leakage or holes). In most cases, a well-defined circle of sediment material will be visible on the filter. If the filtration process is suspect, make a note on the trip sheet, then recollect if additional bottles are available.

Unless otherwise instructed, after sampling, discard the filter from the reusable cartridge, or discard the disposable cartridge.

If problems occur with the transect water pump, the Masterflex peristaltic pump can be used to supply the water pressure for filtration (see Masterflex operating procedures below). The Masterflex pump can be used to pull the sample from depth, i.e., the Masterflex silicon tubing can be attached to the wire-line depressor (Section 4.4, Columbia River Transect Sampling). Or a piece of rigid Teflon tubing can be inserted into the outlet end of the transect water supply line (loosely fitting so that water freely flows around the Teflon tubing), and the Masterflex pump can be used to sample water from the supply line.

Filtered water samples can be collected using a Masterflex portable sampling pump (peristaltic pump) to supply the water pressure. Either the disposable or the reusable filtration cartridges can be used to collect the sample. 
Charging the Internal Battery
The Masterflex pump can be operated using a rechargeable internal battery, an external 12-volt DC power supply, or an external AC power supply. The $\mathrm{AC}$ power supply should be used where possible (e.g., filtered water samples at the Priest Rapids Dam station); however, the external DC power supply (cigarette lighter adaptor) would likely be used for transect water samples, and the internal DC power supply would likely be used for riverbank spring samples.

To check the charge on the internal battery, turn the power switch to OFF, turn the operations dial to INTERNAL BATTERY OPERATION, turn the power switch to ON, and hit the red test button for the internal battery. If the battery has an appropriate charge, the green test light will light up.

The internal battery can be charged using either an $A C$ or $D C$ power source. If the battery has been completely discharged it will not recharge on the RECHARGE ON AC setting until it has received a short recharge using a DC power source.

For an $\mathrm{AC}$ power source recharge, turn the power switch to $\mathrm{OFF}$, turn the operation dial to RECHARGE ON AC. Plug the pump into the $A C$ power source using the $A C$ power cord. Turn the power switch to $\mathrm{ON}$, and allow the unit to recharge for 12 to 16 hours. When the appropriate charge has been reached, the red indicator light will illuminate. Turn the power switch to $\mathrm{OFF}$, and unplug the $\mathrm{AC}$ power cord. Do not overcharge the internal battery.

The procedure for recharging using a $\mathrm{DC}$ power source is similar to the $\mathrm{AC}$ recharge, except that the $\mathrm{DC}$ power cord is used, and the operation dial is set to RECHARGE ON 12V DC.

Attach the Masterflex pump to the appropriate power source.

Masterflex pumps are equipped with "easy-load" pump heads that require approximately 12 in. of flexible silicon tubing (Masterflex 15 or 24 or equivalent) to operate. The peristaltic pump uses a set of rollers to compress the silicon tubing and force the water through the pump head. Install the silicon tubing into the pump head by raising the black handled bar and inserting the silicon tubing. Lower the black handled bar to close the pump head during operation. On each side of the pump head there is a black tension adjuster that prevents the silicon tubing from "moving" through the pump head. Adjust the tension setting as needed to the minimal amount required to secure the tubing. 
Plumb the inlet side of the pump head to the water supply. For some sampling, a single long piece of silicon tubing can be used to draw water from the source, run the pump head, and serve as the outlet hose. Other sampling will require separate tubing to be attached to the silicon tubing at the pump head; for example, sampling for metals generally uses rigid Teflon tubing for both the inlet and outlet connections. The Masterflex pump is rated to sample water from a depth of $29 \mathrm{ft}$ and does not have to be primed.

Once the system is plumbed into the water source, rinse the tubing for several minutes by setting the operations switch to AC

OPERATIONS, 12 VDC OPERATIONS, or INTERNAL BATTERY OPERATIONS. Turn the pump rotation switch to either $\mathrm{CCW}$ or $\mathrm{CW}$ (counter clockwise or clockwise), depending on the flow direction needed. Turn the on/off switch to ON. Rotate the pump speed dial ( 0 10) to a setting that maintains a steady flow.

NOTE: If too low a pump speed setting is used, the pump will be overworked and may blow a fuse. The fuses are located on the back of the pump housing.

Attach filtration cartridge.

For the disposable filtration cartridges, simply attach the cartridge to the silicon tubing using the attached hose barb. Ensure that the water flow is in the direction indicated on the disposable cartridge.

For the reusable cartridges, insert a short piece of rigid Teflon tubing into the silicon tubing coming from the pump head. The reusable cartridge is attached to the rigid Teflon tubing using the Teflon nut at the top of the reusable cartridge. Ensure that the water flow is in the direction indicated on the cartridge.

Place the sampling bottle in a stable location. Adjust the pump speed to allow for a slow flow out of the filter; adjust the water flow to maintain a steady stream without causing the hose barbs to leak. Do not allow the exit end of the filtration cartridge to contact any unclean surfaces. In general, allow approximately $100 \mathrm{~mL}$ of water to pass through the filtration cartridge before collecting the sample.

During sampling, hold the filtration cartridge with the filter parallel to the floor. This ensures that the entire filter surface is used and will maintain the highest flow rate with minimal plugging

Collect the sample using the same procedures as for grab, transect, or riverbank spring water samples (Section 4.1, Grab Samples, Section 4.4, Columbia River Transect Sampling, and Section 4.6, Sampling 
Columbia River Riverbank Springs), except that the filtration cartridge is now inline.

If multiple bottles are to be filled at the sampling location, a single filter or filtration cartridge can be used for all samples provided sufficient flow can be maintained through the cartridge.

After collecting the sample, inspect the filter (not possible for the disposable cartridges) for any unusual patterns on the filter (e.g., leakage or holes). In most cases, a well-defined circle of sediment material will be visible on the filter. If the filtration process is suspect, make a note on the trip sheet, then recollect if additional bottles are available.

Unless otherwise instructed, after sampling discard the filter from the reusable cartridge or discard the disposable cartridge. 


\subsection{SOIL AND VEGETATION SAMPLING PROCEDURES}

\section{INTRODUCTION}

Soil and vegetation samples are collected because atmospheric deposition of materials on the ground and plant foliage, and subsurface uptake of materials by plants are primary pathways of exposure for the general public.

Several types of soil and vegetation samples are collected periodically from several areas within the vicinity of the Hanford Site.

Surface soil samples (Section 5.1) are collected from a number of undisturbed, unirrigated locations.

Terrestrial vegetation samples (Section 5.2) are collected to assess the uptake of radionuclides from the surface and subsurface environs.

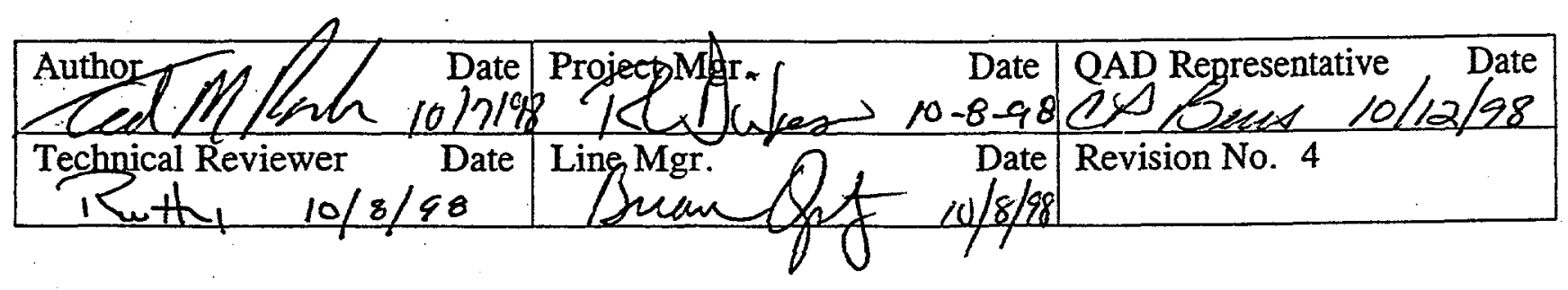




\subsection{SURFACE SOIL SAMPLES}

INTRODUCTION

EQUIPMENT

SAMPLE COLLECTION
Soil samples are collected at a number of locations surrounding the Hanford Site and are analyzed for radionuclides. These samples provide an indication of the buildup of radionuclides that may become available in an exposure pathway to man. Samples are collected from undisturbed areas.

The following equipment may be needed to collect soil samples:

- masking tape

- 14- x 17-in. plastic bags

- trowel

- "cookie cutter" sampler

- sample labels

- trip sheet

- marking pen

- appropriate radiation survey instruments

- portable spring scale and appropriate accessories.

Select five spots that are at least 10 paces apart within the desired sampling area that has a minimum of surface vegetation. If the sample site has come under cultivation, or is otherwise disturbed, notify the Sample Collection Task Leader so an alternate site may be selected. Avoid sampling spots that are wind eroded, rocky, or disturbed significantly by animals.

Place the "cookie cutter" sampler on the spot selected, and press it into the soil until its top is level with the soil surface.

Hold the sampler and use the trowel to clear away the soil around it.

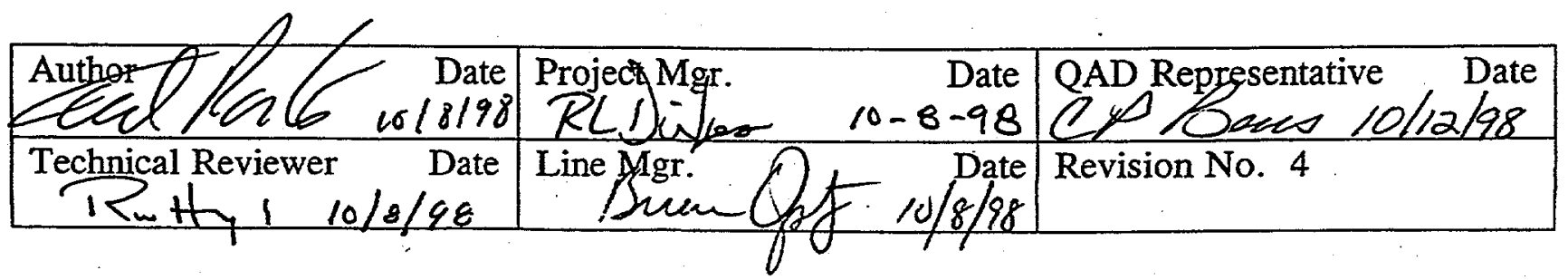


Slide the trowel under the sampler to cut the soil even with the bottom edge of the sampler.

Lift the sampler and trowel together, turn them over, and trim excess soil from the sampler with the trowel.

Pour the sample into a plastic bag.

Repeat for the remaining four samples, putting all the samples from the same area into the same plastic bag.

If appropriate (see Section 8.4), survey the sample, and record the results in the proper locations on the trip sheet. A check mark is sufficient if the reading falls within normal limits. Notify the Sample Collection Task Leader of any unusual readings, and proceed as instructed.

Weigh the sample, and record the weight on the trip sheet.

Verify that the correct sample date is on the label.

Seal the bag with tape.

Double bag the sample with the label between bags, positioned so it can be read. It is not necessary to remove the back of the label.

TRIP SHEET AND SAMPLE SUBMISSION REQUIREMENTS
Deliver the samples to the appropriate analytical laboratory as soon as practical after collection.

Washington State Department of Health (DOH) and U.S. Food and Drug Administration (FDA) samples are generally archived at PNNL before transferring them to their agencies.

See Section 8.1, Trip Sheets, for further requirements for completing trip sheets and submitting samples to an analytical laboratory. 


\subsection{TERRESTRIAL VEGETATION SAMPLES}

INTRODUCTION Terrestrial vegetation samples are collected to establish background concentrations of both naturally occurring and fallout radionuclides and to assess any radionuclide buildup that might be attributable to Hanford Site operations. Samples of new-growth vegetation are taken.

EQUIPMENT

The following equipment may be needed to collect vegetation samples:

- pruning shears or scissors

- leather gloves

- plastic bags

- masking tape

- portable spring scale

- sample labels

- trip sheet

- permanent marking pen (black ink)

- appropriate portable radiation survey instruments.

SAMPLE

\section{COLLECTION}

Select terrestrial vegetation within the designated area for sampling.

The Soil and Vegetation Task Leader will determine which species of shoreline vegetation will be collected at specific locations along the river. Sample collection personnel will include a specialist who can identify the species to be collected.

Collect samples from the perennial shrubs in approximately the same percentages as they grow at each site. For example, if a site appears to consist of $75 \%$ sagebrush and $25 \%$ rabbitbrush, then the sample collected should be approximately $75 \%$ sagebrush and $25 \%$ rabbitbrush. Record the relative percentages on the trip sheet in the comment column.

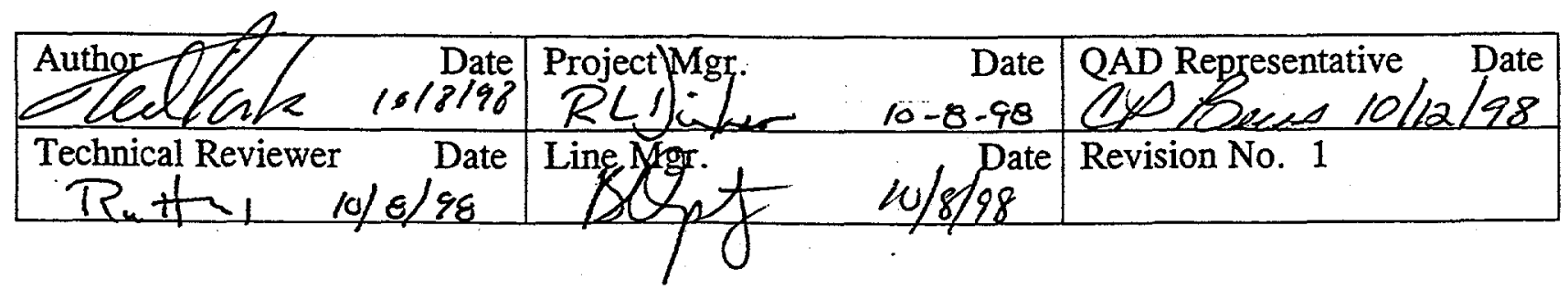


Collect about $1000 \mathrm{~g}(2.2 \mathrm{lb})$ of recent growth. The pieces cut should be no more than 6 in. long. Some species of shoreline vegetation may be more scarce, and you should consult with the specialist regarding how much sample to collect.

The following shoreline plants are the only species to be collected.

- wild onion - bulb and stalk (pick roots and brush off soil) - April and May

- mulberry - leaves and twigs - June

- mulberry - fruit - June

- reed canary grass - leaves, stems - August

- asparagus - adult plants - August

Put the samples in a plastic bag.

If appropriate (see Section 8.4), survey the sample, and record the results in the proper locations on the trip sheet. A check mark is sufficient if the reading falls within normal limits. Notify the Sample Collection Task Leader of any unusual readings, and proceed as instructed.

Weigh the sample, and record the weight on the trip sheet. Verify that the correct sample date is on the label.

Seal the bag with tape.

Double bag the sample with the label between bags, positioned so it can be read. It is not necessary to remove the back of the label.

TRIP SHEET AND SAMPLE SUBMISSION REQUIREMENTS
Deliver the samples to the appropriate analytical laboratory as soon as practical after collection.

DOH and FDA samples are generally archived at PNNL before transferring them to their agencies.

See Section 8.1, Trip Sheets, for further requirements for completing trip sheets and submitting samples to an analytical laboratory. 


\subsection{FARM PRODUCT SAMPLING PROCEDURES}

INTRODUCTION
Several types of farm products are collected periodically from several areas in the vicinity of the Hanford Site including:

- milk (Section 6.1)

- crops (Section 6.2)

- wine (Section 6.3).

Radionuclide concentrations are measured to evaluate potential exposure pathways to humans via food consumption.

Sampling locations for routine sample collection are found in the Environmental Sampling Locations Manual. Alternatively, specific directions may be provided by the Agriculture Products Task Leader or the Sample Collection Task Leader. 


\subsection{MILK SAMPLES}

INTRODUCTION Milk is a sensitive indicator of radioiodine $\left({ }^{129} \mathrm{I}\right.$ and $\left.{ }^{131} \mathrm{I}\right)$ and radiostrontium $\left({ }^{90} \mathrm{Sr}\right)$. Samples are also analyzed for gamma emitters. Samples are collected at locations near the Hanford Site boundary in a direction generally downwind from site facilities and at locations expected to be representative of background concentrations.

EQUIPMENT

The following equipment may be needed to collect milk samples:

- 4-L (1 gal) disposable sample containers

- ice chest and ice

- funnel and goose neck spout

- sample labels

- trip sheet

- marking pen

- 4-L graduated plastic container.

SAMPLE COLLECTION
Obtain a new disposable container for each sample scheduled to be collected.

Milk samples from some sampling areas are obtained from a single farm. At these locations, collect $12 \mathrm{~L}$ ( 3 gal) of milk in three 1 gal containers for routine analysis. If required, collect an additional 4-L (1 gal) sample for ${ }^{129} \mathrm{I}$ analysis.

In other sampling areas, milk for a single sample is collected from up to three farms. The milk from these farms is composited (combined) to create one sample for analysis. Milk samples requiring compositing will be composited in the field or at PNNL prior to delivery of the sample(s) to the analytical lab(s).

For two dairies, collect $6 \mathrm{~L}(\sim 1.5 \mathrm{gal})$ from each dairy. The $10-\mathrm{L}$ composite will consist of $5 \mathrm{~L}(\sim 1.25 \mathrm{gal})$ from each dairy.

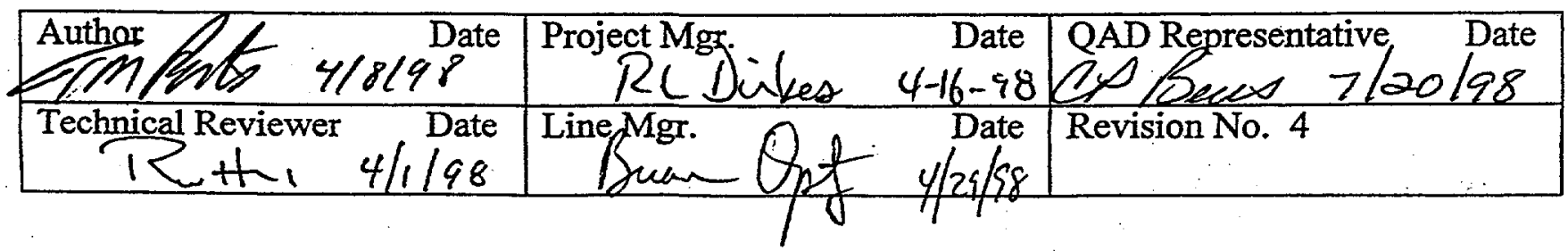


IODINE-129

SAMPLING

TRIP SHEET AND

SAMPLE

SUBMISSION REQUIREMENTS
If three dairies provide milk, collect $4 \mathrm{~L}(\sim 1.0 \mathrm{gal})$ from each dairy. The composite will consist of $3.3 \mathrm{~L}(\sim 0.8 \mathrm{gal})$ from each dairy.

Milk may be provided by the dairy or obtained directly from a raw milk tank (use the funnel and spout if necessary). In both cases, ensure that the sample size meets or slightly exceeds the minimum size requirements.

Using the marking pen, label the containers with date and sample number. If the sample consists of more than one container, label each container with date and sample number, and indicate that each sample is part of a larger sample (for example, if the sample is collected in three containers, label the container with the sample label attached as 1 of 3 ; the other two containers should be labeled 2 of 3 and 3 of 3 ). Record the date and time on the trip sheet. List the dairy names and addresses in the description column to the left of the tear-off lines.

Place the filled sample containers in the ice chest with ice for transport. Protect milk samples from degradation or spoilage by keeping them in cold storage until you deliver them to the appropriate laboratory

Four liters ( $1 \mathrm{gal}$ ) of milk are required for ${ }^{129} \mathrm{I}$ analysis. To generate a ${ }^{129} \mathrm{I}$ composite, mix equal volumes of milk from each farm into a clean 4-L (1 gal) plastic container. The size of the sample needed from each farm will depend on the number of farms supplying milk. For example, if milk were obtained from only two farms, then the composite part from each farm would be $2 \mathrm{~L}(1 / 2 \mathrm{gal})$. Use the graduated container to measure the volume of milk required. Do not "eyeball" the aliquot sizes.

Label the sample container(s) with the collection date and sample number. Write the aliquot volumes and total sample volume on the trip sheet. Securely attach the sample label to the sample container(s).

Deliver the samples to the laboratory's sample-receiving area as soon as practical after collection. If samples cannot be delivered the day they are collected, store them in a refrigerator overnight.

Samples for ${ }^{129} I$ analysis are delivered twice each year to the 320 Building. These samples must be transferred to a 320 Building staff member and are not to be placed in locked storage.

See Section 8.1, Trip Sheets, for further requirements for completing trip sheets and submitting samples to an analytical laboratory. 


\subsection{CROP SAMPLES}

INTRODUCTION

EQUIPMENT

SAMP̈LE COLLECTION
Crops include leafy vegetables, fruit, wheat, and alfalfa. The samples are used to determine if Hanford-originated radionuclides are present in locally produced food or livestock feed. In addition, because fruit, wheat, and alfalfa are major export crops from the Columbia Basin and surrounding areas, sample results enable evaluation of the potential Hanford Site impact on people living in other areas where the crops are consumed.

The following equipment may be needed to collect crop samples:

- plastic bags

- grass clippers or pruning shears

- masking tape

- portable spring scale

- sample labels

- trip sheet

- marking pen

- cash to pay for products.

Table 6.2.1 outlines the special instructions to be used for each sample type and size.

Collect the samples from designated areas or according to the directions of the Sample Collection Task Leader. Two, $1900 \mathrm{~g} \mathrm{(4} \mathrm{1b)} \mathrm{samples} \mathrm{are}$ collected from each sampling area. The duplicate samples may or may not be from the same farm within the sampling area, but each individual sample should consist of material from a single farm. One of the duplicate samples is submitted to the analytical laboratory for analysis, the other is archived pending a review of analytical results. Bulk samples transported to PNNL for splitting and weighing should be bagged prior to transit to prevent contamination from dust.

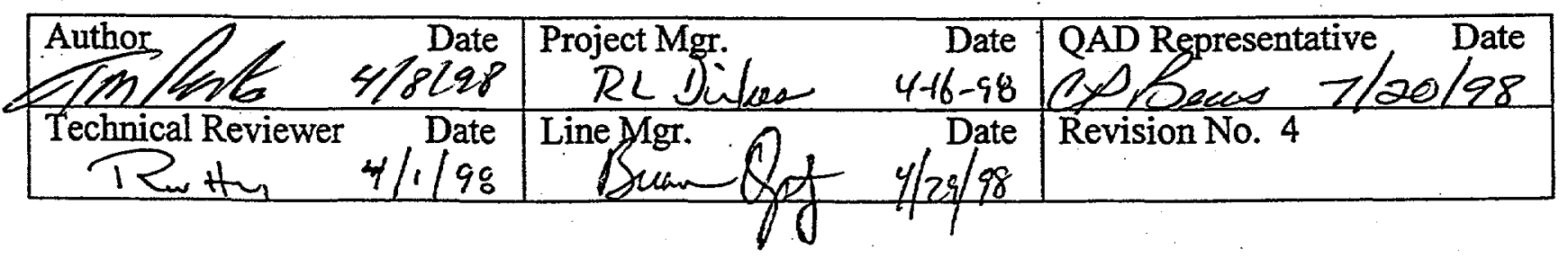


Collect an individual sample for each label (generally, you will have two labels per crop per sample area).

Contact the Sample Collection Task Leader if additional crop sources are needed.

Place the sample into a plastic bag.

Using the marking pen, label the bag(s) with the collection date, sample number, and vegetation type.

Weigh the sample, and record the weight on the trip sheet. (If two or three samples are collected from a single farm, samples can be separated, weighed, and bagged in the field or at PNNL.

Seal the bag(s) with tape.

Record the number of bags used on the trip sheet.

If more than one bag is used, indicate this by writing 1 of 2,2 of 2 , or 1 of 3,2 of 3,3 of 3 on the bags along with the identification information outlined above.

Double bag the sample, making sure the label is between bags and readable. It is not necessary to remove the back of the label. If more than one bag is used, put the label in the first bag marked 1 of X.

List the farm names and addresses in the description column on the trip sheet, to the left of the tear-off lines. This is required even if samples are obtained from a local market.

TRIP SHEET AND

SAMPLE

SUBMISSION

REQUIREMENTS
Deliver the samples to the appropriate analytical laboratory as soon as practical after collection.

DOH and FDA samples are generally archived at PNNL before transferring them to their agencies.

See Section 8.1, Trip Sheets, for further requirements for completing trip sheets and submitting samples to an analytical laboratory. 
Table 6.2.1. Special Instructions for Crop Samples

\begin{tabular}{lll}
\multicolumn{1}{c|}{ Sample } & Sample Size, g (lb) & \multicolumn{1}{c}{ Special Instructions } \\
Cherries & $1400-1900(3$ to 4$)$ & $\begin{array}{l}\text { Collect fresh, ripe fruit. Sample should not contain } \\
\text { dried or spoiled fruit. }\end{array}$ \\
Apples & $1400-1900(3$ to 4$)$ & $\begin{array}{l}\text { Collect fresh, ripe fruit. Sample should not contain } \\
\text { dried or spoiled fruit. }\end{array}$ \\
Grapes & $1400-1900(3$ to 4$)$ & $\begin{array}{l}\text { Collect fresh, ripe fruit. Sample should not contain } \\
\text { dried or spoiled fruit. }\end{array}$ \\
Alfalfa & $1400-1900(3$ to 4$)$ & $\begin{array}{l}\text { Use grass clippers to collect samples of uncut hay. } \\
\text { Bailed alfalfa is acceptable, if available, and its } \\
\text { source location is known. }\end{array}$ \\
Leafy vegetables & $1400-1900(3$ to 4$)$ & $\begin{array}{l}\text { Collect only edible portions. Do not include roots or } \\
\text { dirty leaves. Samples may consist of a mixture or } \\
\text { any one of the following: leaf lettuce, spinach, } \\
\text { mustard greens, turnip greens, beet greens, cabbage } \\
\text { leaves (not the head), or kale. }\end{array}$ \\
Potatoes & $1400-1900(3$ to 4) & $\begin{array}{l}\text { Collect fresh, ripe vegetables. May collect from } \\
\text { fields (after harvesting) or from farmers markets } \\
\text { when specific farm locations are known. Wash off } \\
\text { dirt. }\end{array}$
\end{tabular}




\subsection{WINE SAMPLES}

INTRODUCTION

EQUIPMENT

SAMPLE COLLECTION
Samples of wine, made from grapes grown adjacent to, and downwind of the Hanford Site are collected annually to monitor for radionuclides originating from the Hanford Site. Additional wine samples processed from grapes grown in vineyards upwind of the site, near Prosser and Sunnyside, are analyzed for comparison.

The following equipment may be needed to collect wine samples:

- plastic or glass sample bottles capable of holding at least $1 \mathrm{~L}$ of sample

- marking pen

- trip sheet

- sample labels

- funnel

- cash to pay for products.

The Sample Collection Task Leader will contact the wineries and make arrangements for sample pickup. Each wine should be processed from grapes grown in a specific vineyard and harvested during the current sample year. Grapes used in making red and white wines may be from different vineyards, but all grapes for a single wine must be from the same vineyard.

Samples may be already bottled or obtained from bulk tanks or kegs and collected in our own containers. If already bottled, decant the wine into our own containers.

Two 1-L samples (or bottles) of each wine variety (white or red) are collected.

Wine is usually bottled in 750 -L bottles. Three bottles are needed to obtain at least $2 \mathrm{~L}$ of wine.

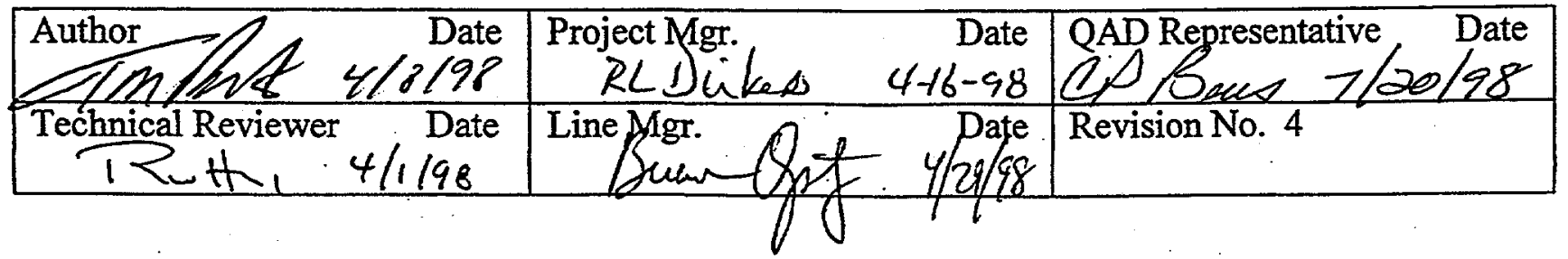


One white wine sample and one red wine sample should be collected from each area (upwind and downwind).

Attach the sample label to the sample container.

Write the sample date and time and sample size in the appropriate locations on the trip sheet.

Write the winery name, vineyard name, and name of the wine on the left side of the trip sheet under the description column.

TRIP SHEET AND

SAMPLE SUBMISSION REQUIREMENTS
Deliver the samples to the appropriate analytical laboratory as soon as practical after collection.

DOH and FDA samples are generally archived at PNNL before transferring them to their agencies.

See Section 8.1, Trip Sheets, for further requirements for completing trip sheets and submitting samples to an analytical laboratory. 
INTRODUCTION

SAFETY AND SECURITY

\subsection{WILDLIFE SAMPLING PROCEDURES}

Wildlife samples are collected to: 1) assess the potential accumulation of long-lived radionuclides in organisms living on or near the Hanford Site, 2) determine potential doses to offsite populations who may consume contaminated animal tissues, and 3) verify the effectiveness of onsite effluent and containment controls.

Wildlife samples collected may include the following:

- fish (Section 7.1)

- waterfowl (Section 7.2)

- rabbits (Section 7.3)

- game birds (Section 7.4)

- deer and elk (Section 7.5).

Species other than those specified in this manual may be collected at the direction of the Wildlife Task Leader.

Hunting safety measures must be observed at all times. Only those personnel who have completed the PNNL gun safety training class shall be issued guns and ammunition. Extreme care must be taken at all times while handling firearms. Any unsafe practice observed should be reported immediately to the Sample Collection Task Leader. Guns shall be cleaned after use, and guns and ammunition shall be stored in the gun cabinet. The gun cabinet shall be locked at all times, except when removing or returning equipment.

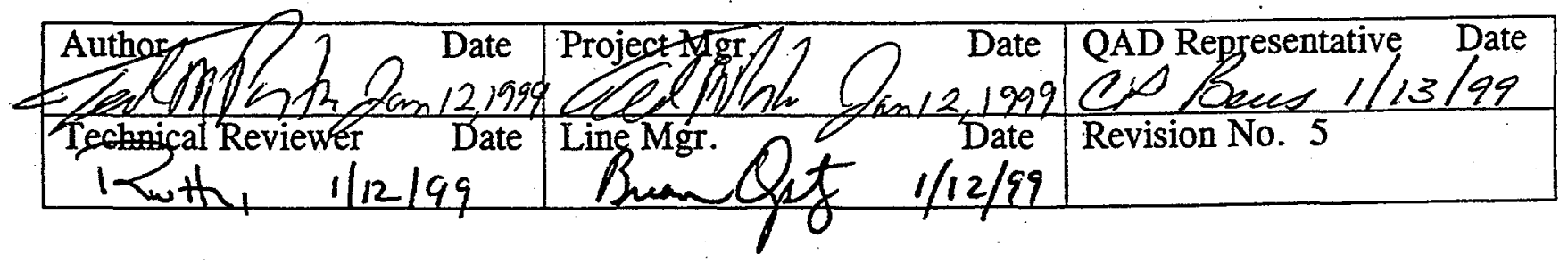




\subsection{FISH SAMPLES}

INTRODUCTION Collecting samples of fish from the Columbia River satisfies three objectives: 1) analyzing potential dose pathways, 2) verifying that the release and storage of radioactive waste materials from Hanford Site facilities are under control, and 3) reassuring the public that sport fish do not provide a means of exposure to harmful levels of radioactive materials of Hanford Site origin. Samples collected to verify control require that similar samples be collected from background areas away from the influence of the Hanford Site to allow the comparison of data and identification of loss-of-control situations.

Fish (carp, bass, and whitefish) may be collected by electrofishing, rod and reel, nets, or other sampling techniques. A valid state collection permit(s) is needed.

Unless otherwise informed, collect bass samples using hook and line from F Slough. The electroshocker can be used at the Hanford Slough.

Carp and whitefish are usually collected using the boat electrofisher, hook and line method, or nets.

When done properly, boat electrofishing is a safe and effective means of collecting fish. Check with the task leader prior to electrofishing to address possible restrictions related to Endangered Species Act (ESA)listed species.

EQUIPMENT

The following equipment may be needed to collect fish samples:

- boat and equipment, including safety gear

- portable ice chest and ice

- fillet knife

- appropriate radiation survey instruments

- plastic bags

- masking tape

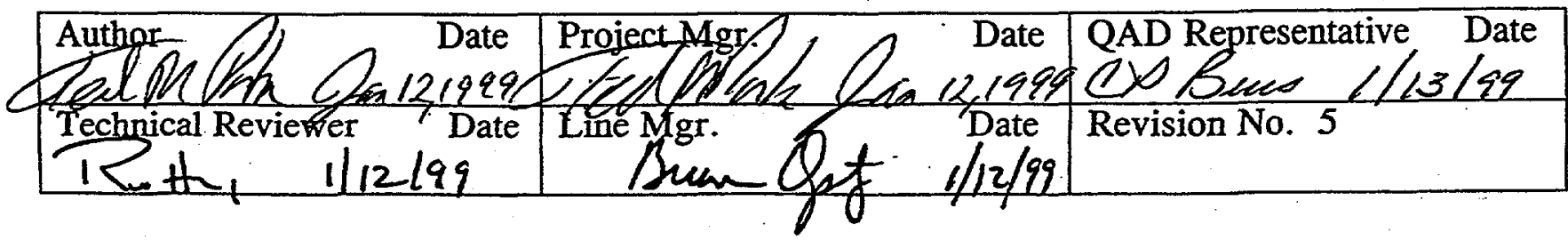


- sample labels

- trip sheets

- permanent marking pen

- sport fishing tackle (rods, reels, landing nets, bait or lures)

- electrofishing equipment

ELECTROFISHING The following equipment is necessary to collect fish with the boat electrofisher:

- research/electrical hazard signs (2 signs)

- hearing protection (ear plugs)

- rubber chest waders (one pair per person)

- rubber electrician gloves (one pair per person)

- 2-way radio/cellular phone

- open boat. Read boat operation procedures and review safety item checklist prior to conducting electrofishing.

- electroshocking generator

- unleaded gasoline and funnel (for refilling the generator)

- Smith-Root electrofisher control unit

- metal booms and arrays (an electrical cable is attached to each of these)

- foot-switch cord with pedal(s) (for either one or two netters)

- connection cord from generator to electrofisher control unit

- portable depth finder (optional)

- generator-powered spot lights (if shocking at night)

- one or two long-handled fish dip net(s) 
- valid state scientific collection permit

- portable ice chest and ice

- spare electrofisher control unit fuses

- polarized sunglasses (optional)

Read Job Safety Analysis (JSA) for electrofishing prior to operation.

Make sure all equipment is in good condition, i.e., no leakage in rubber gloves, no worn connection cords, fuses in generator are good etc.

Setting Up Equipment
The three basic components of the boat electrofisher include a generator, electrofishing control unit, and booms and arrays (see

Figure 7.1.1).

Attach the anode/cathode (boom set) cord to the electrofisher control unit. This can only be fitted with the two-pin circular socket input located near the bottom of the electrofisher control unit.

Attach the safety foot switch cord (for either one or two netters) to the electrofisher control unit. This can only be fitted with the four-pin circular socket input located next to the anode/cathode input. An electrical current is produced when the switch(es) is depressed. The person(s) operating the foot switch(es) must also be the fish netter(s).

Next, connect the power cord to the generator and the electrofisher control unit. This can only be fitted with the three-pin circular socket input on the electrofisher control unit. Plug the cord into the generator in the four-prong $220 \mathrm{VAC}$ input.

At this point, all connections have been made. The following will describe how to turn the electrofisher control unit on. This should be done when wearing all required safety equipment and when the boat is in the water.

The booms (anode/cathode) should be placed so that the arrays are dangling in the water off the side of the boat. The arrays should not be touching anything but the water. The boom labeled "\#1" goes toward the front of the boat.

The ground wire clamps must be secured to the metal hull of the boat.
Electrofisher Control Unit Setup
Make sure the "OUTPUT MODE" switch is set on 120 PPS DC (marked orange). 
Generator

Turning On Electrofisher Control Unit
Set the "PULSE WIDTH" switch to about 6 MS (marked orange).

Set the "VOLTAGE SELECTOR" switch to 884 VDC (marked orange).

Turn the "READY" key clockwise 1/4 turn (marked orange).

Lift the red cover on the "EMERGENCY SHUTDOWN," and move the switch handle to the "ON" (orange side) position.

Check that the generator is full of gas and oil. Turn the engine switch to "ON," and pull-start the generator. You may need to choke the engine before it starts. If so, move the choke lever (gray color) toward the pullstart handle. Once the engine has started, move the choke lever back to its original position.

Be Sure to: Flip the "INPUT POWER" switch of the electrofisher control unit to "ON." When the generator is running, the power indicator light should be on. CAUTION: Be sure the generator is running before this switch is flipped on and be sure to flip the "INPUT POWER" switch off before you shut the generator off. Damage to the electrofisher unit will result if these steps are not followed in order.

At this point the electrofisher is ready for use. When the foot switch is depressed, an electrical current will flow from one boom (anode) through the water and to the other boom (cathode). The person(s) netting the fish must control the foot-switch(es).

Float along the shoreline with the boat pointed downstream and the booms pointed toward the bank. In sloughs and backwater areas there are no currents to contend with, and shocking can be conducted in any direction.

Fish should be shocked in water depths ranging from 8 to $15 \mathrm{ft}$. However, it also may be necessary to shock in shallower water near the shoreline.

Depress the foot switches only when you want to shock. As the boat floats along the riverbank, the foot-switch operator(s) should intermittently activate the electrofisher. When two people are netting, one netter should continually depress one foot-switch.

When a desired fish is stunned in the electric field, maintain the electrical current while the netters attempt to scoop the fish out of the water (NOTE: Be careful not to hit the boat operator or other netter with the net handle.) 
SAMPLE PREPARATION
Place the fish in the cooler for later processing. Check with the Sample Collection Task Leader or the Wildlife Task Leader for the desired species and number to be collected. Refer to the Environmental Sampling Locations Manual for the proper collection locations.

If any animals or humans are in or near the water, do not attempt to electrofish within $100 \mathrm{~m}$ of them.

When collection activities are complete, be sure that all equipment is properly cleaned and stored for future use. Be sure to store all the electrofishing equipment together. The boat should also be cleaned out and refilled with gasoline. If any problems were encountered, be sure to notify the Sample Collection Task Leader.

If possible, eviscerate the fish and leave the entrails at the collection site.

Put each cleaned fish into a separate plastic bag; seal with tape; label each bag with date, species name, and sample number, then put them in the ice chest for transport to PNNL.

At PNNL, lay out a piece of "diaper" paper and prepare skinless fillets from both sides of each fish.

Rinse the fillets briefly in tap water, and blot any excess water with a paper towel.

Place the fillets into a clean plastic bag.

Seal the bag, and label it with sample number, sample date, tissue type, and species name.

Rinse the remainder of the fish (offal) briefly in tap water, blot any excess water with a paper towel, and put the offal into a plastic bag. If the fish is too long to fit in the bag, the sample can be cut into smaller pieces.

Seal the bag with tape.

Weigh the sample(s) and record the sample weight(s) on the trip sheet(s).

Be sure that the collection date(s) and sample number(s) are correct on each label.

Double bag each sample and insert each sample label between bags. Make sure each label is readable.

Label all waste tissues and store in a freezer until the Sample Collection Task Leader issues instructions for disposal. 
TRIP SHEET AND

SAMPLE

SUBMISSION

REQUIREMENTS
If samples cannot be submitted to the analytical laboratory on the day of collection, store them in a refrigerator or freezer overnight.

See Section 8.1, Trip Sheets, for further requirements for completing trip sheets and submitting samples to an analytical laboratory. 


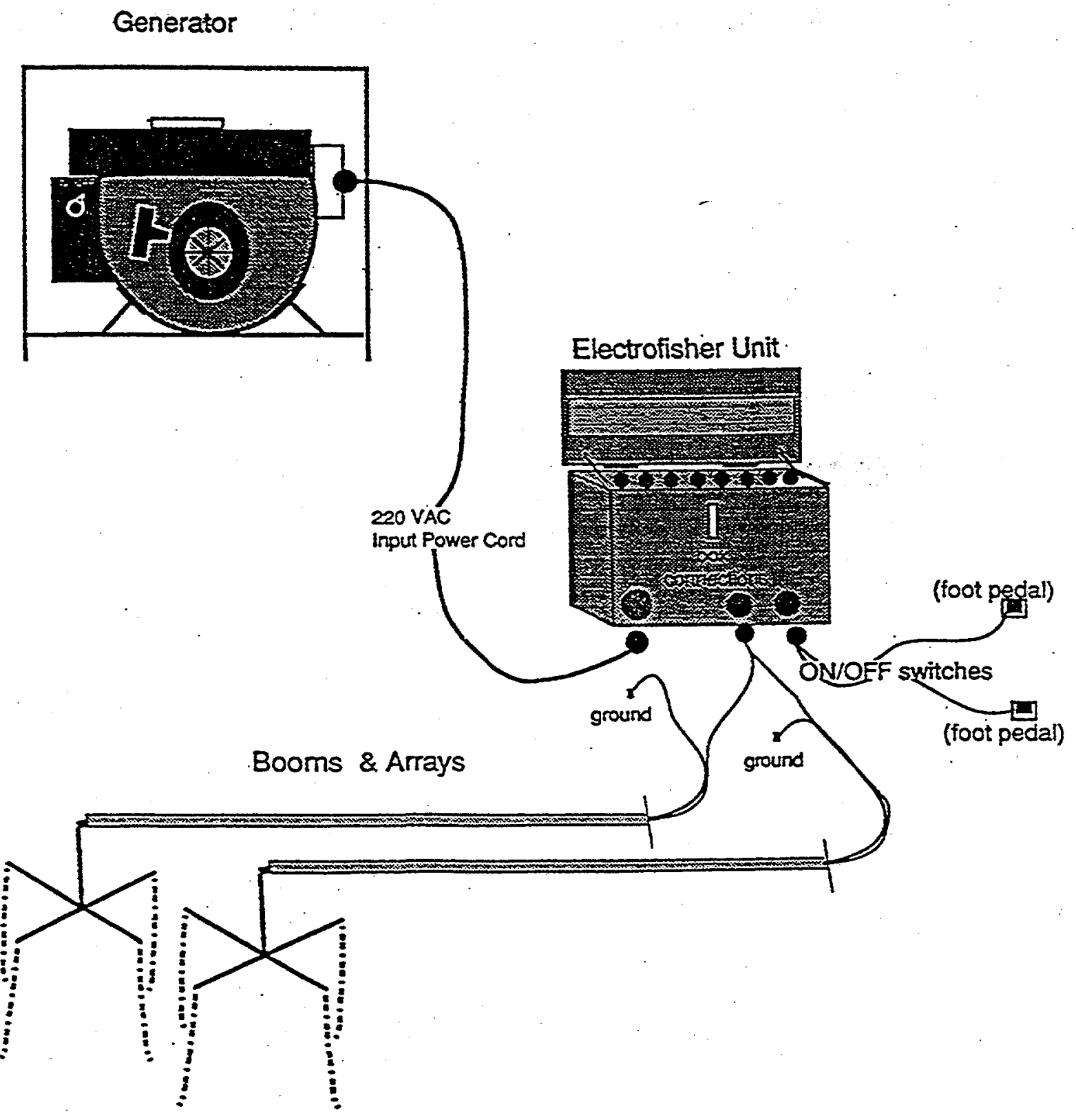

Figure 7.1.1. Electrofisher Components 
INTRODUCTION

EQUIPMENT

\subsection{WATERFOWL SAMPLES}

Collecting samples of waterfowl from the Columbia River satisfies three objectives: 1) analyzing potential dose pathways, 2) verifying that the release and storage of radioactive waste materials from Hanford Site facilities are under control, and 3) reassuring the public that waterfowl do not provide a means of exposure to harmful levels of radioactive materials of Hanford origin. Samples collected to verify control require the comparison of results to background samples or an adequate historical record.

The following equipment may be necessary to collect waterfowl samples:

- shotguns and shells with stainless-steel pellets

- safety glasses

- appropriate hearing protection

- portable ice chest and ice

- sharp knife or scalpel

- disposable rubber or plastic gloves

- portable radiation meters

- "diaper" paper

- plastic bags

- masking tape

- valid collection permits

- sample labels

- bird identification handbook

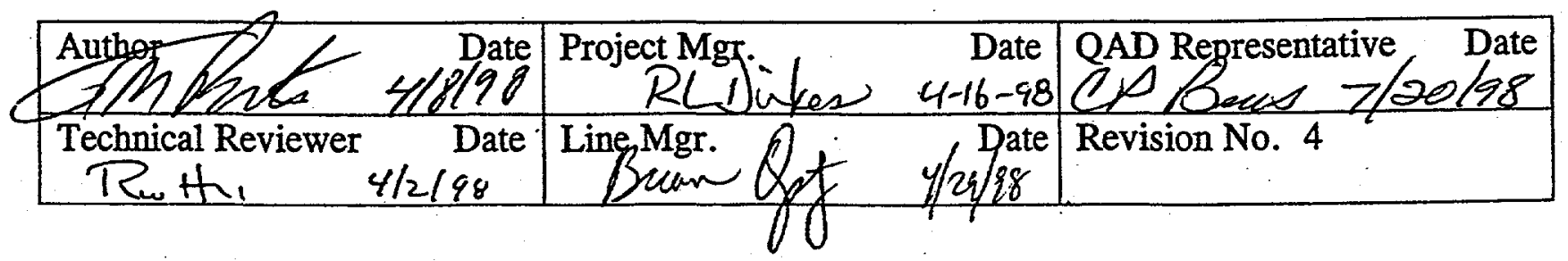


- cervical dislocation instrument and protective plate

- trip sheet

- marking pens

SAMPLE COLLECTION

FIELD SAMPLE PREPARATION

\section{LABORATORY SAMPLE PREPARATION}

Review and comply with all applicable Job Safety Analyses and Radiation Work Procedures (RWPs).

Collect the routine samples using a shotgun.

Waterfowl must be brought back to the lab for sample preparation.

If appropriate (see Section 8.4), survey each sample following applicable RWP requirements, and record the readings in the appropriate locations on the trip sheet. If the survey exceeds releasable levels, notify the Sample Collection Task Leader.

If collecting waterfowl from more than one location, individually bag and label the birds. Be sure to write the species, sample \#, location, date, and time on the bagged samples.

Put on disposable rubber gloves.

Lay out a piece of "diaper" paper, and open a plastic sample bag on the laboratory bench.

Place the sampled bird on a clean plastic bag to remove breast, thighs, and thighbone.

Remove skinless piece of breast muscle.

Rinse the breast muscle samples briefly in tap water, and blot the excess water with a paper towel.

Weigh the sample, and record the weight on the trip sheet. If the weight of the breast muscle is insufficient (as specified on the trip sheet), add muscle tissue from the thighs.

Put the sample into a plastic bag, and seal the bag.

The bag should be labeled with sample date, sample number, species, and sample weight.

Place this bag in another plastic bag. 
Insert the label between bags so that it can be read.

Seal the outer bag.

Write the name of the species collected on the trip sheet. Collection date and sampling location may be preprinted on the trip sheet. If so, verify that they are accurate. If necessary, write this information on the trip sheet where appropriate.

Remove the thighbone from the thigh.

Rinse the thigh from each bird briefly in tap water, blot the excess water with a paper towel, and place the samples in plastic bags as described above.

Each sample should be individually wrapped and labeled.

BONE SAMPLE PREPARATION
TRIP SHEET AND SAMPLE SUBMISSION REQUIREMENTS
Bone samples (two thighs) must be cleaned before submission. Carefully remove all muscle tissue from the bone by scraping with a knife or scalpel.

If appropriate (see Section 8.4), survey the bone samples with a portable survey instrument for possible radionuclide contamination. Report results on the trip sheet.

Weigh the sample, and record the weight on the trip sheet. Double bag the sample in plastic bags as described above.

If appropriate (see Section 8.4), resurvey the samples and record the results in the proper locations on the trip sheet. Samples with elevated readings should be handled according to the appropriate RWP. Notify the Sample Collection Task Leader of any unusual readings, and proceed as instructed.

Store all waste tissues in a freezer until the Sample Collection Task Leader issues instructions for disposal.

Samples must be submitted for analysis on the day of collection, if possible. If samples cannot be submitted on the day of collection, store the samples in a freezer or refrigerator overnight.

See Section 8.1, Trip Sheets, for further requirements for completing trip sheets and submitting samples to an analytical laboratory. 


\subsection{RABBIT SAMPLES}

INTRODUCTION Cottontail rabbits and jackrabbits are collected from onsite areas to provide data for verifying that the release and storage of radioactive waste materials from Hanford Site facilities are under control. Verification of control requires comparison of sample results to background samples or an adequate historical record.

EQUIPMENT

The following equipment may be necessary to collect rabbit samples:

- spotlights (2)

- shotguns, .22 caliber rifle, and appropriate ammunition

- appropriate hearing protection

- rabbit traps

- safety glasses

- portable ice chest and ice

- sharp knife or scalpel

- disposable rubber or plastic gloves

- portable survey meters

- plastic bags

- masking tape

- valid collection permits

- sample labels

- trip sheet

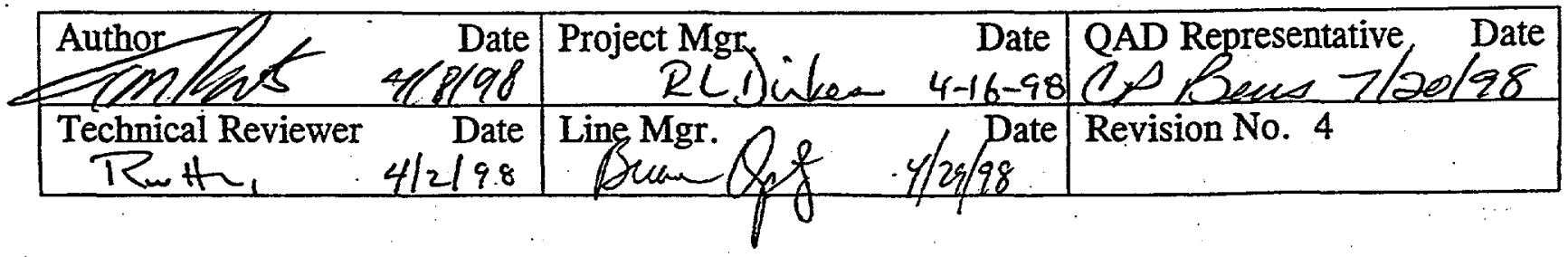


SAMPLE COLLECTION

Spotlighting
- portable scale

- property pass.

Collect the routine samples by using traps or a firearm, as specified in the procedures below.

Review and comply with all requirements for using firearms.

The following procedures include site-specific variations because cottontail rabbits have historically been the only species collected in the 100-N Area, and jackrabbits have dominated collections in the 200 Areas. In general, jackrabbits are more visible at night than are cottontails. For this reason, trapping and firearms will be used during daylight hours to collect samples in the 100-N Area and 300 Area, and firearms and spotlighting after dark will be the preferred technique for collecting rabbits from the 200 Areas. If the preferred sampling techniques fail, spotlighting may be used in the 100-N Area and 300 Area for cottontails, and traps may be set in the 200 Areas for jackrabbits.

Before going into the field, call PNNL Security at 375-2154 and tell them where and when the samples will be collected and how many people will be using firearms.

At sunset (while it's still light), drive through the designated sampling area to ensure the area is clear of people.

Spotlighting should begin immediately after dark. Spotlighting is a two person operation: One person functions as the vehicle operator, the other operates the spotlight and uses the firearm.

Search for rabbits with the spotlight while slowly driving the roads within the sampling area.

Once a rabbit has been spotted, stop the vehicle while keeping the light positioned on the rabbit. The shooter must quietly exit the vehicle with the firearm and the appropriate shells. The shooter can then load the firearm and step into the periphery of the light. In this way, the shooter can see the gun barrel sights and accurately aim at the rabbit.

After shooting, all shells must be ejected from the gun before reentering the vehicle. Be sure to collect the spent shell casings from the ground. 


\section{WARNING: DO NOT}

- jump from a moving vehicle

- discharge a firearm while within or on a vehicle that's either stationary or moving

- discharge a firearm across a vehicle.

Also call PNNL Security when sampling is completed to inform them that you have returned from the field.

Specific steps within this procedure will address the differences associated with setting traps for each species.

Use of Traps

Baiting
Ensure that a "DO NOT TAMPER WITH" tag is affixed to all traps.

Look for areas within the designated trapping area that are heavily used by rabbits. Cottontails will usually concentrate in shady areas around brush patches, rock piles, or along the riverbank. Jackrabbits will tend to concentrate along the edge of dense sagebrush and open areas. Fresh tracks and rabbit pellets along runways are helpful indicators of rabbit activity.

If possible, place unset traps at the chosen trap sites 1 or 2 days prior to the collection period. This gives the rabbits time to become familiar with the trapping apparatus.

Place traps within the area of interest, preferably near, but not directly on, the runway. The traps will need to be somewhat hidden, either tucked into a nearby pile of debris or covered by the surrounding vegetation.

Make sure the openings of the traps are not blocked or hidden from sight and are generally facing the runway.

Use at least four traps per collection area. Individual traps should be no closer than approximately $15 \mathrm{yd}$ apart.

Bait the traps with a combination of lettuce and sliced and shredded carrots and apples. Lettuce can be broken into pieces by hand. The carrot and apple slices should be approximately 1 in. long and 0.5 in. thick. The shredded bits emit more scent, and the chunks prevent the bait from drying up.

Place approximately 4 or 5 cups of bait on the pan, with most located on the back half of the pan. Make sure pieces of bait are not dropped outside of the trap. 
Setting Traps

FIELD SAMPLE PREPARATION
Baiting the traps should occur 1 or 2 hours before sunset.

To set the trap, lift the door lock away from the door, and push down on the door rod, which has an offset loop near the end. This raises the door to a horizontal position (Figure 7.3.1). Catch the flat end of the rod under the bait pan trigger. In this position, the pan should be almost level. Make the set as sensitive as possible by adjusting the trigger mechanism.

Place a 3- to 4-in.-diameter rock gently on top of the door. This will force the door down much faster when the rabbit sets off the trap.

Check and rebait the traps every morning while in use. It is imperative that the traps be inspected as early as possible or provided with shading to reduce heat stress on any trapped animal.

If traps are unsuccessful for 3 consecutive days, relocate them to another heavily used area.

A shotgun and the appropriate upland game bird shells should also be brought to the collection site. If rabbits are seen outside of the traps, they should be collected as needed.

Shoot the rabbit in the trap with a .22 caliber rifle loaded with bird shot. Aim just behind the rabbit's ear, with the barrel no farther than 4 in. away.

If appropriate (see Section 8.4), survey each animal according to the applicable RWPs. If the survey exceeds releasable levels, record the reading on the trip sheet, and notify the Sample Collection Task Leader.

Place the sampled rabbit on a clean plastic bag or piece of "diaper" paper to remove muscle and bone.

Wearing disposable gloves, skin and remove the hind legs (excluding the feet), and place the legs in a plastic bag.

CAUTION: DO NOT CONTAMINATE the samples with dirt, hair, Gastrointestinal (GI) tract contents, or any other foreign material. Samples shall not contain bullets or bird shots.

Close and seal the bags with masking tape. With a marking pen write the date, location, species and sample number(s) on the bag. Place the bags in the ice chest for transport. 
Leave carcasses in the field. If animals were collected within a radiation zone, leave the carcasses in the zone.

If appropriate (see Section 8.4), survey the materials used to prepare the samples, and place them in a clean plastic bag for proper disposal.

LABORATORY SAMPLE PREPARATION
At PNNL, rinse the hind legs briefly in tap water, and blot the excess water with a paper towel.

Remove and weigh the muscle tissue from each leg, and place it in a plastic bag.

Seal the bag, and label it with sample number, sample date, tissue type, and species name.

Record the sample weight on the trip sheet. Ensure that the sampling date is on the sample label and is accurate.

Double bag the sample putting the sample label between the two bags. Make sure the label is readable.

Carefully scrape all the remaining muscle tissue from the thighbone with a knife or scalpel.

Weigh the two hind leg bone samples, and place them in a plastic bag.

Label the bag with the sample number, collection date, tissue type, and species name.

Record the sample weight on the trip sheet.

Double bag the sample and insert the sample label between bags. Make sure the label is readable.

Store all waste tissues in a freezer until the Sample Collection Task Leader issues instructions for disposal.

TRIP SHEET AND

SAMPLE

SUBMISSION REQUIREMENTS
Samples must be submitted for analysis on the day of collection, if possible. If samples cannot be submitted on the day of collection, store the samples in a freezer or refrigerator overnight.

See Section 8.1, Trip Sheets, for further requirements for completing trip sheets and submitting samples to an analytical laboratory. 


\section{Trap Parts}

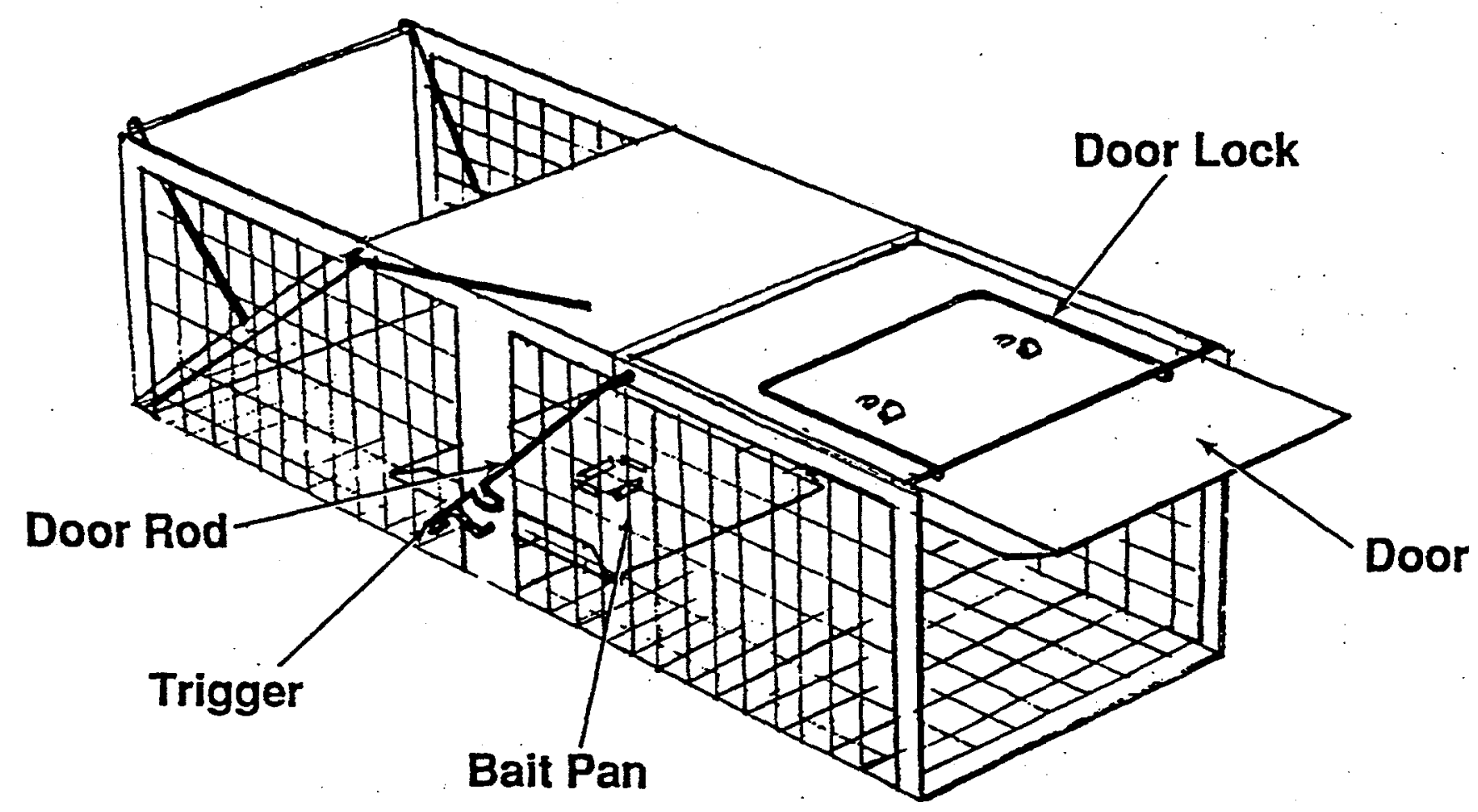




\subsection{GAME BIRD SAMPLES}

INTRODUCTION
Collecting samples of game birds from onsite and offsite locations satisfies three objectives: 1) analyzing potential dose pathways, 2) verifying that the release and storage of radioactive waste materials from Hanford Site facilities are under control, and 3) reassuring the public that game birds do not provide a means of exposure to harmful levels of radioactive materials of Hanford origin. This procedure covers hunting of pheasant and quail, and trapping of chukars.

The following equipment may be necessary to collect game bird samples:

- shotguns and ammunition

- portable ice chest and ice

- appropriate radiation survey instruments

- sharp knife or scalpel

- disposable rubber or plastic gloves

- plastic bags

- masking tape

- "diaper" paper

- valid collection permits

- sample labels

- trip sheet

- cervical dislocation instrument

- chukar trap

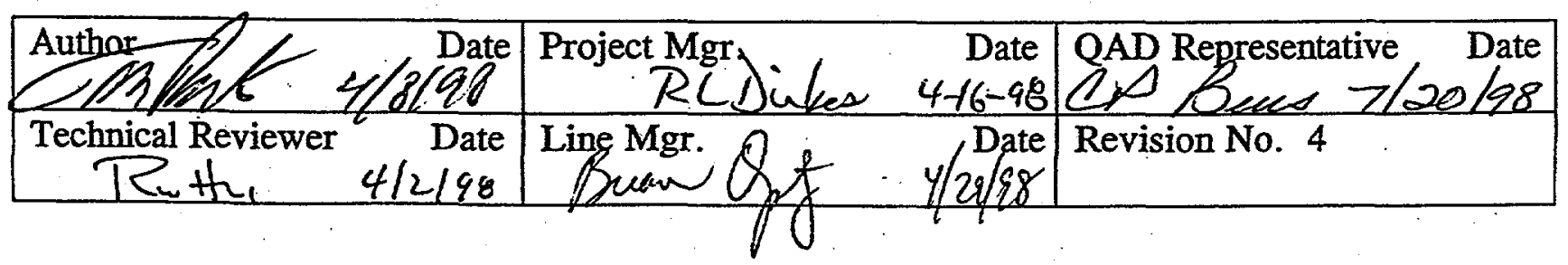


- water trough

- portable water jugs ( 10 gallons total)

- bait (racing feed and cracked corn)

- marking pens

- property pass (for firearms)

- chukar/waterfowl catch cage

- bungee cords

- scale.

SAMPLE COLLECTION

TRAP

LOCATIONS (chukar)

PRE-BAITING
If appropriate (see Section 8.4), review and comply with applicable RWPs for collecting game bird samples from radiation zones.

Collect game bird samples from designated onsite locations in the 100 Areas with a shotgun.

Collect chukar samples from the West Lake area using the chukar trap.

Look for areas within the designated trapping area that show evidence of chukar usage. Consult with field staff that have recent familiarity with the area. Chukars usually inhabit areas near rockslides or cliffs but are often found in gullies with sagebrush. Usually a source of water will be nearby (within 1 mile). Look for droppings, feathers, or tracks going to or from the water source. Direct sighting of chukar is best.

For best results, try to locate the trap site between the chukars daily use area and their water source (i.e., make the water source near the trap more convenient than the natural source such as that between West Lake and the radio transmission repeaters on Gable Mountain).

Once the site has been selected, dig a hole, and bury the water trough so approximately $1 \mathrm{in}$. of the trough is above ground.

Then place a branch or stick into the trough to facilitate the escape of any small mammals or rodents that fall into the trough. NOTE: Try to place the trough in the middle of a level area with a radius of at least $3 \mathrm{ft}$.

Fill the trough with water, and sprinkle some "racing feed" on the ground near the trough. 
Check every other day for signs of chukar activity. Keep the trough filled with fresh water.

Once it is evident that chukars are using the site, the trap should be moved to the location. Place the trap over the trough, and stake it to the ground.

Run the stakes through the conduit on the trap frame and drive into the ground. NOTE: If the soil is loose or sandy, use the trap with the chicken wire bottom or the chukars will tunnel out.

Wire the door on the trap open.

Bait the trap with half a gallon of both racing feed and cracked corn. Put most of the bait inside the trap, but also sprinkle some around the outside and in the entrances. This will get the birds used to entering the trap itself.

Ensure that a "DO NOT TAMPER WITH" tag is affixed to the trap.

Once they have eaten all the bait, it's time to set the trap. NOTE: Racing feed can be used alone and will produce better results than just cracked corn.

To set the trap, wire the side door closed. The trap is a confusion entrance (or funnel type) trap with three entrances (or funnels). Once the door is closed, the trap is set.

After closing the door, make sure the entrances are 2 in. wide; if not, bend the wire until the entrance width is 2 in.

Refill the water trough, and re-bait the trap with more racing feed and cracked corn.

CHECKING THE TRAP
Check and re-bait the trap every day as necessary until the desired sample is collected. Traps should be checked in the afternoon if possible. In hot weather conditions, place some brush on, or against, the trap to provide shade.

If chukar are in the trap, open the door and attach the waterfowl/chukar catch pen to the trap with bungee cords. The catch pen attaches similar to the waterfowl traps, but must be on its side to line up with the exit on the trap.

After attaching the catch pen, go to the far side of the trap and scare the chukar into the catch pen.

Slide the catch pen door closed. 
EUTHANASIA

SAMPLE PREPARATION

FIELD SAMPLE PREPARATION
To kill the birds, use the cervical dislocation instrument. Slide the bird's neck into the slot of the protection plate, and pinch its neck with the instrument.

Samples may be processed in the field or returned to the laboratory for processing.

If appropriate (see Section 8.4), survey each bird following applicable RWP requirements and record the readings in the appropriate locations on the trip sheet. If the survey exceeds releasable levels, record the reading on the trip sheet and notify the Sample Collection Task Leader.

Place the sampled bird on a clean plastic bag or piece of paper to remove breast and thighs with bone.

Wearing disposable gloves, remove skinless pieces of breast muscle, and place them in a plastic bag.

Skin and remove both thighs with the bones, and place them in the plastic bag with the breast muscle.

Ensure that the sample date on the sample label is accurate.

CAUTION: DO NOT CONTAMINATE the samples with dirt, feathers, gastrointestinal (GI) tract contents, or any other foreign material.

Double bag the sample putting the sample label between the two bags so that it is readable.

Complete the remainder of sample processing at the laboratory.

Leave carcasses in the field. Do not remove them from a radiation zone if they were collected there.

If appropriate (see Section 8.4), survey the materials used to prepare the samples, and place them in a plastic bag for proper disposal.

Notify the Sample Collection Task Leader if the survey reading exceeds releasable limits. 


\section{LABORATORY SAMPLE PREPARATION}

When samples are brought in from the field for processing, the same initial steps outlined for field sample preparation should be used.

Rinse the breast muscle samples briefly in tap water, blot the excess water with a paper towel, and place the sample into a plastic bag.

Weigh the sample. The sample weight should be $500 \mathrm{~g}$ or larger. If additional muscle is needed to meet a minimum weight of $500 \mathrm{~g}$, include some thigh muscle and note this on the trip sheet.

Label the bag with sample date, sample number, tissue type; and species name.

Seal the bag.

Double bag the muscle sample, making sure that the sample label is between bags and is readable.

For chukars, two birds will be combined into one composite sample. Most of the skin and feathers can be peeled away from the carcass allowing easy access to the breasts, thighs, and wings.

Carefully remove all muscle tissue from the bone by scraping the surface with a knife or scalpel.

Ensure that the sample number and sample date are on the label and are correct.

Put the completed samples into individual labeled plastic bags.

Weigh the samples, and write the weights on the sample labels.

Double bag these samples as described above, and close and seal them with masking tape.

All waste tissues must be bagged, labeled, and stored in a freezer until the Sample Collection Task Leader issues instructions for disposal.

Samples must be submitted for analysis on the day of collection, if possible. If not possible, store samples in a refrigerator overnight, or in a freezer.

See Section 8.1, Trip Sheets, for further requirements for completing trip sheets and submitting samples to an analytical laboratory. 


\subsection{DEER AND ELK SAMPLES}

INTRODUCTION

EQUIPMENT
Collecting samples of onsite deer satisfies three objectives of the surveillance program. Samples provide data for 1) analyzing potential dose pathways, 2) verifying that the release and storage of radioactive waste materials from Hanford facilities is under control, and 3) reassuring the public that deer do not provide a means of exposure to harmful levels of radioactive materials of Hanford origin. Verification of control requires the comparison of sample results to background samples or an adequate historical record.

The following equipment may be necessary to collect deer samples:

- shotguns and ammunition (slugs)

- binoculars

- portable ice chest and ice

- sharp knife or scalpel

- bone saw

- appropriate radiation survey instruments

- "diaper" paper

- disposable rubber or plastic gloves

- plastic bags

- masking tape

- valid collection permits

- sample labels

- trip sheet

- property pass for guns

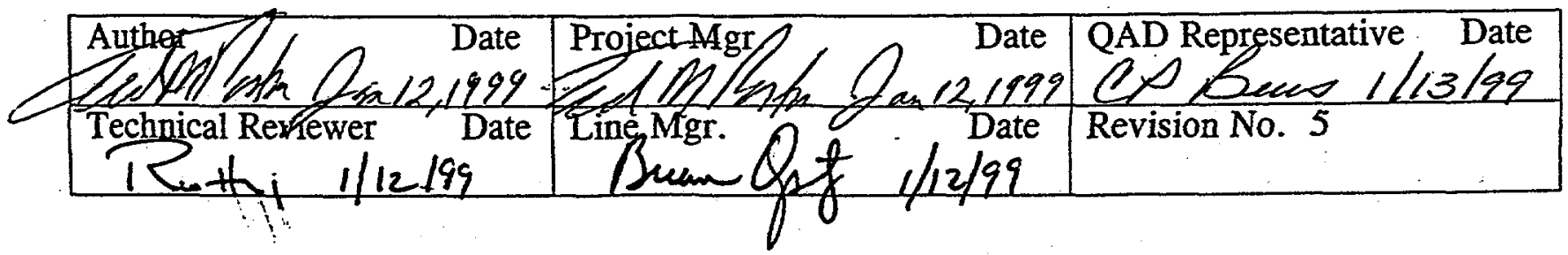




\section{SAMPLE COLLECTION}

Two deer may be sampled from the 200-East Area near B Pond, and two may be sampled from the 100-N Area. Other samples are to be collected from road-killed deer or elk as specified by the Sample Collection Task Leader.

If appropriate (see Section 8.4), survey the animal following applicable RWP requirements. If the survey reading exceeds releasable levels, record the reading on the trip sheet, and notify the Sample Collection Task Leader.

Be sure to wear disposable gloves.

While in the field, remove at least $500 \mathrm{~g}$ of muscle from the hind legs, and place it in a plastic bag.

Remove $200 \mathrm{~g}$ of thighbone.

Place the bone in a plastic bag.

CAUTION: DO NOT CONTAMINATE the samples with dirt, hair, gastrointestinal (GI) tract contents, or any other foreign material. Samples shall not contain slugs.

Close and seal the bags with masking tape.

Write the species name, date of collection, and location on the bags, and place them in an ice chest for transport to PNNL.

Leave carcasses in the field. Do not remove them from a radiation zone if they were collected within a zone.

If appropriate (see Section 8.4), survey all materials used to prepare the samples (gloves, paper, etc.) and place them in a plastic bag for proper disposal.

At PNNL, rinse the muscle sample briefly in tap water, blot the excess water with a paper towel, and place the sample in a plastic bag.

Label the bag with sample number, collection date, tissue type, and species name.

Weigh the sample, and record the weight on the trip sheet. Verify that the collection date is on the label and is accurate.

Seal the bag with tape.

Scrape all muscle tissue from the bone samples with a knife or scalpel. 
Place the bone sample in a plastic bag, and label the bag with sample number, collection date, species name, and tissue type.

Weigh the sample, and record the weight on the trip sheet.

Double bag and label the sample as previously described.

Seal the bags with tape.

Store waste tissues in a freezer until the Sample Collection Task Leader issues instructions for disposal.

If appropriate (see Section 8.4), survey the samples and record the results in the proper locations on the trip sheet. Notify the Sample Collection Task Leader of any unusual readings, and proceed as instructed.

TRIP SHEET AND SAMPLE SUBMISSION REQUIREMENTS
Samples must be submitted for analysis on the day of collection, if possible. If samples cannot be submitted on the day of collection, store the samples in a freezer or refrigerator overnight.

See Section 8.1, Trip Sheets, for further requirements for completing trip sheets and submitting samples to an analytical laboratory. 


\subsection{MISCELLANEOUS PROCEDURES}

\section{INTRODUCTION}

The procedures discussed here are either not routinely used for sample collection or they broadly supplement other sample collection procedures described in the manual. Included in this section are procedures for the following:

- trip sheets (Section 8.1)

- radiation work permits (Section 8.2)

- unusual findings notification (Section 8.3)

- radiological surveys of samples (Section 8.4)

- procedure for the safe handling, transport, and storage of firearms (Section 8.5)

- determining geographic positions using the Trimble Geoexplorer II (Section 8.6).

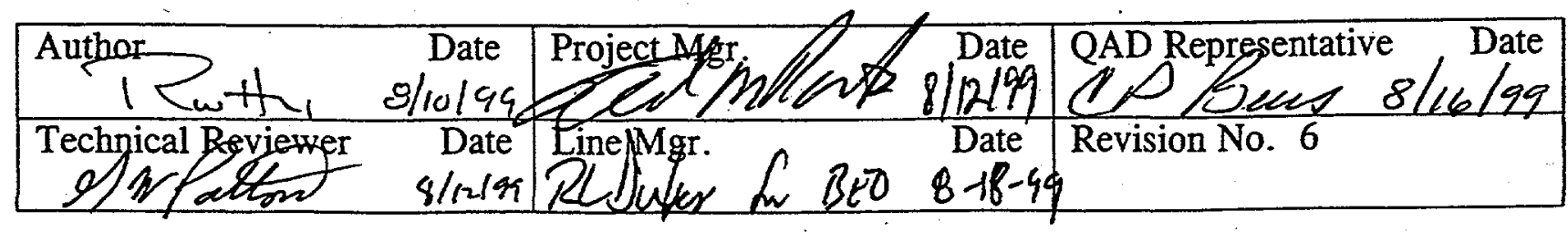




\subsection{TRIP SHEETS}

INTRODUCTION
The collection of environmental samples for the SESP is documented on trip sheets, also referred to as environmental surveillance trip logs. Trip sheets provide the SESP with a day-to-day record of field operations and function as official chain-of-custody forms for submitting samples to the analytical laboratory, or for placing them into an archiving facility.

Several types of media-specific trip sheets are used when collecting samples. Sheets with distinct formats are generated for air samples, composited water samples, water grab samples, continuous water samples, wildlife samples, and river shoreline and terrestrial thermoluminescent dosimeters (TLDs). (Figures 8.1.1 - 8.1.7). A single format is used for food and farm products, sediment, soil and vegetation samples (Figure 8.1.8).

Trip sheets are computer-generated forms that contain information about the samples being collected. Each sheet consists of an original, or front, copy and a carbonless duplicate, or back copy. Certain information is generally pre-printed on the trip sheets. This information usually includes the sample number, sample location, contract number, work package number, the name of the analytical lab, as well as other data specific to each media. If this information is not pre-printed on the trip sheet, then the person collecting the samples must review earlier trip sheets or contact the Data Management Task Leader to obtain the information needed. This must be done prior to delivering the samples to the analytical laboratory.

If non-routine samples are to be collected, the appropriate sampling information must be provided to the Data Management Task Leader so that trip sheets and labels can be generated prior to sample collection. If this is not possible, blank trip sheets can be used then filled in by hand when the samples are collected. However, the Data Management Task Leader will need to generate sample numbers (or a new trip sheet) and labels for these samples before they can be submitted to the analytical laboratory. The use of handwritten trip sheets should be avoided if possible.

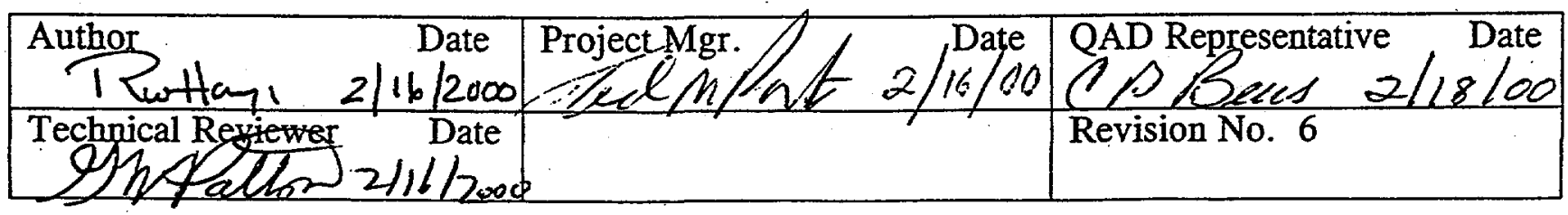


TRIP SHEET ENTRIES
NOTE: The importance of providing complete and accurate information on the trip sheets cannot be overemphasized. The information found on the trip sheets may be of the utmost importance in analyzing the data, accounting for anomalies in the data, and providing historical documentation of the samples being collected.

Data must be entered in ink. Errors or changes must be marked out with a single line, initialed and dated.

Ensure that the sample collector's name is printed at the top of each trip sheet.

Verify that the "date off" on the trip sheet is also written in the "OFF" field on the sample label.

Ensure that the sample number, location name, date/time on, start flow, etc., are included (if appropriate) on each trip sheet. If necessary, enter this information in the appropriate trip sheet locations.

If appropriate, verify that the sample size (also called sample weight and sample volume) recorded on the trip sheet agrees with the sample size recorded on the sample label. If necessary, change the label to match the trip sheet.

The trip sheet should be filled out as the samples are collected. Any observations about conditions near the sampling site that might influence sample results (such as construction or farming activities) should be noted in the comments column. All problems with the sampling systems or the samples themselves should also be recorded in the comments column.

IMPORTANT: Verify that the sampling dates on all sample labels, trip sheets, field record forms, and chain-of-custody forms are correct. Labels and trip sheets are often printed days or weeks before sampling and the dates may need to be changed to reflect the correct sampling date.

NOTE: With the exception of the radiation survey columns (GM and PAM), each entry space for each sample listed on the trip sheet should contain a data entry. In some cases, an X or a line in the empty entry box may be appropriate. 
COESP Trip Sheet

NO SAMPLES

STORING

SAMPLES OVERNIGHT
In addition to the above entries, Community-Operated Environmental Surveillance Program (COESP) personnel must complete their trip sheets by writing their name (signature) and date in the first "Relinq. By:" space at the bottom of the sheet and by writing "Station Locked Storage" and the date in the corresponding "Relinq. To:" space. This certifies that the samples are stored securely until they are picked up and delivered to the analytical laboratory. The person picking the samples up at the COESP station must write "Station Locked Storage" in the second "Relinq. By:" space, and sign and date in the second "Relinq. To:" space. This transfers custody of the samples to the person picking them up.

If a scheduled sample 1) cannot be collected, 2) is below a specified sample size, or 3 ) is associated with questionable or missing collection data, it may be treated as a "NO SAMPLE." If a sample is classified as a "NO SAMPLE," the trip sheet and sample label must be filled out as completely as possible (including the DATE OFF, indicating the sampling attempt) and the words "NO SAMPLE" must be written on both the trip sheet and sample label. Additionally, a "NO SAMPLE" justification must be written in the comment column on the trip sheet. A classification of "NO SAMPLE" can be determined by the Sample Collection Task Leader, the Data Management Task Leader, the appropriate media task leader, or by reading the pertinent sample collection procedures. If the "NO SAMPLE" is part of a composited sample (the label will indicate whether it is to be saved for a composite sample), the trip sheet must be reviewed by the Sample Collection Task Leader, and the trip sheet and sample label must be submitted to the analytical laboratory in normal fashion. If the "NO SAMPLE" is not part of a composite sample, the trip sheet and sample label must be returned to the Sample Collection Task Leader, who will forward them to the Data Management Task Leader.

Samples should be submitted to the analytical lab promptly, but can be retained overnight or over a weekend if within sample holding time requirements, properly stored, and secured in a restricted access area.

If samples are stored at PNNL overnight, the sample custodian must sign and date the trip sheet in the "relinquished by" space and note in the "relinquished to" space that the samples were placed in storage at a specific location on a specific date.

When the samples are picked up for delivery to the laboratory, indicate that the samples are "relinquished by" secured storage and "relinquished to" the person picking up the samples. 
TRIP SHEET REVIEW

SAMPLE SUBMITTAL
Before submitting the samples to the analytical laboratory or archiving them, the trip sheets must be reviewed for accuracy and completeness by the Sample Collection Task Leader, Data Management Task Leader, or another SESP task leader who is familiar with the media. The reviewer must sign and date each trip sheet in the appropriate location to acknowledge the review.

Deliver the samples to the analytical laboratory or designated archiving facility on the day of collection, if possible. Delayed deliveries must be authorized by the Sample Collection Task Leader or the SESP task leader responsible for the samples.

Prior to delivery of samples to Severn Trent Laboratories (STL, Richland), formerly Quantera Environmental Services, remove and dispose of the description column (location names) from the front copy of the trip sheet by cutting or tearing along the double dotted lines. Do not remove the description column from the trip sheet duplicate (back copy). Unless otherwise instructed, removal of the description column is not necessary when routine samples are delivered to other laboratories for analysis.

At the analytical laboratory, sign and date the trip sheet in the "relinquished by" space, and have the person receiving them sign and date the trip sheet in the "relinquished to" space. The analytical laboratory will keep the original (front copy) of the trip sheet for their records. Verify that the trip sheet duplicate (back copy) is legible.

When delivering samples to the 320 building, sample collection personnel must complete their trip sheets by writing their name (signature) and date in the first "relinquished by" space at the bottom of the trip sheet and by writing " 320 locked storage" and the date in the corresponding "relinquished to" space. The front copy of the trip sheet will remain with the samples.

Immediately return the trip sheet duplicate (back copy) to the Sample Collection Task Leader. The Sample Collection Task Leader will ensure that the duplicate (back copy) is provided to the Data Management Task Leader within 2 working days following sample collection.

If archiving the samples, sign and date the trip sheets in the "relinquished by" space, and write "archive storage," and the date, in the "relinquished to" space.

The original trip sheets must be archived with the samples, and a photocopy of the trip sheet(s) must be provided to the Data Management Task Leader. Samples (with sample labels attached) are retained in the archive storage cabinet or refrigerator/freezer, whichever is appropriate. 
SUBMITTING

ARCHIVED

SAMPLES TO AN

ANALYTICAL LABORATORY
The person delivering the archived sample to the analytical laboratory must write "archived storage," and the date, in the first "relinquished by" space and sign and date the trip sheet in the first "relinquished to" space. All of this is to be done when the sample is removed from storage.

This individual is now the sample custodian. Be sure that the information on the label is correct and that the collection date on the label matches the collection date on the trip sheet.

Before submitting the samples to the analytical laboratory, the trip sheets must be reviewed for accuracy and completeness by the Sample Collection Task Leader, Data Management Task Leader, or another SESP task leader who is familiar with the media. The reviewer must sign and date each trip sheet in the appropriate location to acknowledge the review.

Upon delivery of the archived sample to the analytical laboratory, the sample custodian must sign and date the trip sheet in the second "relinquished by" space and have the person receiving them sign and date in the second "relinquished to" space. The analytical laboratory will keep the original (front copy) of the trip sheet for their records. Verify that the trip sheet duplicate (back copy) is legible.

Deliver the duplicate copy (back copy) of the trip sheet along with the copy of the collection, or original, trip sheet, to the Sample Collection Task Leader so that they can be transferred to the Data Management Task Leader within two working days following sample collection, as described previously. 
**** BATTELIE ENVIRONMENTAL SURVEILIANCE TRIP IOG **** Page 1 Route: 02 Lab: QTESRL Contract \#248789-A-B3 Battelle - F02582 Air Cal. \# Date: THURSDAY 12/30/1999 Collected By (print): Date:

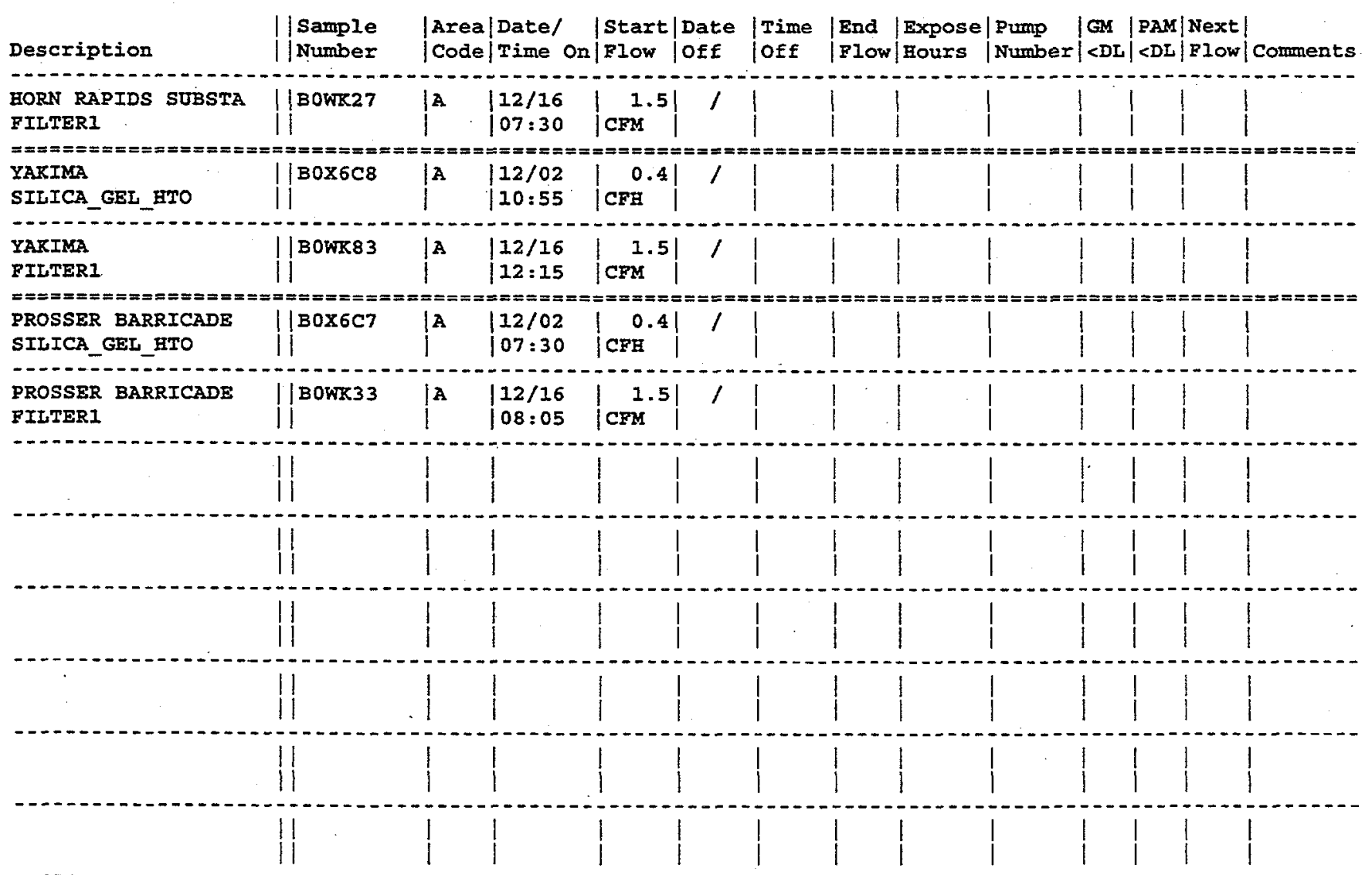

Relinq. By:

Reling. To

Reling. By:

Reling. To

Reling. By: $-1$

Relinq. To

Reviewed By:

11

Figure 8.1.1. Environmental Surveillance Trip Sheet for Air Samples 


\section{**** BATTELLE ENVIRONMIBNTAL SURVEILIAANCE TRIP LOG **** Page 1 \\ Route: 01 Lab: QTESRL Contract \#248789-A-B3 Battelle - F02584 Date: WEDNESDAY 12/29/1999 Collected BY (print):}

Date:

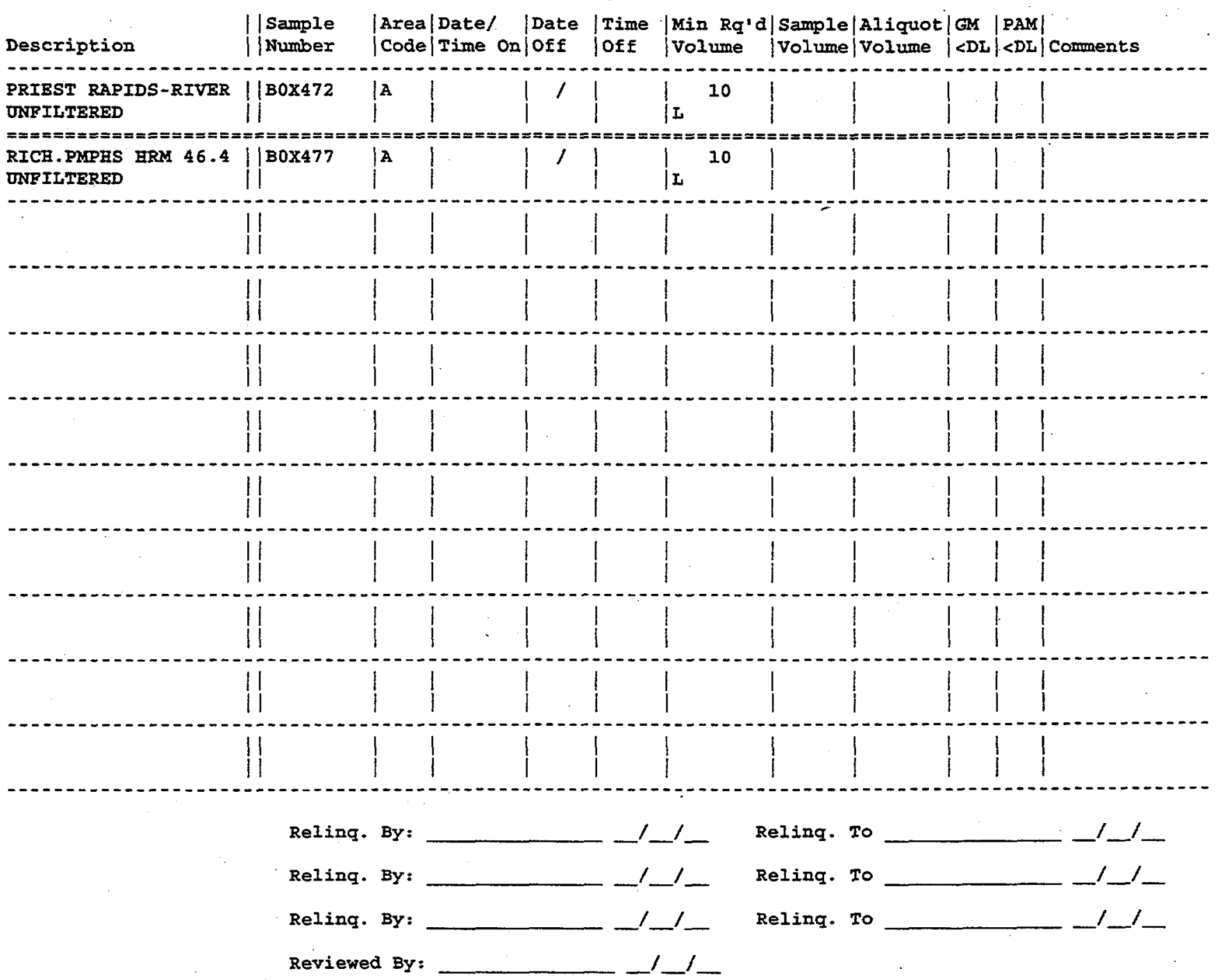

Figure 8.1.2. Environmental Surveillance Trip Sheet for Composited Water Samples 


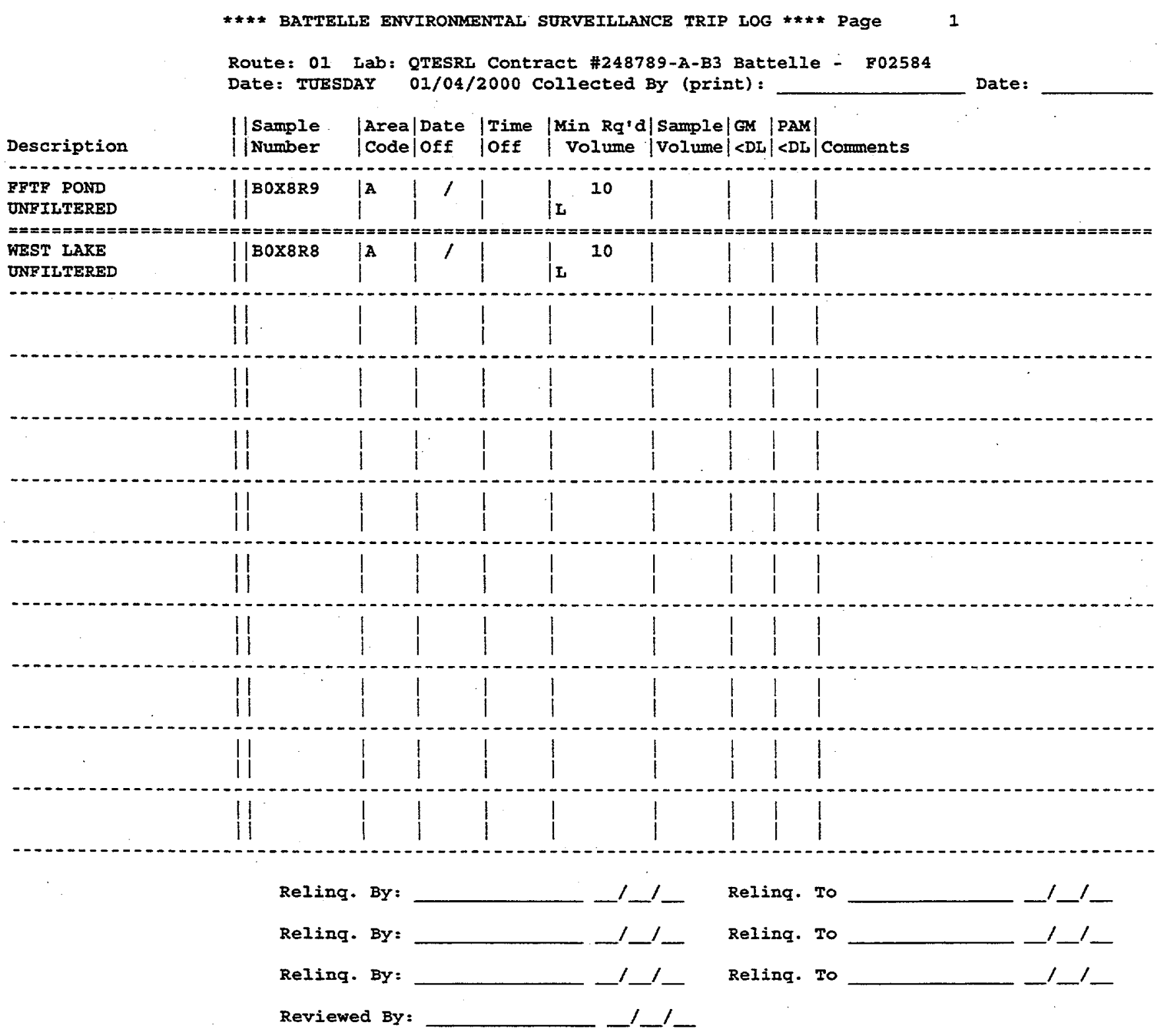

Figure 8.1.3. Environmental Surveillance Trip Sheet for Water Grab Samples 
Route: 01 Iab: QTESRI Contract \#248789-A-B3 Battelle - F02584 Date: WEDNESDAY 12/29/1999 Collected BY (print):

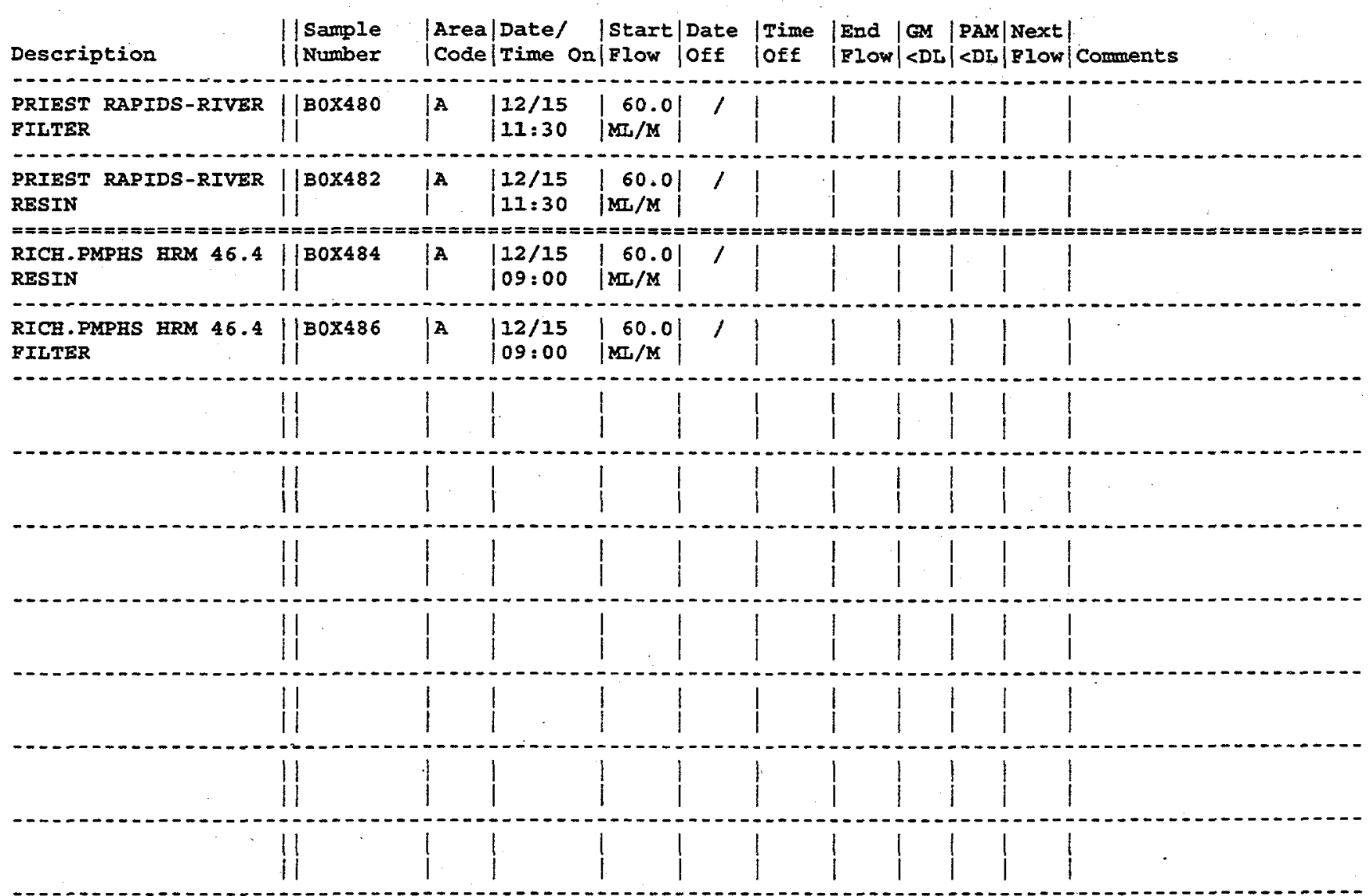

Relinq. By:

Relinq. By:

Reling. By:

Reviewed BY:
Rezing. To

Reling. To

Relinq. To

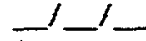

$-1-$ $-1-$ $-1$

Figure 8.1.4. Environmental Surveillance Trip Sheet for Continuous Water Samples 
Route: 8 Lab: OTESRL Contract \#248789-A-B3 Battelle - K94508 Balance ID \# Date: FRIDAY 05/07/1999 Collected BY (print) : Date:

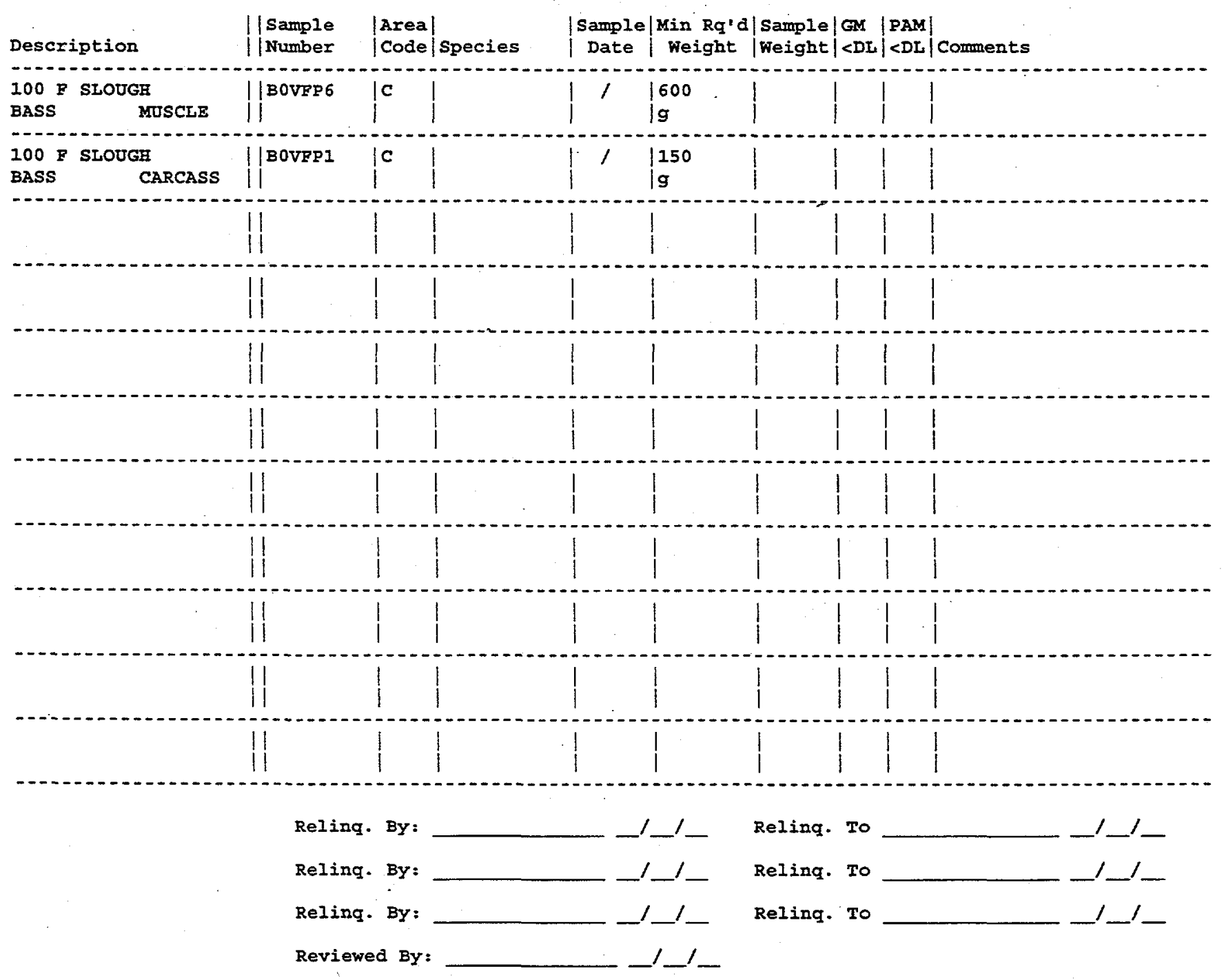

Figure 8.1.5. Environmental Surveillance Trip Sheet for Wildlife Samples 


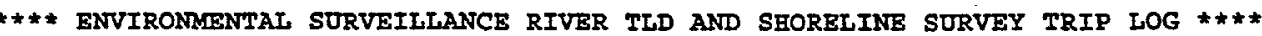

Route :2Date: MONDAY Bicron ID \#

01/03/2000 RPT Name (print) : Page 1

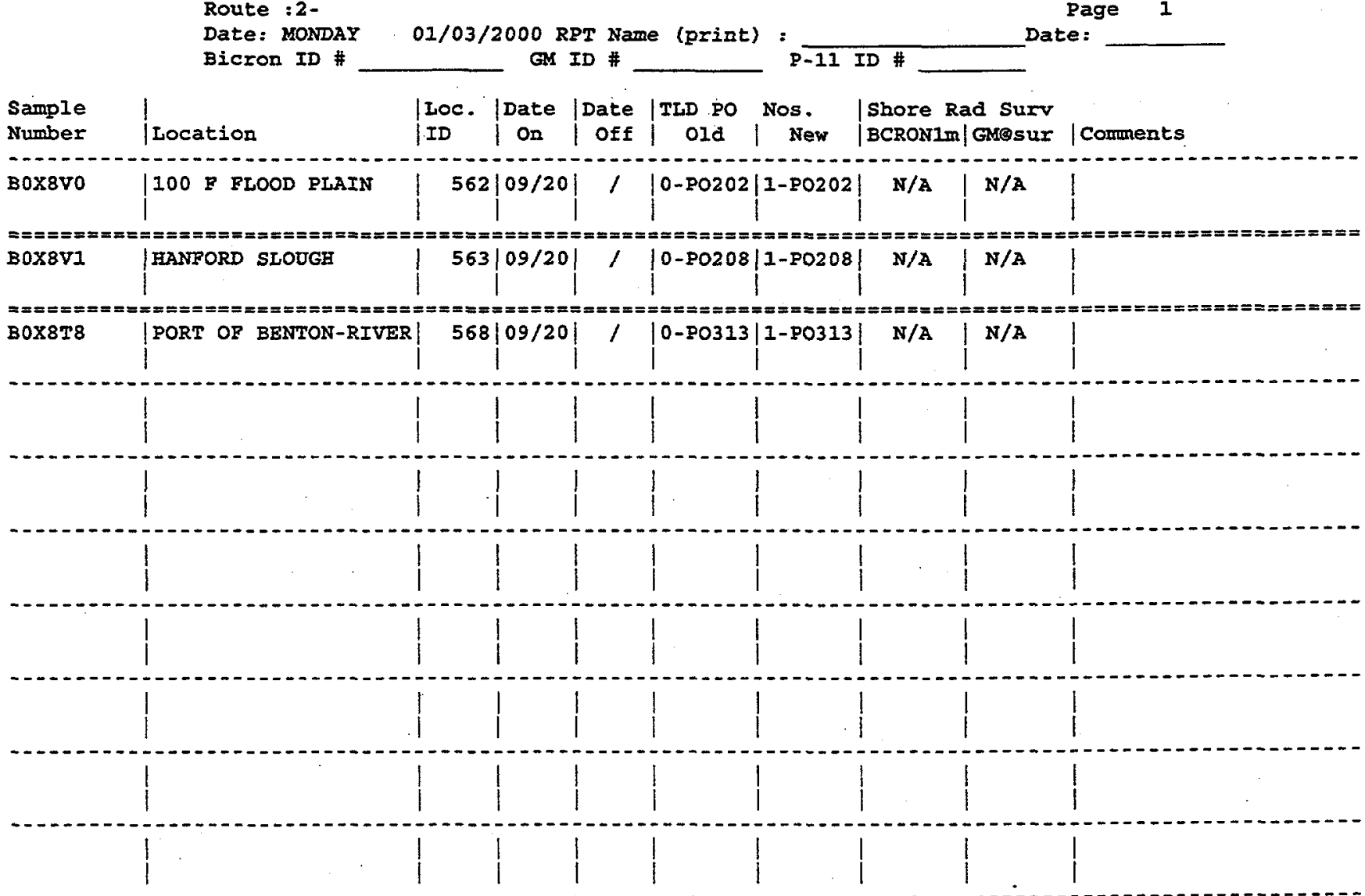

Reling. BY:

Reling. By:

Reling. BY:

Reviewed By:
Reling. To

Reling. To

Reling. To

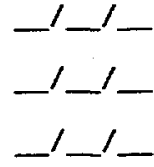

Figure 8.1.6. Environmental Surveillance Trip Sheet for River TLDs and Shoreline Surveys 


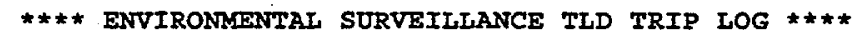

Route : 02

Date: THURSDAY 12/30/1999 RPT Name (print) :
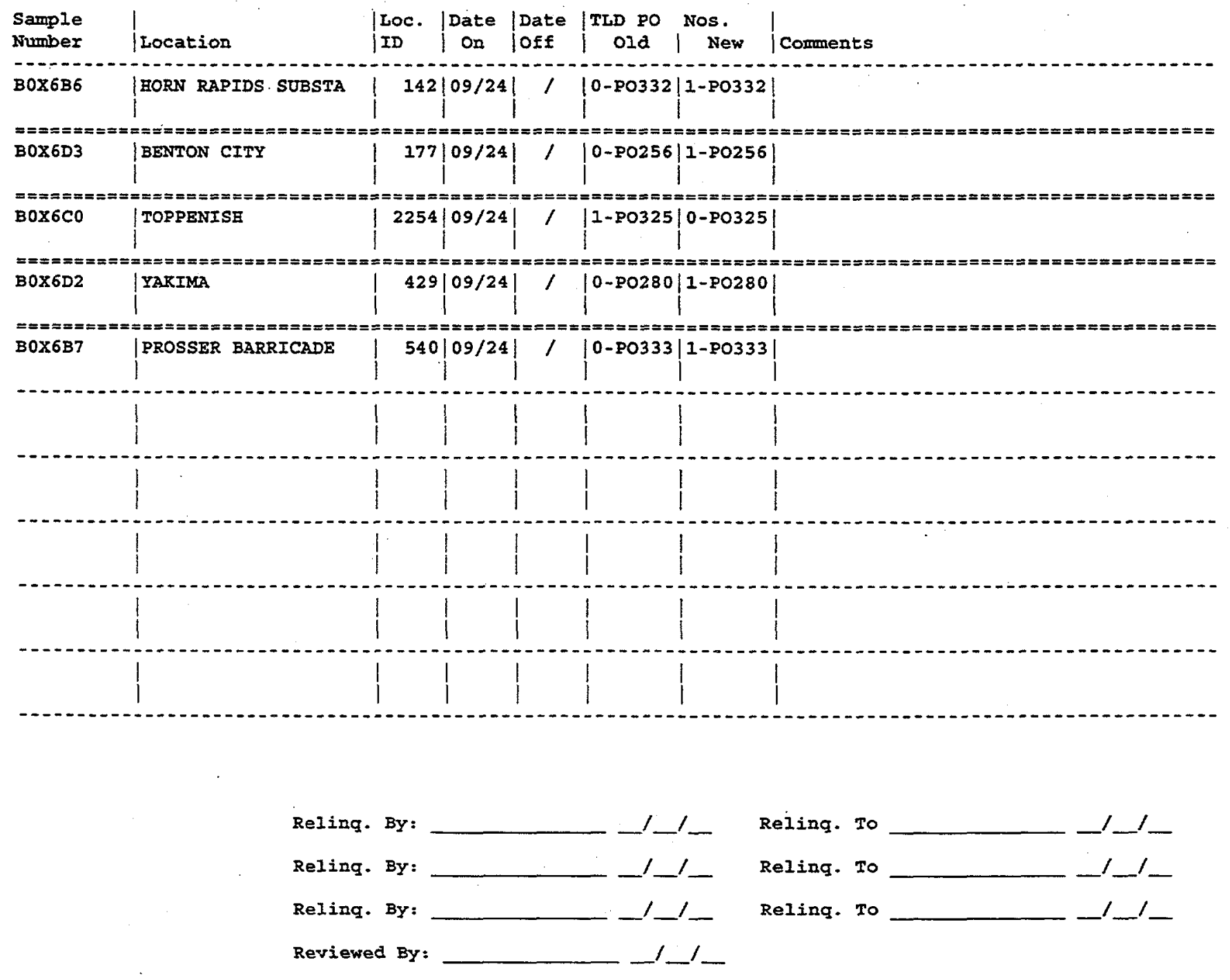

Figure 8.1.7. Environmental Surveillance Trip Sheet for Environmental TLDs 


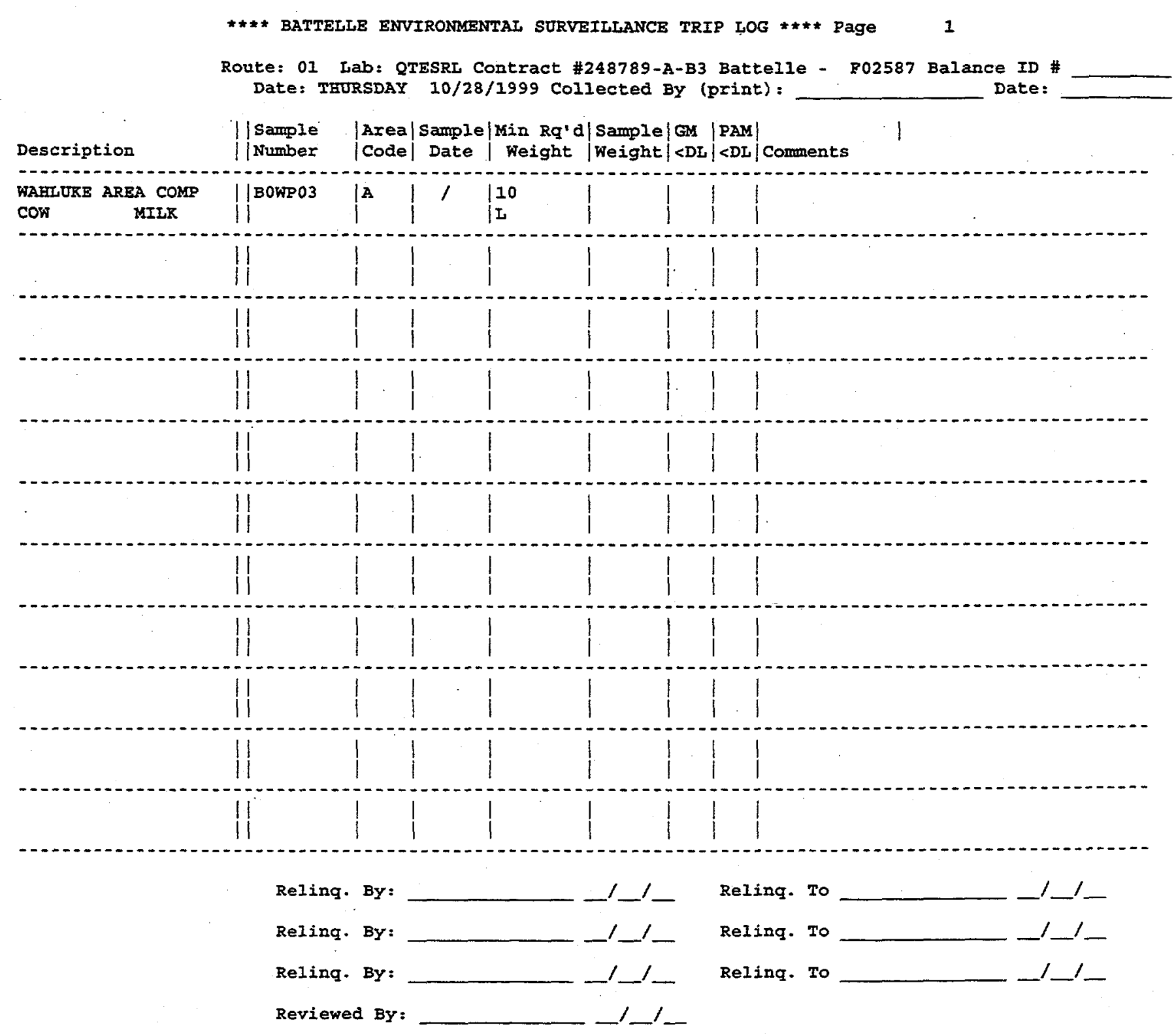

Figure 8.1.8. Environmental Surveillance Trip Sheet for Food and Farm Product Samples, Soil and 


\subsection{RADIATION WORK PERMITS}

INTRODUCTION

Radiation Work Permits (RWPs) are required for some environmental monitoring tasks on the Hanford Site. Depending on the sampling location, RWPs may be issued by any of several contractors on the site. If unsure as to the radiological status of a specific area and/or the applicability of an RWP, contact the Sample Collection Task Leader. Do not enter area without ensuring RWP requirements are being met.

Regardless of the issuing contractor, all SESP sample collection staff must read, understand, and comply with the requirements of all applicable RWPs.

Whenever possible, RWP requirements for a specific sampling area should be identified prior to conducting field operations. All RWP requirements that impact the ability of sample collection personnel to conduct their work should be brought to the attention of the Sample Collection Task Leader as soon as possible.

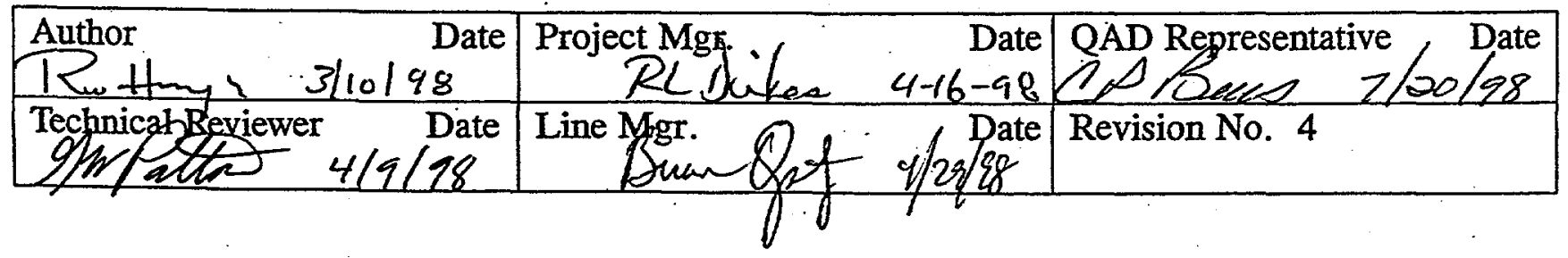




\subsection{UNUSUAL FINDINGS NOTIFICATION}

INTRODUCTION

During routine surveillance activities, unusual findings may be noted. Examples of these include, but are not limited to, higher than normal external radiation levels, higher than normal radiation levels on air filters, and contaminated vegetation, soil, or animals. When these situations arise, contact one of the following people to notify them of unusual findings. Attempt to contact them in the order shown. Telephone (hard wired) or personal contact is preferred. However, a two-way radio or cellular telephone may be used to establish initial contact or summon assistance. Minimize discussion of contamination levels or serious problems over the radio or cellular telephone.

\section{SESP}

- Bill Hanf, $376-8264$ Sample Collection Task Leader

- Ted Poston, Project Manager

$376-5678$

- Brian Opitz, Technical Group Manager

$372-0069$

\section{COESP}

- Bill Hanf, COESP Task Leader

$376-8264$

- Barb Gillespie, Air Task Leader

$376-5802$

- Ted Poston, Project Manager

$376-5678$

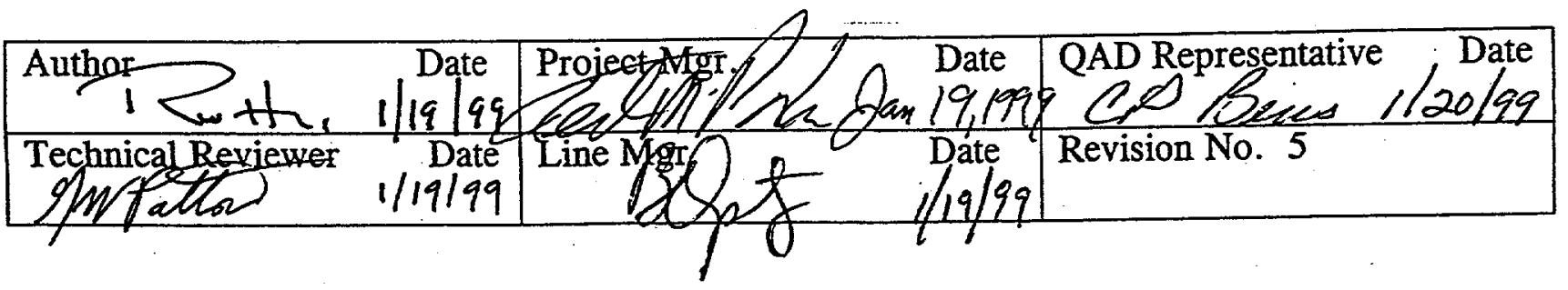




\subsection{RADIOLOGICAL SURVEYS OF SAMPLES}

INTRODUCTION Radiological surveys of SESP samples collected on and off the Hanford Site are not necessary unless:

- samples are collected from a posted radiological zone

- surveys are required by the procedures outlined in this manual

- surveys are required by SESP management

- $\quad$ surveys are required by PNNL, federal, state, or site contractor regulations. Currently PNNL only requires surveys when samples are collected in a posted radiological zone or when sample collection staff suspect the presence of radiological contamination.

Routine sample surveys by COESP personnel are recommended for information.

\begin{tabular}{|c|c|c|}
\hline Author $\quad 3 / 10 / 98^{\text {Date }}$ & $\begin{array}{rr}\text { Project } \cdot M g r \\
R(d) \text { ifles } & \text { Date } \\
\end{array}$ & QAD Representative $1 / 20 / 98$ \\
\hline 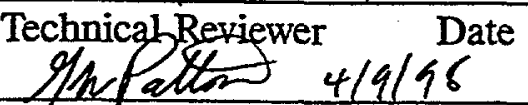 & Line Mgr. Ofor & Revision No. New \\
\hline
\end{tabular}




\subsection{PROCEDURE FOR THE SAFE HANDLING, TRANSPORT, AND STORAGE OF FIREARMS}

HANDLING OF FIREARMS
The following protocol will be followed by anyone using a firearm for SESP work. Firearms included in this procedure include rifles and shotguns.

No one will use a firearm until they have taken the Firearms Safety Training Course and have been trained in specific use of the firearm to be used.

On removing any firearms from the storage cabinet, check the chamber, magazine, and barrel for ammunition or other obstructions.

Only unloaded firearms will be transported.

At no time will a loaded firearm be allowed in a building, automobile, or boat.

Staff on medication, which could impair motor skills or judgment, are not to use firearms unless cleared by a physician.

Battelle Security (375-2154; email: ^PNL Control Room) will be notified prior to the transport and use of a firearm in the field on the Hanford Site.

Upon approach and arrival to the area of use, be watchful for signs of other personnel, vehicles, or structures whose safety may be compromised because of your use of firearms. Ensure the hunting area is clear, and be constantly alert for changing conditions. Prior to loading any firearm, the chamber and barrel shall again be checked to ensure that the firearm is free from obstructions. Firearms shall not be loaded while inside a vehicle. Loading will be done outside the vehicle and with the firearm pointed in a safe direction, away from all people, equipment, and structures.

Hunter orange vest will be worn while hunting.

Only proper size ammunition will be used in a firearm.

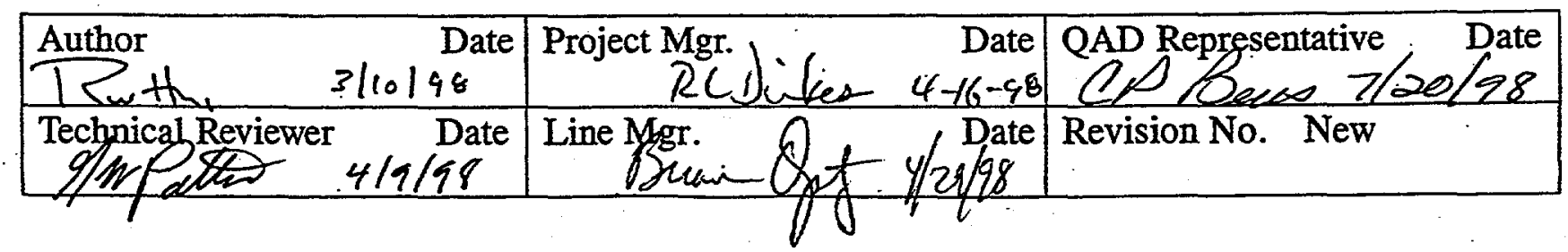


STORAGE OF FIREARMS AND AMMUNITION
While carrying a loaded firearm, the user will at all times, keep the safety on and the firearm pointed in a safe direction.

Immediately after use, the firearm will be unloaded. It will not be placed in a case or in a transporting vehicle until it has been unloaded. Transport the firearm with the action open. When returning a firearm to its storage location, again check that it is unloaded and the action left open.

All firearms will be stored in a locked cabinet. Firearms will be signedout/signed-in on the Firearms Sign-out/Sign-in Sheet located in the gun cabinet.

Firearms will be rechecked to confirm they are unloaded and the action left open before placing in the gun cabinet.

Do not leave the firearm in a gun case while it is stored in the gun cabinet.

Firearms will be cleaned upon return from the field commensurate with its use, or arrangements will be made to clean the firearm within a reasonable amount of time from its use.

Any malfunctioning firearm shall be tagged and reported to the immediate supervisor. It will be the firearm custodian's responsibility to see that it is repaired.

Ammunition that misfired or is damaged will be given to the firearm custodian for proper disposal. 


\subsection{DETERMINING GEOGRAPHIC POSITIONS USING THE TRIMBLE GEOEXPLORER II}

INTRODUCTION The Trimble GeoExplorer II (GE0-II) is a handheld Geographical Positioning System (GPS) that is able to determine real-time field positions with an accuracy of approximately $\pm 100 \mathrm{~m}$. The GEO-II can also be used to measure differentially corrected field positions with higher accuracy; however, this type of measurement is beyond the scope of this procedure. This procedure is designed to provide the minimal steps required to measure field positions that will be documented on a trip sheet (i.e., the positions will be handwritten onto trip sheets in the field and not recorded as electronic files).

PERSONNEL

Field sampling must be conducted by staff who have received training on these sampling procedures and are familiar with the sampling equipment.

This procedure requires one (1) person for efficient operation.

EQUIPMENT

The following equipment and supplies may be needed for the collection of geographic position data:

- Trimble GeoExplorer-II Unit

- GeoExplorer-II Quick Reference Card

- external power supply (either lead acid battery or Autostarter battery)

- internal power supply (either 4 AA batteries or one 3-volt lithium battery)

- cables to connect external power supply to GEO-II

- trip sheet

- pens/pencils

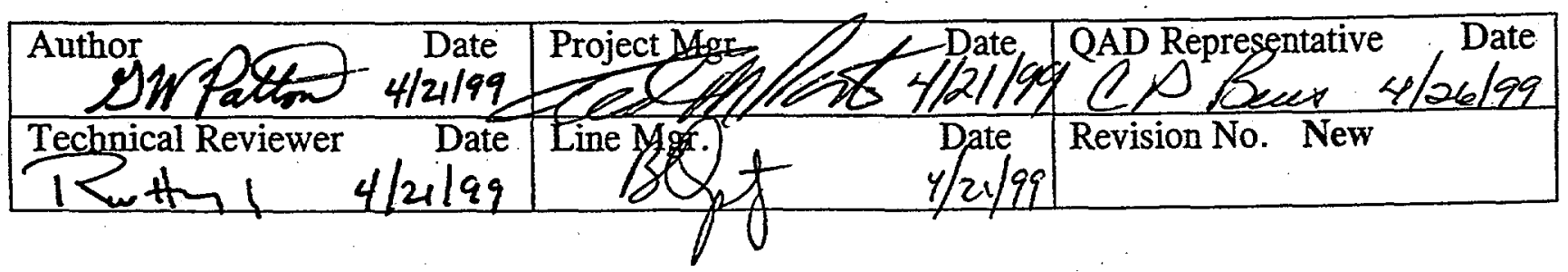


DATA

COLLECTION

CHECK

CONFIGURATION SETTINGS
One to two days prior to sample collection, contact the GPS equipment custodian (currently Bob Fulton - 376-9121) to obtain the GEO-II unit and fresh internal and external batteries.

Proceed to the sampling location.

Connect the external power supply to the GEO-II (Figure 8.6.1). The external power can be supplied by a lead acid battery, Autostarter battery, or cigarette lighter connection in a vehicle. Once external power is supplied, the green light near the power supply port on the GEO-II should light up.

Turn on the unit by pressing the on/off button (the black button with the vertical line). The unit will display either the last measured position (old position) or the main menu. Hit the yellow diamond key to bring up the main menu (if display shows last measured position).

NOTE: If the GEO-II has not been used for several months, it may have to acquire a current almanac of satellite positions (this condition is diagnosed by a reading of "old position" with no new position acquired after several minutes). This reacquisition is conducted by turning on the unit, exposing it to an unobstructed view of the sky, and allowing it to acquire satellite information for approximately 20 minutes.

NOTE: The GEO-II unit has a software menu that is accessed by using the up and down arrow button to scroll through the menus. To select a menu option, hit the yellow diamond key. The ESC key (escape key) is used to exit the current screen and return to the previous screen. To adjust the screen contract for bright or low light conditions, hold down the on/off button and press either the up or down arrow buttons.

Check configuration settings by using the up/down arrows to scroll to the configuration screen (\#6 in main menu). Hit the yellow diamond key to bring up the configuration menu.

Move to configuration screen \#3 (coordinates) and scroll to UTM using the up/down arrow keys. Hit the yellow diamond key to select UTM.

Move to configuration screen \#4 (datum) and scroll to N-AM.1983 (NAD 83) using the up/down arrow keys. Hit the yellow diamond key to select N-AM.1983 (NAD 83).

Move to configuration screen \#5 (units) and select metric using the keys as above. 
Page 3

Move to configuration screen \#6 (date and time), and hit the yellow diamond key. In the time and date menu, scroll to screen \#2 (set local time), and hit the yellow diamond key. Set the local time using the up/down arrow keys (time increments are fairly coarse, set as close as possible), and hit the yellow diamond key to accept the new date and time. Hit the ESC key twice to return to the main menu.

Once configuration settings have been set, they will stay in the memory for the entire day and should not require resetting if the unit is turned off.

COLLECTING GEOGRAPHIC POSITIONS
Move to main menu screen \#2 (position), and hit the yellow diamond button.

Record all the screen information on the trip sheet. For example: GPS Position, UTM II 325390.4, T 5134812.8, 3 D HAE $117 \mathrm{~m}$. The bold numbers should change as you go to different locations.

To turn the GEO-II unit off, hold the on/off button for 5 seconds. The external batteries should provide power for 2-3 hours of continuous operation or a full day of operation if the unit is turned off between measurements.

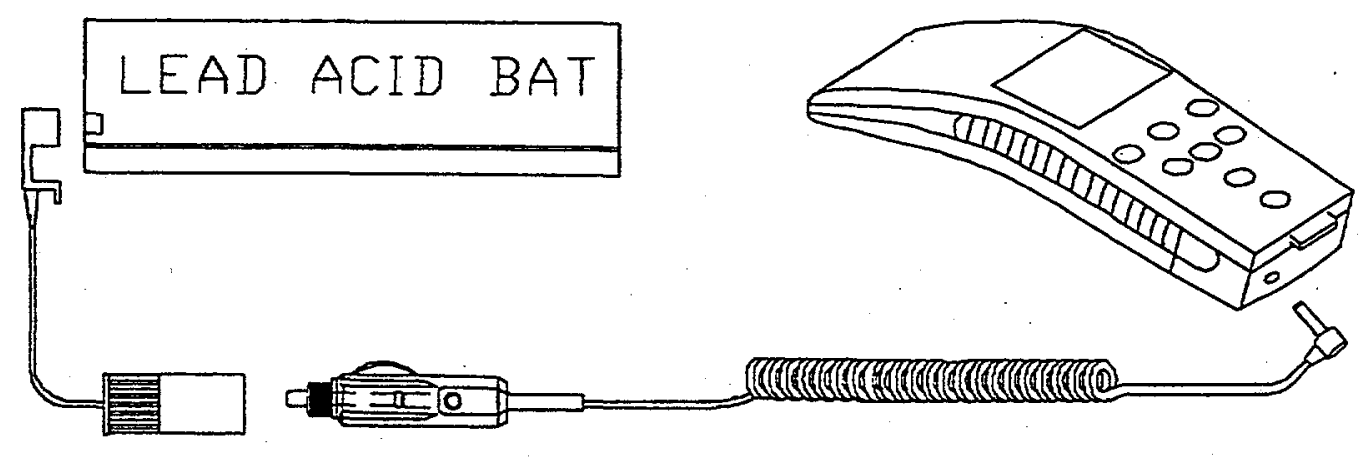

Figure 8.6.1. Connecting the Lead Acid Battery to the GeoExplorer II 


\subsection{RADIATION SURVEY PROCEDURES}

INTRODUCTION External radiation levels are measured at several locations in the Hanford Site environs. Measurements are performed to estimate levels attributed to sources on the Hanford Site, estimate background, demonstrate compliance with applicable regulations, and support the assessment of exposure to onsite and offsite populations. Thermoluminescent dosimeters and portable survey equipment are the primary means used for measuring external radiation. The procedures contained in this section include:

- environmental thermoluminescent dosimeter (Section 9.1)

- pressurized ionization chamber (Section 9.2)

- shoreline dose rate and contamination measurements (Section 9.3).

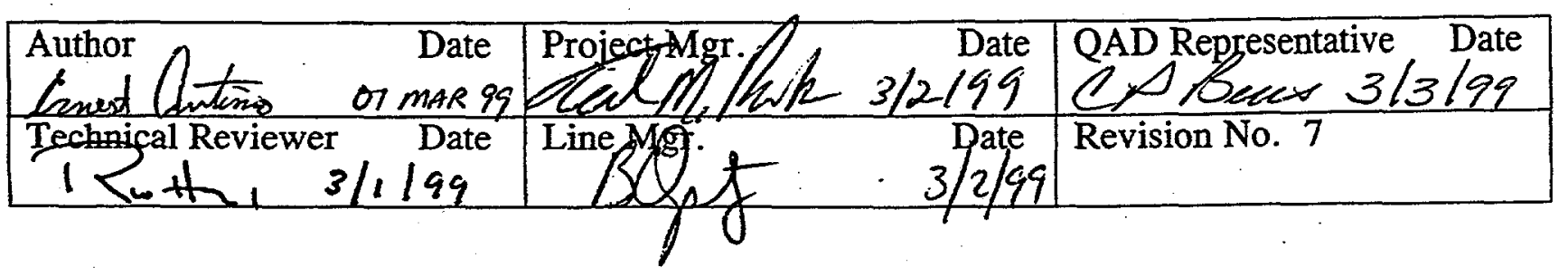




\subsection{ENVIRONMENTAL THERMOLUMINESCENT DOSIMETER (TLD)}

INTRODUCTION

\section{EQUIPMENT.}

PROCEDURE
Ambient external dose rates are currently measured throughout the Hanford Site environs using the Harshaw 8807 Environmental dosimeter. The Harshaw 8807 Environmental dosimeter consists of two lithium fluoride (LiF) chips (TLD-700) and two $\mathrm{CaF}_{2}$ chips (TLD-200). Each TLD card is placed in a plastic dosimeter cardholder, and dosimeters are mounted approximately $1 \mathrm{~m}(3.28 \mathrm{ft})$ above the ground. Dosimeters are routinely exchanged and the chips are read on a quarterly schedule.

The following equipment may be necessary for collecting dosimeters from the field:

- unexposed dosimeters

- trip sheet

- pen

- weatherproof clipboard

- spare TLD posts and a sledge hammer or post driver

- spare orange triangle

- spare PVC pipe $(1 / 2 \mathrm{x} \sim 12$ in. $)$

- wire.

Obtain dosimeters from the External Dosimetry Technical Group in the 318 Building on the morning of deployment.

In the field, sample collection staff will:

1) Remove the exposed dosimeter from the TLD post by unclipping the dosimeter from the wire holding it in position.

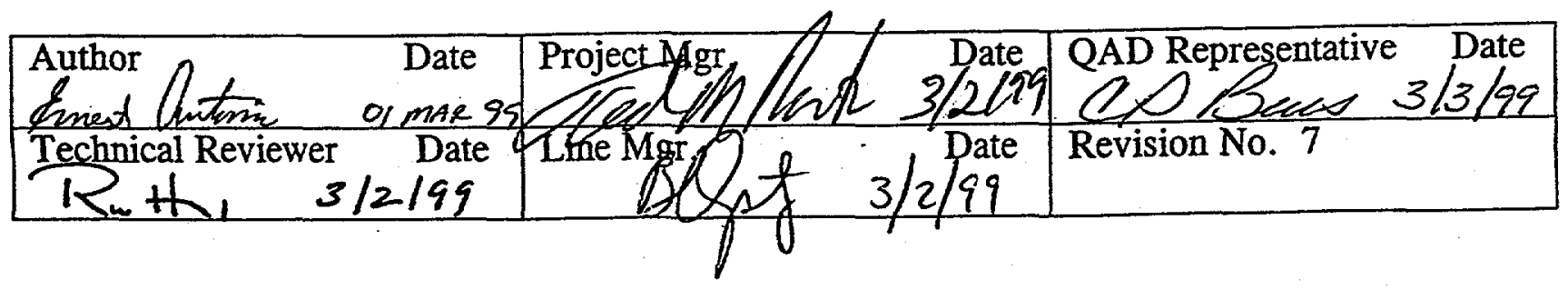


2) Check the identification number on the individual TLD to ensure it coincides with the $\mathrm{ID}$ number on TLD being placed in the field at that specific location and that both sets of $\mathrm{ID}$ numbers correspond with the location ID on the trip sheet.

3) Mount the unexposed dosimeter to the wire on the TLD post.

4) Double check the location $I D$ number on the dosimeter label with the location $\mathrm{D}$ number listed on the trip log to verify that the correct exchange was made.

5) Check that the correct exchange date is listed on trip sheet.

6) Record any significant observations or variations in the procedure (e.g., date changes, TLD found on ground, missing dosimeter, possible incorrect dosimeter exchanges, possible unusual radiation sources in the area, etc.) in the comments section of the trip sheet.

7) Take all exposed dosimeters and all trip sheets to the External Radiation Task Leader, Sample Collection Task Leader, Data Management Task Leader, or another SESP media task leader who is familiar with the media for review and sign-off.

8) Return exposed dosimeters to the External Dosimetry Technical Group in the 318 building, and have the person receiving the dosimeters sign the trip sheet as having taken possession of all dosimeters listed on the trip sheet.

If unable to relinquish dosimeters to the External Dosimetry Technical Group on the same day they were retrieved from the field, place them in the lead receptacle located in Room 1517 of Sigma 5 Building, sign the trip sheet as relinquishing the dosimeters to "Locked Storage." As soon as possible, sign the dosimeter out of locked storage and deliver the exposed dosimeters to the 318 building. 


\subsection{PRESSURIZED IONIZATION CHAMBER}

INTRODUCTION

EQUIPMENT
The pressurized ionization chamber (PIC) is a sensitive gamma or $\mathrm{X}$-ray radiation ( $>70 \mathrm{keV}$ energy) detection instrument: The PIC system (PIC/RSS-112) measures exposure rate in $\mu \mathrm{R} / \mathrm{h}$, provides a continuous display of it on either a Light Emitting diode (LED) or Liquid Crystal Display (LCD), and record these data on an internal computer microprocessor. It is typically used for special studies of environmental external radiation levels. Measurements are normally performed with the detector at about $1 \mathrm{~m}$ above the ground to estimate the actual dose from external radiation.

The PIC system is a self-contained component system, housed in two cable-connected, weatherproof cases. One case contains the detector chamber, an 8-L spherical ionization chamber pressurized to 300 psi with a $300-\mathrm{V}$ potential applied when operating. The other case holds the electronics enclosure (control circuitry, readout displays, rechargeable battery, and a $300-\mathrm{V}$ non-rechargeable bias battery). The rechargeable battery typically can last about 100 hours under normal usage. The 300 $\mathrm{V}$ non-rechargeable bias battery has a typical usage life of 1 to 2 years (depending on shelf time and environmental factors). An AC power cable/adapter is provided for battery recharging/ $\mathrm{AC}$ power.

The following equipment may be necessary for collecting exposure measurements:

- PIC system

- PIC

- signal cable

- electronics enclosure (RSS-112)

- carrying case

- Geiger-Müller Survey Meter (GM)

- memory cartridge

- tripod

- $\mathrm{AC}$ power cable/adapter

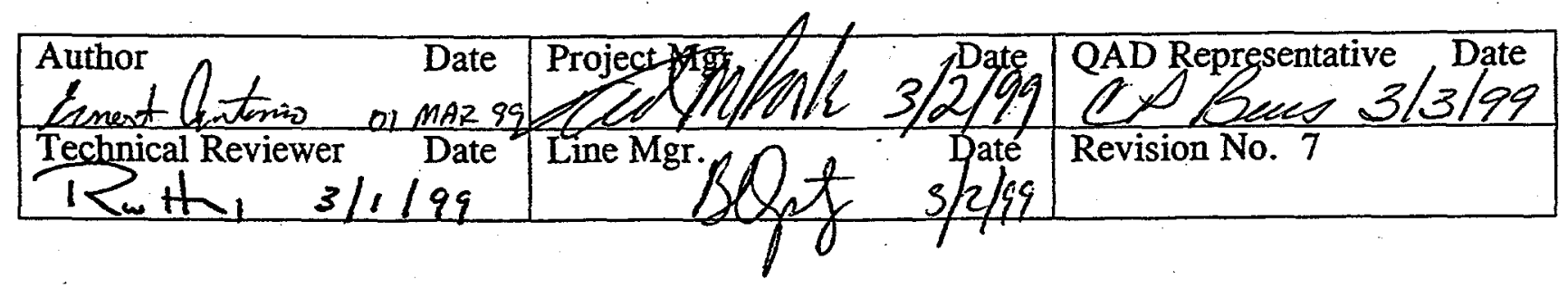


SURVEY PROCEDURE
WARNING: The sensor housing contains an ionization chamber with high internal pressure ( $300 \mathrm{psi})$ and high voltage ( 300 volts $\mathrm{DC})$ on its surface. Removal of chamber from its protective housing or mishandling could cause serious personal injury.

\section{CAUTIONS:}

- The lithium battery may explode or leak if recharged while disassembled or heated above $100^{\circ} \mathrm{C}\left(212^{\circ} \mathrm{F}\right)$. Do not short circuit.

- The rotary power switch on the rear of electronics enclosure must be turned to the "off" position before the sensor is connected or disconnected. The cable carries approximately $300 \mathrm{~V} \mathrm{DC}$.

\section{PIC With RSS-112 Model}

Report to the External Radiation Task Leader with the electronics enclosure (RSS-112) and PIC before deploying it in the field. The task leader will provide any special instructions, check the instrument settings, and program the RSS-112 computer memory specifically as needed for the study. The External Radiation Task Leader or a delegate will likely accompany the team deploying the PIC unit.

After arrival at the survey location, choose a monitoring point that is flat and level on which to set the equipment. Choose a location that is away from any nearby structures, a distance of at least twice the approximate height of the structures (e.g., buildings) and not in a valley or hollow where standing water could collect, if possible (e.g., take a measurement that is at least $30 \mathrm{ft}$ away from a 15-ft-high building.)

Adjust the tripod legs to a length of $2.5-3 \mathrm{ft}$, and tighten their collars. Attach the PIC to the tripod stand by screwing the bolt from the tripod stand up into the threaded receptacle in the base of the PIC using the Allen wrench in the carrying case.

If $120-\mathrm{V}$ AC power is available from an outlet, plug the $\mathrm{AC}$ adapter into the outlet receptacle marked "Power" on the rear of the electronics enclosure.

Connect the electronics enclosure to the PIC by connecting the signal cable to the PIC and the receptacle marked sensor on the rear of the enclosure. Make certain to mate the correct male and female ends to the receptacles to avoid damaging the pins. 
ACQUIRING DATA
AFTER THE SURVEY
Turn the electronics on by rotating the switch on the rear of the enclosure to the "ZERO" position. Verify that the LCD display reads less than 0.3 $\mu \mathrm{R} / \mathrm{h}$ in the box titled "CURRENT DATA."

Turn the switch to the "READ" position, and allow the system to warm up for approximately 20 seconds before making survey readings. Typical ambient background exposure rate levels fluctuate between approximately 7 to $11 \mu \mathrm{R} / \mathrm{h}$.

Observe the display for the appearance of a star $\left(^{*}\right)$ in the right upper corner. If a star $(*)$ appears, report this system error message to the Sample Collection Task Leader and do not continue with this procedure until the cause of this has been investigated.

Memory Cartridge Data Recording Initiation: (performed only if instructed by the External Radiation Task Leader).

After setting up and starting PIC measurements, push on the soft-key arrow in the front panel of the electronics enclosure pointing at "EXIT" on the display to enter the Main Menu.

Press on the soft-key arrow pointing at "MEMORY CART" on the right side of the display.

Press the soft-key arrow pointing at "START ACQUIRE," and then press the same soft-key again to continue.

Press the soft-key arrow pointing at "MORE" twice in a row, and then press it again when "EXIT" appears. Observe that the Main Menu appears, and the display rotates back to display the Current Data measurements.

Perform any further special operations according to instructions given by the External Radiation Task Leader or the Sample Collection Task Leader.

After the survey, prepare the electronic unit for return following these steps:

Press the soft-key arrow pointing at "EXIT," then the soft-key arrow pointing at "MEMORY CART," then the soft-key arrow pointing at "STOP ACQUIRE". Go directly to turning the system off. Do not remove the cartridge.

Survey all equipment with a Geiger-Müeller (radiation detector), if the equipment has been deployed on the Hanford Site. 
Turn the switch on the rear of the enclosure to "OFF."

Unplug the $\mathrm{AC}$ power cord from the outlet and the enclosure and roll it up.

Disconnect the signal cable from the PIC and the enclosure and roll it up.

Unscrew the PIC from the tripod.

Adjust the tripod legs to their smallest height and tighten their collars.

Place the electronics enclosure, signal cable, and power cord into the carrying case. Secure the tripod to the carrying case, using the holding straps on the outside of the case. Return the electronics enclosure to the External Radiation Task Leader if the memory cartridge was used to collect data. 


\subsection{SHORELINE DOSE RATE AND CONTAMINATION MEASUREMENTS}

INTRODUCTION

\section{EQUIPMENT}

DOSE RATE SURVEYS

Micro-Rem-Meter - $\gamma$ Exposure Rate
Selected shoreline locations along the Columbia River are designated for measurement of external dose rate and contamination level. These locations are reached by land or water (boat) and routine measurements are taken quarterly.

The following equipment may be necessary for performing measurements:

- boat

- micro-rem meter (Bicron or equivalent)

- Geiger-Müller (GM) survey meter w/P-11 probe

- portable instrument survey form

- unexposed thermoluminescent dosimeters (TLDs), if required.

- trip sheets and labels, if needed

- weatherproof clipboard.

Refer to Section 9.1, Environmental Thermoluminescent Dosimeter, for instruction to exchange TLDs.

Beach the boat at the designated shoreline locations.

Turn the micro-rem-meter on, and ensure that it is working properly by checking battery level and high voltage.

Using the slow-response time setting, hold the instrument steady within 1 $\mathrm{m}$ of TLD post, $1 \mathrm{~m}$ above the ground surface, and at least $10 \mathrm{~m}$ away from any cars, air samplers, or other devices that may concentrate airborne radioactivity. (This is very important.)

Pause for approximately 20 seconds to allow the instrument to reach a steady state. Take a reading with the range switch set at the lowest range where the needle does not extend to its full scale.

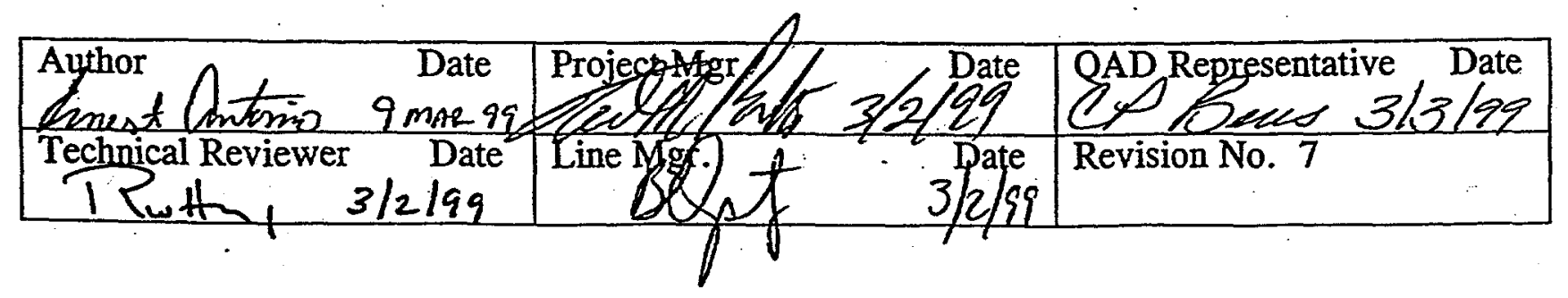


GM with P-11

Probe - B, $\gamma$ Count

Rate at Surface (counts/min)
Turn off the instrument.

Record the reading and the range setting on the trip sheet.

If operation of the meter is suspect or if measured exposure rates exceed $1500 \mu \mathrm{R} / \mathrm{h}$, contact the External Radiation Task Leader or Sample Collection Task Leader for further instruction.

Note in the "Comments" on the trip sheet if an instrument other than a Bicron micro-rem-meter is used.

If necessary, consult micro-rem meter operating instructions. Typical micro-rem meter background readings are in the range of 5-15 $\mu \mathrm{rem} / \mathrm{h}$.

Turn the instrument on, and ensure that it is working properly.

Check high voltage, perform battery check, check instrument response with check source.

With the audible switch ON and the instrument set for a medium response time, hold the $\mathrm{P}-11$ probe approximately $2.54 \mathrm{~cm}(1 \mathrm{in}$.) above the surface and survey $9 \mathrm{~m}^{2}(3 \times 3 \mathrm{~m})$ of the ground within $1 \mathrm{~m}$ of the TLD post.

Determine the maximum general surface contamination reading (exclusive of any reading obviously caused by discrete radioactive particles). Discrete radioactive particles will cause significant increase in the count rate of the Geiger-Müeller probe.

Turn the instrument off.

Record the maximum general reading and the range setting.

Record presence or absence of discrete radioactive particles. If present, record maximum reading and note location carefully.

Draw map of survey area relative to TLD.

If operation of the meter is suspect, or if readings are $>10,000$ counts $/ \mathrm{min}$ (cpm), contact the External Radiation Task Leader or Sample Collection Task Leader for further instruction.

If necessary, consult the GM and micro-rem meter operating instructions. Typical GM background readings are in the range of $<10 \mathrm{cpm}$. 
Exchange TLDs as described in Section 9.1, Environmental

Thermoluminescent Dosimeter, at locations specified on the trip sheet if required.

Report any unusual conditions observed during the shoreline survey to the Sample Collection Task Leader. Record these observations in the "Comments" on the trip sheet.

Record Bicron micro-rem meter and Geiger-Müeller instrument identification numbers in the appropriate place at top of trip sheet. 